University of Rhode Island

DigitalCommons@URI

Open Access Dissertations

1997

\title{
Cynics, Spaces, and Subjects: Toward a Tactical Ethics of Rhetoric
}

Kristen Francis Kennedy

University of Rhode Island

Follow this and additional works at: https://digitalcommons.uri.edu/oa_diss

\section{Recommended Citation}

Kennedy, Kristen Francis, "Cynics, Spaces, and Subjects: Toward a Tactical Ethics of Rhetoric" (1997). Open Access Dissertations. Paper 1116.

https://digitalcommons.uri.edu/oa_diss/1116

This Dissertation is brought to you for free and open access by DigitalCommons@URI. It has been accepted for inclusion in Open Access Dissertations by an authorized administrator of DigitalCommons@URI. For more information, please contact digitalcommons-group@uri.edu. 
CYNICS, SPACES, AND SUBJECTS: TOWARD A TACTICAL ETHICS OF RHETORIC

BY

KRISTEN FRANCIS KENNEDY

A DISSERTATTON SUBMITTED IN PARTIAL FULFILLMENT OF THE

REQUIREMENTS FOR THE DEGREE OF

DOCTOR OF PHILOSOPHY

IN

ENGLISH

UNIVERSITY OF RHODE ISLAND 


\begin{abstract}
Cynics, Spaces, and Subjects: Toward a Tactical Ethics of Rhetoric explores the problem of ethics within the postmodern, a moment, as well as a theoretical posture, that leaves questions of transformative subjectivity and agency to be answered by an ethical "anything goes." In response to the often destabilizing tendencies of postmodern ethical theory, my dissertation is a rhetorical response to claims that there are no foundations for ethical thought and action. I argue that rhetorical theory is well-suited for this task because of its emphasis on action and discourse. At the same time, however, I borrow some of the insights and strategies of postmodern theory--its penchant for space and its emphasis on the local, contingent, and tactical uses of discourse--to create tactical rhetorics that can help to meet the problem of ethics in the postmodern. These strategies are important for negotiating what is essentially an either/or dichotomy in ethical theory: on one hand, we encounter the radical skepticism of postmodern ethical theory, and on the other, the foundational tenets of universalist positions.
\end{abstract}

As I argue in Chapter One, there is a "space-between" the rather strategic use of this dichotomy in the rhetorical concept of kairos (timing). Kairos combines contingencies of context with an ethic of action. A kairotic ethics is, then, one of several rhetorical strategies employed to meet the problem of ethics in the postmodern. Chapters Two and Three are dedicated to excavating the rhetorical repertoire of the ancient Cynics, a roving band of philosophers who were committed to living and speaking their ethical stances. The tactics of parrhesia, diatribe, and exile are explored for their ethical and political contributions for contemporary rhetorical theory. I then examine the field of rhetoric and composition to trace historically how ethics gradually disappeared from college writing curricula as training for business and professions became vital to emerging American industry. In response to what I see as the field's continued ambivalence 
toward ethics, I conclude my dissertation with a pedagogical project that serves to revive critical ethics in the classroom. 


\section{Acknowledgments}

Writing a dissertation is very much like living with another person. You have to nurture it, criticize it, feed it, talk to it, and on occasion, fight with it. And not unlike most live-in relationships, there were times when I wanted this "person" to be gone when I got home at the end of the day. When the dissertation was finally and for all practical purposes finished, I actually missed it. I had kept waiting for it to move out, pack its articles, its books, its notes and leave the building. Now that it has, there are times when I miss its constancy, the way one might miss an elephant in the living room. It was always there, looming relentlessly every time I clicked on the television or picked up a novel and reminding me of the work I had to do. Other times, it provided a certain stability, the kind of constancy you feel when traveling familiar roads.

The comparison between my dissertation and a relationship is an appropriate one for these acknowledgments. There are so many relationships that are and have become so important to me, my intellectual growth, and my teaching. For starters, I want to thank Nedra Reynolds, the big dog of my dissertation committee, for her friendship, support, and guidance. Traces of her work, her ideas, and her inspiration are everywhere throughout these pages. Thanks also to the other members of my dissertation committee--Lynn Pasquerella, Judith Anderson, Bob Schwegler, and Dana Shugar--for their commentary and criticism. A special thanks goes to Anne Suter for her time and research and Arthur Riss for the generous task of reading and commenting on my work.

Of course, I have to thank the Kennedy clan, Kim, John, and especially my Mom who invested in me, hoping I'd be "a bright bulb on the tree" and my late father who always encouraged me--in his own very Cynical way-"to piss with the big dogs." I am grateful for my parents' dark wit, their penchant for aphorism, and their quiet but steady support. 
I also want to acknowledge the graduate students of Independence 303 who provided conversation, support, and "spirits" all along the way--in particular, Kevin Swafford and Sarah Holmes for sharing the neurosis. Whether it was a chat over beers at the Mews or a conversation in the office, they are all in some way responsible for challenging my arguments and ideas. Thanks to my students who over the years have graciously submitted to my occasional classroom experiments and who always remind me that I have so much more to learn. In addition, Melody Bowdon, Dan Johnsen, Christina Felix, and Molly Dugan, my friends from too far away, have continually provided strong shoulders, sympathetic ears, and timely email responses (well, most of them). To Craig Kleinman, I owe a major debt of gratitude for, among other things, washing the dishes. Thanks also to Andy Doolen who challenged me to make connections--between theory and practice and between knowledge and love. Last, but certainly not least, I thank Lisa Lebduska for talking, walking, and shopping me through this, especially during this past year when I made so many demands upon our friendship. Thank you, Lisa, for letting me know I could always come home. 


\section{TABLE OF CONTENTS}

$\begin{array}{ll}\text { Introduction } & 1\end{array}$

$\begin{array}{lr}\text { Chapter One } & 27\end{array}$

Spatial Agents and Ethical Plots: Toward a Theory of Kairotic Ethics

Chapter Two

Cynic Rhetoric: The Ethics and Tactics of Resistance

Chapter Three

Hipparchia the Cynic: Feminist Rhetoric and the Ethics of Embodiment

Chapter Four

Ethical Subjects: Composition, Pedagogy, and the Postmodern Classroom

Chapter Five

Ethics and HIV Testing: Toward a Pedagogical Project

Bibliography 


\section{Introduction}

I wish I could have slipped surreptitiously into this discourse which I must present today, and into the ones I shall have to give here, ... I should have preferred to be enveloped by speech, and carried away well beyond possible beginnings, rather than have to begin it myself.

Michel Foucault

The Order of Discourse

If you knew when you began a book what you would say at the end, do you think that you would have the courage to write it? What is true for writing and for a love relationship is also true for life. The game is worthwhile insofar as we don't know what will be the end.

MichelFoucault

Technologies of the Self

As I trace the beginnings of this project, to give readers some sense of the pattern of argument, how it has developed, and where these pages come from, I think back to the "salad days" of course work. Much of my work here is a direct consequence of a series of problems I saw emerging from my reading and writing in those courses. In particular, the work of Michel Foucault is perhaps most significant for its engagement with questions of subjectivity, agency, and later, ethics. Like most "theory neophytes"-as the graduate director at the University of Delaware stamped on my admissions application-I was fascinated by the questions of subjectivity, ideology, and discourse raised by postmodernism and poststructuralism. ${ }^{1}$ At the same time, I found myself struggling with equally important questions of responsibility and agency. What I didn't 
quite know then was that I was concerned with questions of ethics and the possibilities of articulating ethics within a postmodern framework.

Questions about agency, ethics, and the responsibilities of theory were brought home to me in an introductory theory seminar I took early on in my doctoral program. The subject of discussion was Volume 1 of The History of Sexuality wherein Foucault discusses, among other things, the creation of the confessional subject in Western history. His central thesis concerned the "repressive hypothesis," the long-held belief that sex was something that has not been and is not discussed. Foucault's genealogy reveals the complex discursive interdictions created to sustain, not silence, constant and exploratory discussions of sexuality. A woman in the seminar questioned Foucault's initial example of the discourses surrounding sexuality, prohibition, and a pathology of deviance. The example was the clinical examination and legal punishment of a "simpleminded" farmhand who had "obtained a few caresses from a little girl" who later reported the incident to her parents (31). Foucault describes this event and the fevered policing that followed as a petty investigation of an assumedly innocent event.

What is the significant thing about this story? The pettiness of it all; the fact that this everyday occurrence in the life of village sexuality, the inconsequential bucolic pleasures, could become, from a certain time, the object not only of a collective intolerance but of a judicial action, a medical intervention, a careful clinical examination ... (31)

The student in this theory seminar asked whether Foucault's rather glib use of this example was intended to condone this behavior as "an everyday occurrence," one that resulted in the unwarranted persecution of a farmhand. The professor's response sidestepped the problem of child molestation and directed us to Foucault's larger purpose, that of exposing how the confessional subject of sexuality has been catalogued, described, and controlled through various disciplinary techniques, and in the process, creating a clear identification of categories of normalcy and deviance. 
In short, a discussion of ethics and the ethical implications of Foucault's theory were effectively foreclosed in that classroom. The message was that a discussion of ethics constituted an irrelevant examination into the consequences of theory, indeed even replicated the very discourses Foucault's work sought to interrogate for their support of compulsory heterosexuality and "productive" sexualities. Although his transformative work on systems of thought surrounding sexuality is invaluable, Foucault's initial examination of subjectivity and sexuality does force us to confront how such a theory can recast what we would now, as in the case of the eighteenth-century French farmhand, consider a heinous, violent crime against a child. How do we reconcile a shift in thinking the subject with community norms of appropriate and inappropriate behavior? How can ethics work within the structuralist universe created in his work?

These questions, raised initially in the theory seminar, only became more pronounced upon reading "What is an Author?" in a rhetorial theory seminar. Rather than shying away from difficult questions of ethics and subjectivity, rhetorical theory engages directly with ethics in maintaining the centrality of ethos in the production, circulation, and reception of discourse. The construction of subjectivity in "What is an Author?" reduced the speaking/writing subject to a function of discourse. The authorfunction, as an example of Foucault's conception of subjectivity, operates, then, as a construct, a composite and conduit of the workings of discourse and power. In particular, Foucault asks at the close of the essay, "What matter who's speaking?, a question that confronts the rhetorical consideration of ethos. For the barrage of questions that respond to this inquiry ask about the rhetorical and ethical implications of such a question: Who is responsible for statements, especially when they can be abstracted to functions? How is ethos created in the wake of such an abstraction? What are the ethical and political implications of generalizing the speaker, and in the process, negating the identity that speaks through/in the subject? In more precise terms, Jane Flax asks about the seeming contradiction of ethos and subjectivity, "Without 
Enlightenment concepts of self, truth, and reason, what authorizes subjects to speak?" (197)

Critics are suspicious about the timing of Foucault's question, especially because of its implications for theorizing subjectivity. Of course, Foucault is not responsible or available to answer the questions raised by his work, but as Nancy Hartsock observes, "[S]ubjecthood becomes problematic" just when the silenced begin to speak (163). Hartsock's point is well taken in her mention of resistance movements, such as the women's movement, that were borne of a subjectivity that took as its starting ground the oppression of women. To erase the importance of subject positions through abstraction de-legitimizes the political force they attempt to achieve. Abstracting subjectivity to an effect of discourse "flattens" the subject to a generalized, universal construct, a move that denies the creative, political ways individuals manage and resist power. Furthermore, such an undifferentiated theory of power assumes that it constrains and oppresses all in a uniform fashion. In evaluating his theory of power for women, Hartsock finds Foucault's position, "the perspective of the dominator" (165), to be incompatible for a theory of power and gender relations. Resistance rather than transformation is the only available position in his work. "Because Foucault refuses the ground of foundationalism and the 'ungrounded hope' of Rorty, he stands on no ground at all and thus fails to give any reasons for resistance" (170).

Hartsock raises two key concerns in Foucault's work: 1) the political, ethical, and rhetorical ramifications of the subject who is an effect of discourse; and 2) the ultimate groundlessness of resistance. Both concerns point to the impasse that confronts the articulation of a postmodern ethical theory. Hartsock's hesitation to embrace Foucault's theory of power and subjectivity stands as an important objection to the totalizing tendencies of his work, especially its extremes of subjectivity.

More importantly, Hartsock also implicitly responds to the limits of the structure-agency model offered in Foucault's early work. I will directly address the 
limitations of this model in the following section, but for now, Hartsock's objections are a good place to start in recommending a different, and perhaps, more viable metaphor and model for mapping subjectivity and ethics, a model that does not concieve of resistance in merely reactionary terms, as the structure-agency model does. To this end, a move toward a spatial understanding of subjectivity and ethics might provide us with a more descriptive metaphor with which to conduct the present discussion. A spatial move may also help in my attempts to re-theorize a rhetorical understanding ethics and subjectivity in light of Foucault's late work on ethics and the self. However, I do not want to claim that Foucault's later work on ethics and the self in any way revised his ideas on subjectivity. ${ }^{2}$ Rather, his later work points to the limitations of a structureagency model for a discussion of ethics. What I want to emphasize is that Foucault's early work on subjectivity marks a moment, as well as a strain, in theory that has profound implications for ethical and rhetorical theory. Because of these limitations, as well as the paradigmatic development of his thought, I both begin and contend with Foucault to chart some of the central concerns and contexts of my dissertation. It is also because, as Bernstein confers, much of Foucault's thought suggests the impossibility of agency (223). In effect, Foucault serves as a major "plot" on the map of my work, not only as a point of departure and return, but also as an extended example of the difficulties and contradictions inherent in a discussion of the key terms of my dissertation: subjectivity, ethics, and discourse.

The anecdote I used to open this section, as well as my initial questions about the seeming theoretical incompatibility of ethics and subjectivity, shows how my interest in ethics developed from what I saw as the curious silence surrounding the ethical consequences of theory. In hindsight, the professor's handling of the student's questions about the ethical responsibilities of theory provides another important illustration and exigence for this dissertation. That is, the professor's refusal to discuss ethics suggests a certain discomfort with talking about the ethical in the public space of the classroom. 
Because ethics is tightly bound up with associations of the personal and private, I think there is an implicit but demonstrated ambivalence surrounding what we generally regard as within the realm of personal choice and private morality. While I do not think that avoidance of the private was the primary motivating factor for why the class did not pursue the ethical implications of Foucault's concept of subjectivity and agency, I do think that there was perhaps a pedagogical discomfort with raising serious ethical questions about postmodern theory. In response to what I see as a problematic lack of discursive space for talking about ethics, my dissertation is, in many ways, an attempt to "go public" in theory and in the classroom with a discussion of ethics, to contend with the ethical in the public space of the classroom and in the discursive space created by this project.

\section{Why Space?}

Ethics in the postmodern assumes that ethics cannot stand "for all time," and that subjects are also situated spatially and temporally. Foucault's dynamic sense of the subject and discourse recognizes the long-standing assumptions of power's workings through discourse, but it also sees, in the revised metaphor of space, the possibility of "other" spaces not offered in the structure-agency model. Space, then, works in this dissertation as a metaphor through which to discuss ethics and subjectivity. In this section, I want to map out how a move toward the spatial provides, not a solution to the problem of ethics and subjectivity, but a method to be used in understanding how a structure-agency model no longer yields a complex portrayal of politics, discourse, and ethics.

Upon reading The Use of Pleasure and The Care of the Self, one can almost hear the philosopher banging his head against the wall in the pursuit of a new paradigm for thinking the subject. I see this frustration as the exhaustion of the structure-agency model that has been with us since the Enlightenment, a model that describes resistance 
as a transcendence of structural determinants. Indeed, Foucault's project launched from this model to a large extent. While theoretically decrying the Enlightenment goal of transcending of social constraints, Foucault's praxis served this very goal in the attempt to carve out interstices of resistance. However, resistance is always implicated in the structures of control: "'discourse' [is] neither structure nor agency and both structure and agency" (Pile and Thrift 4). In other words, resistance comes from "wwithin,' for resistance is never in a position of exteriority in relation to power" (History of Sexuality 95).

Gilles Deleuze illustrates the possibility of agency and conscious selftransformation that surfaced in Foucault's later work. "The inside as an operation of the outside: in all his work Foucault seems haunted by this theme of an inside which is merely the fold of outside" (318). Foucault was attempting to find a doubling of a self, a self's relationship to oneself that assumes an "independent status" (320) than that of the outside. Deleuze observes, "[ $t]$ his is the Greek version of the snag and the doubling differentiation that leads to a folding, a reflection" (320). In other words, Foucault was attempting to rethink the metaphor of subjectivity outside of or beyond a structureagency model, a symbiotic and implicated process of resistance and domination. This later work gleans the possibility of an "undiscovered" or perhaps even "recovered" dimension of subjectivity, one "derived from power and knowledge without being dependent on them" (321).

We are left, then, without a viable revision of the subject, but Foucault's attempt to find that "independent status" (320) is an important place to start, especially as his later work focused on the possibility of ethical agency for the self. But this struggle suggests the possibility that our critical fallacy has been to see agency as a static place within discourse. Notably, Deleuze's use of the external and internal self, the inside and outside of subjectivity, suggests the spatial dimension of subject formation. The possibility of an inside that is more than a reflection of the outside is the promise we 
must pursue in articulating a theory of ethical subjectivity. More likely, though, we will find that there is no certainty of an "independent status," only new metaphors and histories to describe it.

Mapping allows for the simultaneous spatial and temporal deployment of coordinate plots. In my understanding, "mapping the subject" involves plotting the coordinates of subjectivity and ethics, with each of these plots rhetorically conceived. As Thrift and Pile aptly observe in Mapping the Subject: Geographies of Cultural Transformation, the paradigm of mapping provides a more useful and productive understanding of the subject and agency (5). Furthermore, it does not assume, as many agency theorists have, that transcendence of structure is either possible or desirable. "Thus the focus of an analysis of the self or body has changed from identifying their location on the continuum between structural and personal determination to looking at the ways in which subjectivity is reproduced in time and space" (5). Such a revision of the structure-agency model (re)casts the subject and the possibility of agency in terms of mobility. In the structure-agency model, we have resistance only in terms of and against power and oppression. Tactics for change, intervention, and critique can only be configured in reactionary, negative, or transcendent terms. A change in metaphor allows us another way of thinking the subject and the question of ethics in more productive terms than those in which it has formerly been cast. "The map-as allegory of space and time--and the subject-as allegory of place-in-the-world and limit-of-the-world--reveal that 'space' is actively constitutive of the practices of authority and resistance, of grounding meaning and re-placing meaning" (Thrift and Pile 49).

While mapping and the spatial are the most viable models for the present discussion, there are problems with these metaphors. The disposition to travel and movement suggested by such a model may not be quite as radical or enabling as it might sound (Thrift and Pile 24). Citing Charles Taylor's hesitation to embrace such a model, Pile and Thrift observe, "[n]ot only is the language of movement and mobility... 
nowhere near as radical as is often imagined but it can often simply displace rather than reformulate questions of subjectivity" (24). This point is well taken, especially when such theoretical acrobatics may overlook important questions of agency and ethics rather than clarifying or providing forays and "exits" for practical considerations. They warn: "The practices of visual representation of the map serve to disguise the power that operates in and through cartography. Maps are not empty mirrors, that at once hide and reveal the hand of the cartographer" (48). Mapping subjectivity is just as ideological and potentially obfuscating of relations of power as the aforementioned structure-agency model. The metaphor of mapping, however, is still helpful when used critically for establishing a relationship between the foundation of time that structures both the structure-agency model and traditional ethics and the dimension of space that provides a more mutable method and metaphor for this discussion.

Foucault's own work signaled a recognition of geography and the spatial conception of discourse and power. In "Questions on Geography," Foucault identifies the time-space dichotomy that has until recently been the dominant one for organizing and understanding politics, knowledges, and history. "Space was treated as the dead, the fixed, the undialectical, the immobile. Time, on the contrary, was richness, fecundity, life, dialectic" (70). This observation is developed in the critical social theory of both Edward Soja and Doreen Massey, with each critiquing and amending the assumptions of this dichotomy in their arguments. Edward Soja argues that it has been time, not space, that has been privileged in historical thought and imagination, and even when geography has been the "first term" of discussion, it is always conceived in temporal terms. Using the example of Marxist geography, Soja identifies how space came to be known as an inert category. Western Marxism had two key features: "an emancipatory interest in the power of human consciousness and social will to break through all exogenous constraints; and a critical inscription of this social power and potentially revolutionary subjectivity in the 'making of history', in historical modes of 
explanation and interpretation, confrontation and critique" (30). Any focus on space was seen as a negation or avoidance of history, and consequently counter to the goals of enlightened struggle; geographical emphasis assumedly harbored territorialism and nationalism. The entrenched structure-agency model is a perfect example of the value of time over space; one "makes history" by transcending or becoming exterior to it. Mapping forecloses on this opportunity to transcend time by replacing the importance of space in its relationship to time, thereby locating the subject as well as her attempts at agency well within the very framework she seeks to escape; in short, space assumes that there is no "outside," only other spaces "within" that can be occupied, taken, and negotiated.

One of the critical omissions in the temporal emphasis is and has been the relationship between the social and the spatial, an assumption that has further characterized space as a dead category. I think it is interesting that Soja equates the subordination of space in critical social theory with then current rejections of the relationship between environmental factors and human consciousness--in other words, a refusal to think of the individual in terms of subjectivity.. Soja's is an attempt to even the scales between the space-time imbalance, one that favors the mapping of human geographies. In so doing, Soja asserts "spatiality, temporality, and social being" (25) as the dimensions of human experience. Early twentieth-century social theory saw little or no relationship between "environmental causality... and the formation of human consciousness" (35). In effect, the subject of liberal humanism was not "subject to" constraints and causalities of space and time; in speaking and acting, the liberal subject transcended these conditions through personal will and rational autonomy. Because of this, Soja argues for a "socio-spatial dialectic" (79), an understanding "that social relations are simultaneously and conflictually space-forming and space-contingent" (126). Space is not merely the reflection of social relationships, nor are social relationships determined solely by space; rather, the dialectical interplay of the two give 
meaning to space and spatial practices. Because space is social, "it can engender contradictions and transformational potential" (82). To this end, the spatial provides a more operative metaphor for conceiving agency and ethical subjectivity.

The postmodern penchant for space should not, however, completely overlook the importance of time. Instead, space needs to be understood in its relationship to time. To this end, Doreen Massey argues that re-valuing or celebrating the spatial is not enough in reinscribing the spatial into social theory, a theoretical "upgrade" that Soja attempts. Instead, Massey interrogates the binary logic that has erected the longstanding space-time dichotomy, arguing for a simultaneous deployment of space/time. Space "is not absolute, it is relational" (261). In this way, space retains its dynamic possibilities because, similar to Soja's view, space is social. It is not merely a fixed place for social relations to take place. It is, moreover, "a moment in the intersection of configured social relations" (265). Massey notes that this configuration, by virtue of its inherently social dimension, produces conflict as well as solidarity (265). Space thus operates in moments of order and chaos (265); that is, order comes from the management and use of space, while chaos exists in the relativity of various locations. Without the underlying rationality of temporal organization, the spatial takes on a unpredictability and lack of causality endemic to spatial relations. Despite this "erratic" possibility of the spatial, Massey asserts that space can and does, in fact, operate by a logic not unlike that of time. To examine this, we need to re-think our approaches to the social in order to see the ways in which the spatial is involved in the production of history. Ultimately, Massey wants to insert a specifically political dimension to the spatial, a possibility that has been reserved for historical/temporal readings.

\section{In Search of ... Agency: Foucault's Ethics and the Problem of Subjectivity}


As Jeffrey Harpham argues, Foucault never broke free of the legacy of the Enlightenment. He did not resolve or synthesize the polarity created by the overdetermined subject of discourse and the anarchic autonomy of the free self (Norris qtd. in Harpham 537). This problem is clearly illustrated by reading his early work on subjectivity against his later work on the self. In this section, I want to "revisit" Foucault's departure from questions of subjectivity and his turn toward Hellenistic philosophy. My point here is to show how Foucault's later work confronts his early constructions of subjectivity, a confrontation that helps both to situate and portray the political and philosophical problems of ethical subjectivity . More importantly, my goal is to illustrate how his work on the ancient Greek notion of the self indicates the historical rift that occurs between ethics and politics, a distancing that had both spatial and political consequences.

In moving toward the goal of promoting "new forms of subjectivity," Foucault excavated the ancient Greek idea of the self (Rabinow and Dreyfus 216). But his goal was not to liberate the individual from the state; rather, it was "to promote new forms of subjectivity through the refusal of this kind of individuality which has been imposed upon us for several centuries" (Rabinow and Dreyfus 216). What I see emerging in this work is a tension between his earlier conception of the subject as a function and effect of discourse and the transformative self discussed in the last two volumes of The History of Sexuality. Once a determined space in discourse, resistance configured only in terms of its relationship to power, the subject needed a way out, a response to the internalized external that could, in some way, forge a productive political self. Thus, the problem of ethics is inextricably tied to configurations of the self and subjectivity (Dreyfus and Rabinow 231). With this problem in mind, he searched for a new way to discuss and situate the subject. His search took him to the ancient Greeks, in particular the Hellenistic philosophies of the Cynics, Stoics, and Epicureans. In this work, Foucault excavated an ethic of care for the self, one based on the self-abasing life practices of the 
early Cynics. In The Care of the Self and his last lecture series at the College de France, ${ }^{3}$ Foucault articulates a theory of the self that concentrates on asceticism as a pathway to freedom. This theory suggests agency, or freedom as Foucault names it, in the aesthetic performance of ascetic existence. While such a move attempts a productive theory of the subject-as-self, it "complicates" politics in the aestheticization of individual control over the body, dietary practices, and material possessions. His focus, then, was no longer on the orders of discourse, but instead on how the individual acts upon himself to attain a state of happiness or perfection (Technologies 4).

In The Care of the Self, Foucault outlines exactly what the care of the self involves. Although much of the text concerns sexual ethics, Foucault is here embarking on a revised conception of the subject and one that will appear in his later work in Technologies of the Self and the College de France lectures. According to Foucault, the care of the self involves the transformation of "existence into a kind of exercise" (The Care of the Self 49). It is a techne of becoming and continual self-transformation.

Circulating about this transformed self, Foucault writes, is the larger practice of speaking and writing the self (54). The practice of reflection and record of the self's daily toil and accomplishments toward the minimum, the extremes of Cynic and Stoic asceticism, turn this process into "the division of the subject into a judging authority and an accused individual" (61). In bipolar fashion, the self is simultaneously called upon to make a record of its habits of dress, thought, comportment, and diet and to judge this behavior. "An ethics of control" (65) derives pleasure and delight in keeping base desires "managed." A sense of domination over desire assumes a juridical model of control (65). Such restrictions on the self, he warns, should not be read as repressive systems of authoritarian restraint akin to modern conceptions of morality. Rather, for the ancient Greeks, ethical subjectivity "had more to do with the manner in which the individual needed to form himself as an ethical subject" (67). This model did not subjugate desire but worked toward the formation of ethical subjectivity: "Self-mastery' (63) was still a 
purpose but one with a different emphasis. It did not involve the control of desire, of the mind's superior faculty over corporeal drive. Instead, the health and maintenance of the entire person, body and mind, was the goal of Greek ethics, and that each would work in harmony with the other. "This regimen does not require that one institute a struggle of the soul against the body, nor even that one establish the means by which the soul might defend itself against the body. Rather, it is a matter of the soul's connecting itself in order to be able to guide the body according to a law which is that of the body itself" (The Care of the Self 134). As I have been suggesting, another theory of the subject operates in this work: the constructed subject we are familiar with, the bare "function derived from the statement" (Deleuze 325) is in contrast to a transformative self that uses its existence as the example of freedom and ethical integrity.

Even while he appeared to be moving toward a sort of apolitical aestheticization of the self, Foucault was experiencing the tension of negotiating the political and the ethical, two poles that were once historically aligned. We might read his turn to Hellenistic philosophy as a search for just how these poles disconnected from their initial relationship. The Hellenistic period, according to Foucault, is characterized by attention to action and practice, but in taking care of the self, one had to "leave politics to take better care of the self" (31). Ethics became, then, a means of struggle, "an invitation to a practice of liberty, to struggle and transgression, which seeks to open up new possibilities for new relations to self and events in the world" (Bernauer and Mahon 154).

In the last two volumes of The History of Sexuality and the College de France lectures, Foucault discusses not a subject of power but a transformative self, one that engages in care as a practice of freedom. In what reads as an ironic turn toward the autonomous Enlightenment self, the subject is granted some possibility for negotiating subjectivity. The ethic of care of the self is not informed by a disciplinary system of ethics; rather, it is an ethics of self-governance. Dreyfus and Rabinow outline four 
aspects of Foucauldian ethics articulated in The Use of Pleasure that serve as a model of critical ethics: 1) "the ethical substance" or the ethical problem; 2) "the mode of subjection ... the ways people recognize moral obligations"; 3) "the means by which we can change ourselves in order to become ethical subjects"; and 4) "which is the kind of being to which we aspire when we behave in a moral way" (239). This model does not contend with a priori truths or categorical imperatives, but attempts a process of examination of the process of ethical decision-making and the ways in which individuals are called upon as ethical subjects as well as the discourses they negotiate in choosing ethical stances. Rabinow and Dreyfus confer that Foucault "does not seek to deconstruct the subject but to historicize thoroughly the deep self in order to open the possibility of the emergence of a new ethical subject" (my emphasis 254). Arnold Davidson makes this point even more precisely but implicitly warns against reading Foucault's turn to the self as a continuation of his work on subjectivity: "Foucault's conceptualization of ethics as the self's relation to the self does not depend on any modern understanding of subjectivity. Writing this history of ethics is part of writing a history of the self" (133).

\section{III. "Going Public": Habermas, Ethics, and the Public Sphere}

While this project is clearly indebted to the theoretical insights gathered from my reading of Foucault, Jürgen Habermas's work on the public sphere is also indispensable for my discussion of how ethics circulates within a spatial and social economy of the public and private spheres. My dissertation responds to the separation between politics and ethics, a disconnection that inevitably raises the complicated relationship between the public and private sphere. And while Foucault stands as a major point in plotting the critical intersections of subjectivity and ethics, Habermas's work is vital, because it provides a model of the public sphere that is historically connected to communication, ethics, and politics. 
In The Structural Transformation of the Public Sphere, Habermas traces the changing meanings and uses of the public sphere in democratic societies. Beginning with the etymological trace of private and public, Habermas sets out to describe and historicize the bourgeois public sphere from its early, ideal formation in the eighteenth century through the decline of its original possibility and emancipatory potential. In its ideal form, "[t]he bourgeois public sphere institutionalized, according to Habermas, not just a set of interests and an opposition between state and society but a practice of rational-critical discourse on political matters" (Calhoun 9). Thus, the public sphere is that social space designated by rational communication and reasoned argument wherein “private people come together as a public" (Habermas, Structural Transformation 27).

The public sphere underwent transformations that compromised its potential as a space for "debate over the general rules governing relations in the basically privatized but publicly relevant sphere of commodity exchange and social labor" (Structural Transformation 27). The public sphere initially emerged as a space separate from the state and government and was associated with the patriarchal family and economics. The depoliticization of the public sphere came about gradually and due to a variety of causes. The most marked was the collapse of the public/private dichotomy as private organizations grasped public power "while the state penetrated the private realm" (Calhoun 21). The state became aligned with society, and economics--"private" industry and labor--became a more powerful theme in the public sphere, while the private became primarily a space of the family, but one that was becoming more public in its function. Furthermore, Habermas sees the decline of critical discourse as central to these structural transformations. Notably, however, the decline of the public sphere can be reversed through the re-emergence of critical democratic discourse, a project Habermas takes on in a different way in Moral Consciousness and Communicative Action. 
In acknowledging the impossibility of rescuing the eighteenth-century model of the bourgeois public sphere, Habermas focuses primarily on the possibility of critical discourse as a remedy for the public sphere's decline. An ethic and logic of consumption as well as the mass media are principally to blame for the weakening of this discourse and the fracturing of subjectivity that characterizes the late modern period. The result of such a splintering of subjectivity is a lack of focus, cynicism, and the inability of critique (Calhoun 24), a condition that further results in the "loss of a notion of general interest and the rise of a consumption orientation, ... [as a result], the members of the public sphere lose their common ground" (Calhoun 25). Without the possibility of "common ground," politics becomes entirely personalized and the intelligentsia--those left "to produce culture and criticism of it"--become more specialized and increasingly less public (Calhoun 25). The centrality of the media and the decline of critique results in public communication that relies solely on persuasion, rather than critical debate. A project of revitalization would then focus on "the struggle ... to find a form of democratic public discourse that can salvage critical reason in an age of large-scale institutions and fuzzy boundaries between state and society" (Calhoun 28). Transformation comes through making publicity "a source of reasoned progressive consensus formation rather than an occasion for the manipulation of popular opinion" (Calhoun 28).

For Habermas, revitalization of the public sphere is an attempt to rejoin politics and ethics through debate and reasoned argument. As I discuss in depth in Chapter One, his move toward communicative rationality could be read as a practice of transhistorical communication based not in the institutions of a society but in the foundational principles of argumentation. Several problems emerge from such a shift, although I will not examine them here. But what Calhoun and the contributors to Habermas and the Public Sphere observe are the oversights of Habermas's work on the public sphere. A few of them should be noted here because I do not want readers to 
assume that I am working for the very goals that Habermas outlines in his work. Criticism of Habermas's argument include his scarce treatment of our current moment, late twentieth-century capitalism, with the same critical eye with which he reads the eighteenth and nineteenth centuries (Calhoun 38). By categorizing and characterizing the public sphere as an uncritical, passive space for consumption rather than critical discourse, Habermas neglects social movements and agency, those "struggles by which both the public sphere and its participants are actively made and remade" (37). Furthermore, and as I argue in Chapter Three, Habermas does not consider the gender implications of his divisions of the public and private spheres.

Notwithstanding the limitations of his work, Habermas's concern for the political and communicative ineffectiveness of the modern subject is where my inquiry begins. Despite my departures from his lament for the Enlightenment and its universalist claims of reason and transparent communication, I do find the promise of a transformative public sphere and the integral role of argument in it an important starting point for the rhetorical theory I propose in Chapter One. However, Habermas's attempts to join the ethical and political remain within an economy of the public. Thomas McCarthy observes that Habermas's moral theory is really a "'political morality'--of social justice rather than of moral virtue, character, feelings, and judgment, or of ethical life, community, and the good" (51). The exemptions to this "political morality"--affect, decision-making, and ethical life--are the very concerns of "private justices" that this study--at times explicitly, at others implicitly--works toward integrating and negotiating in the larger project of re-connecting rhetoric, ethics, and politics.

\section{Only Connect: Rhetoric, Ethics, and Space}

The spatial-temporal insights of critical social theory are important for understanding and reconceiving ethics. Ethics are embedded in social practices and the production of spaces. Thus, ethics can be conceived as spatio-temporal practices. If we 
consider the assumption of time employed by ethical absolutism, that certain values and ethics can stand "for all time" and for all rational beings, then I think we can see the importance of critiquing the authority of time over space as well as the temporal assumptions of the structure-agency model. Plotting subjectivity and ethics spatially provides a more active and changeable metaphor for theorizing a rhetoric of action. In so doing, a spatial rhetoric emerges in the mapping of these coordinates. Moreover, the idea of social space works to foreshadow my later consideration of ethics in the public sphere, a discussion that highlights the problems associated with spatializing ethics and politics in terms of sites.

Within the field of rhetoric, the spatial dimension of discourse has long been recognized. In a very general sense, rhetoric is a discipline "in space"; it does not derive an identity based on disciplinary sites or fix itself within specific boundaries. In historical terms, Keimpe Algra notes that Aristotle's topoi, the basis for invention, means spaces. ${ }^{4}$ We might then read Aristotle's advice on choosing topics and the appropriate means of persuasion as ways of finding spaces from which to speak. In terms of pedagogy, Sharon Crowley describes teaching and writing as having "a certain locatedness. That is, both are carried on by given human beings in given communities. The relationships that develop between teacher and students, among students, and between writers and readers are always specific to a certain time or place" (332). While she addresses the literal contexts in which communication takes place, Crowley conceives of these relationships--the rhetorical context--as inherently spatial. Nedra Reynolds's understanding of rhetoric as spatial leads her to a reading of ethos as location. By tracing the etymological and social nuances of this concept, Reynolds argues for more active and transformative notions of ethos, ones that "help to reestablish ethos as a social act and as a product of a community's character" (327). This revision of former conceptions of ethos foregrounds the cultural matrix in the creation of authoritative spaces from which to speak. Thus, a spatial rhetoric is well-poised to 
carry on the critique of ethics and to provide a direction for developing a discussion of ethical subjectivity because it can account for the discursive spaces created by and in culture as well as offer ways of reading how ethical discourses are occupied by subjects.

In general, argument is a key rhetorical mode used in many models of the public sphere and in many contemporary proposals for talking about ethics in a public way. That is, argument has traditionally been invoked as the dominant mode of most models of public discourse. Likewise, critique and argument are central to a rhetorical understanding of ethics and provide the rhetorical tools in most models of ethical discourse. However, the attempt to rebuild the ethical foundations of public discourse by advocating argument rests upon the unexamined assumption that there is presently a public space available for a discussion of ethics and politics and that argument provides a public way of talking about ethics. Furthermore, most proponents of argument-as the means of deriving ethics as well as continually critiquing the normative grounds of ethical claims--overlook the essentially spatial moves that their proposals enact.

Examples of rhetoric's reliance on the assumed "goods" inherent to argument are evident in many recent contributions to the creation of a discourse ethics. James A. Herrick furthers rhetoric's importance for ethics in deriving an ethic of rhetoric that is suggested by the practice of rhetoric itself (133). Although he looks specifically at the virtue ethics of Alisdair MacIntyre, Herrick makes an important observation of rhetorical norms: "the adversarial nature of rhetoric actually enhances its moral character for all members of society in which rhetoric is freely practiced" (134). Although his assumptions of a free society are questionable, Herrick keeps alive the importance of reasoned argument in debating questions of ethics, for the "goods" internal to a dialogic model of ethics are derived from rhetoric. Thomas Frentz seconds the communicatory locus of ethics in his support of a "rhetorical conversation [that] is a narrative episode in which a conflict over opposing moral viewpoints re-unites the agents with their own moral histories, with the moral traditions of which they are a part, and--perhaps most 
important-with an awareness of the virtues" (4). Lawrence Kimmel makes the strongest argument for the past and continued link between rhetoric and ethics, unifying these two poles in the imperative of public or community discourse: "Rhetoric, availing us through language of the means of persuasion, is the basic tool of practical affairs and is thus essentially connected to ethics" (2). Kimmel emphasizes the importance of reinstating community in the discussion of ethics, even as an ethic of its own. In response to increased privatization of the social sphere, Kimmel argues for both an ethic of community as well as a rhetorical understanding of argument and consensus in ethical decision-making.

What all these theorists share, despite their different configurations of virtue and ethics, is a reinstatement of rhetoric's ethical foundations. Their examinations implicitly assume and create a public space in the formation of discourse communities, especially as their sense of "public" or "civic" hinges upon an inert or undifferentiated public sphere. Notably, they each allude to the current search to excavate ethical foundations in the creation of discourse models and the valorization of community, an emphasis that has carried over into composition studies and the reliance on Aristotelian models of civic discourse. Implicitly, their arguments advocate the reunion of ethics and politics in the civic sphere, with each drawing upon Aristotelian notions of public discourse for the maintenance of political community. In the process, their advocation of argument hits a snag on the problems of discussing a particularly spatial use of ethics and rhetoric: ethics invariably calls up notions of the public and private spheres. This snag occurs because ethics is traditionally aligned with the private moral decisions of individuals, not as Kimmel, Frentz, and Herrick argue, in the public realm of community discourse. Their work testifies to the recent trend to reconnect rhetoric to both politics and ethics, three poles that have become distanced in political discourse. Within rhetoric and composition studies, this attempt to link politics and ethics has often drawn upon the 
very model of public discourse they employ in arguing for argument as a communicative grounding for ethics.

Generally speaking, ethics maintains a rather ambivalent relationship with rhetoric and composition. This ambivalence stems from the fact that we do not yet have a public way of discussing ethics, especially one that does not replicate a traditional ethicist's emphasis on universalist norms in ethical decision-making. To understand the potential problems with these models, as well as their valuable contributions to building an ethical rhetorical theory that can meet the problem of subjectivity, we need to plot the central terms of this discussion--ethics and rhetoric-as a spatial rhetoric, one informed by an understanding of the social, ideological, and political dialectic of culture and space. We need also to understand rhetoric as choice, a specification that addresses the ethical dimension of the judgment, production, and circulation of discourse. To this end, I want to proceed with James Porter's articulation of the important connections between rhetoric and a distinctly postmodern ethics.

Ethics in the postmodern sense, then, does not refer to a static body of foundational principles, laws, and procedures; it is not to be confused with particular moral codes or with particular sets of statements about what is appropriate behavior or practice. Ethics is not a set of answers but a mode of questioning and a manner of positioning. That questioning certainly involves principles--but it always involves mediating between competing principles and judging those principles in light of particular circumstances. Ethics is decision making--but it is decision making that involves question and critique. It is informed, critical, and pluralistic decision-making. (218)

In Porter's use, rhetoric provides the tools for adjudicating among competing, plausible principles. The process of negotiation bridges the ethical and rhetorical in each act of discursive decision making for "rhetorical action always involves ethical judgment" (Porter 221). But Porter's attempt to theorize postmodern ethics for rhetoric is only one 
of the few recent attempts to discuss postmodern ethics for and in the field. As Porter makes clear, postmodern ethics retains ethical decision-making, but it also maintains a skeptical eye toward judgment by keeping in mind contingencies of context--or in the terms that I have used--spaces. In effect, the ethical turn in rhetoric-albeit an ambivalent one--is about the renewed relationship between discourse and action. In other words, because rhetoric involves the relationship between discourse and action, rhetoric is fundamentally concerned with ethics. One aspect of this relationship is the (dis)placement of the subject in "acting out" a rhetorical process of judgment.

\section{The Map}

Because my sense of ethical decision-making relies on a simultaneous understanding of space and time, mapping serves as the best way to describe and propose a way of reading my dissertation. Already, several key plots--space, ethics, rhetoric, and subjectivity-appear and return as I examine each in relationship to the other. In keeping with this approach, Chapter One, "Spatial Agents and Ethical Plots: Toward a Theory of Kairotic Ethics," begins where my inquiry into subjectivity ends in this introduction: with the problem of ethical decision-making. I begin this project with an eye toward negotiating a process of rhetorical decision-making in the postmodern. This goal serves to illustrate initially how contemporary ethical theory has been cast into the polarized extremes of "either" an ethics based upon foundational premises "or" ungrounded skepticism. In light of this dichotomy, I argue for a "space-between" the ethical relativism offered in postmodern theory and the foundationalism suggested by universalist positions, opting for the rhetorical and ethical space of a kairotic ethics; kairos here refers to the rhetorical process of timing, when discursive intervention might best be made. In the process, I will examine current investigations into ethical theories, an inquiry that identifies the spatial practices suggested by them and how they both include and exclude important rhetorical considerations. Ethics, while being read 
rhetorically, will also be read spatially and temporally-that all attempts at judgment are spatial practices. Ethics becomes, then, "less about the ability to formulate rules than by knowing how to act in each particular situation" (Thrift and Pile 29). Notably, this revision of rules to a sense of timing and action resembles the rhetorical concept of kairos. I conclude by offering the implications and possibilities of kairos--in both its temporal and spatial meanings--as one possible way of both theorizing and understanding ethics in its relationship to subjectivity. In my reading, kairos suggests important rhetorical and ethical foundations that can be used in creating an ethics "inbetween."

Chapter Two, "Cynic Rhetoric: The Ethics and Tactics of Resistance," taking as its starting point Foucault's work on the Cynics, argues for a rhetorical reading of the Cynic philosophers, and in particular, the character of Diogenes of Sinope. The Cynics are important for this discussion namely because little has been done to excavate what they offer for the history of rhetoric, even as they are currently being rediscovered in other fields. Furthermore, because they serve as examples of the important, demonstrated link between politics and ethics indicative of the public sphere in ancient Greece, the Cynics have resonance for our current lament for this kind of public sphere, one wherein the political and the ethical are closely joined through rhetoric and action. Chapter Two locates the Cynics within Hellenistic rhetoric, a period that has seen too little inquiry in terms of what kind of rhetorical repertoire developed out of this period. My re-reading focuses on the tactical ${ }^{5}$ uses of parrhesia, diatribe, exile, and parody by the Cynics as these rhetorics acted out a uniquely Cynic ethics, one that worked to bridge the connections between ethics and politics.

Chapter Three, "Hipparchia the Cynic: Feminist Rhetoric and the Ethics of Embodiment," continues the discussion of exile as a critical rhetorical stance, a discursive position I discuss briefly in Chapter Two. This chapter sets out to reclaim exile as a tactical rhetorical space for a feminist ethics. Beginning with Hipparchia the 
Cynic, I use her presence in Cynicism as the starting point for my discussion of ethics and the problem of embodiment. From here, I question how the specificity of embodiment often leans upon essentialist theories of woman, theories that also build off of questionable notions of the feminine and the female body that have been used to establish a specifically feminist ethics. While a good deal of this chapter serves to critique feminist ethics as it has been adopted by feminist rhetoric, I conclude with a case study of Fauziya Kasinga, an exile from Togo, who sought asylum from genital mutilation by illegally entering the United States. Her case raises important questions about gender as an historically unprotected category of immigration law as well as an example of how both ethics and the public sphere has and continues to assume male embodiment as the norm, an assumption that avoids "the particularities" of race and gender (Landes 99).

Chapter Four, "Ethical Subjects: Composition, Pedagogy, and the Postmodern Classroom," examines the ambivalent connections between rhetoric, ethics, and politics in the field of rhetoric and composition studies. My emphasis here is clearly on presenting composition studies as a discipline that has been only marginally successful in articulating postmodern ethics for the classroom as well as the field as a whole. For evidence of this, I look to the field's historical reliance on prescriptive or traditional ethics to point out the need for a more critical ethics, one that will not repeat the universalist, normative foundations evident in college curricula of the early university. Many attempts to bring the moral and ethical into the classroom draw upon Aristotelian notions of civic discourse and political community, a recurring return that risks an uncritical use of an ancient Greek model of the public sphere which bears little resemblance to the public spheres available in late twentieth-century life. And, because ethics is currently bound up with the private sphere, an attempt to "go public" with ethics by setting up an Aristotelian civic community betrays the complex relationship that exists between public and private spheres, a complexity that was not nearly as 
evident in the ancient Greek polis as it is today. My tentative "solution" to this problem is to argue for Foucauldian ethics that would help to motivate a move toward a more critical ethics for composition studies.

Chapter Five, "Ethics and HIV Testing: Toward a Pedagogical Project," works as both a conclusion and a practical application of how I see many of the issues raised in the dissertation working out on the local level of a classroom. In this short chapter, I engage with questions of private and public spheres, ethics, rhetoric, and the ways in which the self turns herself into an ethical subject. To enact the complex relationship between the key terms discussed throughout the dissertation, I turn to the issue of HIV home-testing as one that works off of the relationship of the public and private spheres. While initially creating certain kinds of subjects--the subject of public health, of disease, and of testing--the call for testing both complicates and re-erects associations of disease and disclosure. The issue of HIV testing is both timely and important for the writing classroom because it simultaneously draws upon our private, even secret, associations of sexuality and HIV status in their relationship to the public management of disease and ethical responsibility. HIV home-testing is an issue that directly confronts the dichotomies, as well as the links between, the political and the ethical. This issue and my proposed treatment of it in a classroom project on the study of HIV testing advertising also engages with Foucault's four modes of ethical subjectivization, a pairing that I hope to have future students examine in their study of ethics and HIV hometesting. 


\section{Chapter One \\ Spatial Agents and Ethical Plots: Toward a Theory of Kairotic Ethics}

Contemporary rhetorical theory has been receptive to the discursive turn in poststructuralist and postmodern theory. The discussion and inclusion of thinkers such as Friedrich Nietzsche and Michel Foucault in Patricia Bizzell and Bruce Herzberg's canon-forming The Rhetorical Tradition: Readings from Classical Times to the Present is certainly evidence of how major shifts in thinking the subject, discourse, and ideology have found their way into the field. In addition, Lester Faigley's Fragments of Rationality: Postmodernity and the Subject of Composition is an argument for reading and repositioning rhetoric's companion, composition, in light of such philosophical shifts. Faigley's text is also an inquiry into what a postmodern rhetoric might look like in the local space of the classroom. To this end, he looks to the directions offered by electronic communication for an enactment of a postmodern conception of the subject. More importantly, to meet the changing conceptions of the subject, discourse, and discursive responsibility, he draws on the work of Jean-François Lyotard to help in the project of reconfiguring ethics in light of the fragmented and unauthorized vision of the subject in postmodernism.

While I will address Faigley's text directly in Chapter Four, what his work-as well as Bizzell and Herzberg's--establishes for this discussion is an inquiry into what a contemporary rhetoric informed by postmodernism and poststructuralism would look like. If we follow Lyotard, as Faigley does, a postmodern rhetoric resembles a blend of Sophistic rhetoric and Aristotelian ethics. It would dispense with foundational premises for rhetorical authority, replacing these with spatial or "site-based" metaphors of authority. A postmodern rhetoric would interrogate the value and artifice of rationality by "playing" with logocentric patterns of development and exposition. In contrast, it 
would challenge the authority of discursive genres and the imposition of rhetorical context by creating experimental, hybrid texts. Postmodern rhetoric would value opinion and contingent knowledges rather than seeking "trans-discursive" truths about language and subjectivity. In short, postmodern rhetoric, if enacted, would dramatically change the way we think about language, our responsibilities to audience, and our conceptions of ourselves as authoritative and authorized speakers and writers.

While I endorse the theoretical possibilities of this rhetoric, I have questions about how a postmodern subject can negotiate agency and resistance. If there is no "outside" of discourse--no stable ground on which to authorize action-how do subjects write or speak their way into discursive situations that require their response? Because I understand rhetoric as choice and action, I have serious concerns about the ethical implications of a rhetoric that theorizes choice and action in such a way as to make them inert and that implicitly sees ethics as just another discursive imperative parading as truth. The question of the ethical is briefly addressed at the end of Faigley's text, but the marginally helpful response found in Lyotard's The Differend points to the immediate, and in some sense, imperative need for an ethics that will guide rhetoric's embrace of the postmodern. To this end, I will be working toward a theoretical account of kairotic ethics--an ethics informed by kairos--that is attentive to philosophical and epistemological shifts produced by postmodernism, but one that will not drown in the extreme relativism suggested by a postmodern ethics.

When we come to the question of postmodern ethics, we need only to consider the answer provided in the most general claims about postmodernism's destabilizing tendencies. The end of metanarratives of truth and rationality, radical skepticism, and the reduction of culture and capital to the endless play of signifiers, are a few of the theoretical obstacles that stand in the way of creating a viable postmodern ethical theory. That is, the question of postmodern ethics becomes a difficult proposition in ethics's historical dependence upon universal criteria for judgment. Indeed, how can the 
question of deriving and applying principles that will dictate behavior be asked within the postmodern? How can judgment be achieved when "opirion politics" (Lyotard 81) guide discussion, when there are no available criteria for judgment? Furthermore, how can any viable social theory be created if it can be easily dismantled by charges of relativism, a consequence of contingency ethics?

When cast in the terms of these questions, postmodern ethics stands on shaky ground because it assumedly stands on no ground at all; there is nothing authorizing or legitimating this ethics except context and situation. In contrast, traditional or universalist ethical theories rely upon normative, "grounded" imperatives and guides for ethical decision-making, and ask for consistency in applying ethical norms to divergent situations. I use these oversimplified definitions intentionally because they serve to illustrate the fundamental dichotomy existing between universalist and postmodern ethics. On the one hand, we have the "ungrounded," contingent judgments in the postmodern; on the other, we have ahistorical norms of judgment, those firmly authorized stances associated with the universalist position. In my view, neither position is tenable for creating an ethics for postmodern rhetoric. Furthermore, the dichotomy that structures this debate considers only these two extremes, leaving out a whole range of "in-betweens" that can provide important and overlooked ethical and rhetorical possibilities. Michael Bernstein observes a similar and "specious" dichotomy between the postmodern and universalist positions. "[E]ither there are universal ahistorical normative foundations for critique or critique is groundless. This specious "either/or" closes off the topos that needs to be opened for discussion, the topos toward which so much of the polemic of modernity/postmodernity gravitates" (222).

As I contend, "this specious 'either/or" is a rhetorical move within theory, one that effectively helps to set up a "straw-man" of either postmodern or universalist ethics, and one that deserves a rhetorical response. Reducing ethics to a choice between two extremes forecloses on the possibility of something between radical skepticism and 
universalism and oversimplifies the complexities of each. Interestingly, Bernstein responds to a closing off of "the topos," those spaces between the dichotomy that need to be opened up for discussion. I look to that kairotic space between to create an ethics of rhetoric that merges some of the important insights of postmodern ethical theory with its seemingly polar opposite of normative decision-making.

Choice and decision-making are central components of rhetoric. Furthermore, I want to retain rhetoric's historical emphasis on discourse and action in meeting the destabilizing tendencies of the postmodern. This task requires not only a tenable theory of ethics, but also a spatial and temporal reworking of the rhetorical concept of kairos to help meet this challenge. Within rhetorical theory, little has been done to combine postmodern and traditional ethics, especially into an inquiry that draws from the contemporary philosophical arguments put forth by Jürgen Habermas and Jean-François Lyotard, two theorists who represent the extremes of the "either/or" dichotomy and who are being imported into the field for what discourse models they provide. Notably, both are speaking in very rhetorical terms about discourse, ethics, and judgment. Because of this, rhetoricians are attempting to provide a way of talking about ethics and how the models created in their work might help to meet our contemporary rhetorical needs. But simply by virtue of their foundationally opposed projects, their extremely different proposals for ethics in the contemporary sphere point to the need for a rhetorical theory that opens up some other spaces-between, ones that I find are more sensitive to context as well as the need for action.

In this chapter, I look at the space between the "either/or" dichotomy to map a spatial rhetoric of the subject, ethics, and kairos that will work toward meeting the seemingly impossible and imperative task of creating an ethics of rhetoric, one that will "neither" wade into the extreme relativism of postmodernism "nor" the ahistoricism of universalist paradigms. The move toward the spatial, this new topos, assumes space not as an inert category, but as those localized, lived practices that occur in social and 
political contexts. This spatial reading of ethics understands ethics as the responsibility to respond both to the social order and "the social other" (Nealon 134).

But merely endorsing the spatial over the temporal re-erects another either/or dichotomy. That is, just as the false presentation of the postmodern and universalist postions closes off spaces, so too does the postmodern penchant for space, an emphasis that overlooks the importance of time in ethical decision-making. Therefore, in this discussion, ethics exists in both time and space. That is, ethics are temporally embedded in social practices and the production of spaces in discourse. They are historically located as weil as spatially enacted. Similarly, kairos, a concept that has often been read as mere "timing," has much to offer this discussion in a spatial reading of its ethical implications as well as its possibilities for rhetorical action. In my discussion, kairos marks the space-between the extremes in ethical theory.

\section{Clearing a Space for Kairos}

A spatial rhetoric that plots subjectivity and ethics is able to examine the discursive implications of emerging theories of ethics and judgment, such as those offered by Lyotard's important contribution to this theme. But Lyotard is the "straw man" sitting on one side of the either/or dichotomy; Habermas sits squarely on the other. In both, we meet philosophers who have a curiously rhetorical and spatial understanding of judgment and ethics. To illustrate the either/or dichotomy and where the space-between needs to appear, I want to look at the rhetorical and spatial practices suggested by their work and respond to the oversights and exlusions of both. In particular, they both omit an understanding of time's relationship to space in conceiving their respective approaches to ethics.

\section{I. "Either" Lyotard}


One of the central criticisms of Lyotards's work on ethics--and one that is fairly obvious by now--is that judgment cannot exist in the absence of criteria, and that within such a suspension, the subject operates in an ethical void, one without consequences and action. To some extent, this charge is valid, but there is more working in Lyotard that favors judgment, and consequently, ethics, in a limited sense. To represent Lyotard, I look at Just Gaming and The Differend not in the goal of recommending them as a basis for a postmodern approach to ethics, but to illustrate what, in its extremes, yields little for a rhetorical theory of ethics, and thereby demands a more viable space-between.

There is a distinct split between what Lyotard calls paganism and what I will call Kantianism in Iust Gaming. The pagan involves judgment without criteria; affect and feeling are used to make decisions (16); pleasure and pain motivate judgments (48). Normative claims hold no validity in the pagan because they attempt to exist beyond or above language games. This is not to suggest that there are no rules in the pagan; rather, rules are determined by language games and are unique to each game. Lyotard adopts a Sophistic position in asserting the impossibility of judging anything but opinion and of choosing anything but statements of opinion. In the pagan, "[o]ne does not know whom one is speaking to; one must be very patient; one must negotiate; one must ruse; and one must be on the lookout when one has won" (43). Paganism exists in the refusal to claim one great or master narrative before others. Instead, one adopts different orders of discourse ( for example, Lyotard identifies prescriptives and narratives as two genres of discourse). The goal of the pagan is to change games, to invent new ones (61). Like the Sophist, the pagan plays with the rules of language and obeys only those that determine different genres. For example, justice is a language game, a genre of discourse, that is played in the genre of prescriptives (62). Ironically, as Jean-Loup Thébaud points out in the close of the dialogues, "[t]he only prescriptive is that one 'ought" to be pagan ... [to] maximize as much as possible the multiplication of small narratives" (59), a postmodern ethical imperative which serves as a master narrative itself. 
Assuming the position of the rhetorical skeptic, Lyotard attempts to continue the questioning process rather than to judge, but in the imperative of renewed dispersal is the potential for judgment. For what is unjust is "that which prohibits ... the question of the just and the unjust" (67) All acts of terror, annihilation, and oppression are thus unjust because they prohibit a kind of argument or conversation that would continue to allow for a sort of freedom of speech, a freedom that would allow for the splintering of discourses of totalitarianism and control. Lyotard also holds out the possibility of judgment on a case-by-case basis. As Thébaud asks, "Where do I get [this] ability to judge? If all opinions are acceptable, then I cannot decide?" (81). Here, Lyotard responds with the limited possibility of the judge in certain questions. The judge must interrogate which norms and conventions of opinion are embedded in the conflict. The judge then has three possibilities for deciding a case: suspending judgment in the face of conflicting opinions; deciding in favor of "heavier" opinion, of a group consensus; or using a "guide," a "horizon" that is not of itself a set of criteria, but, like the culturallysituated knowledge of phronesis, acts as a guide to specific cases and judgments (82).

By asserting an "opinion politics" in place of rational criteria for judgment, Lyotard hits a dangerous snag in paganism. Under paganism, justice can be determined as what the majority hold to be an opinion of the just. By refuting Kant's supposition of rational beings existing before discussion and debate, Lyotard confers that a "rational politics" is over; what we now have is a belief that "it is not true that a rational knowledge of social and political facts is possible, at least insofar as they imply judgments and decisions" (75). This is, of course, a dangerous proposition as the example of Nazism is but one outcome of an opinion politics--a politics of judgment that produces a consensus of the just based on opinion. While he never adequately deals with this possibility, Lyotard does hold out the hope that heterogeneity will overwhelm any totality which may arrive under opinion politics. How, then, does this possibility of judgment engender a postmodern ethics? 
Whenever we encounter questions of judgment, we are inevitably involved in deriving or assuming an ethical or normative foundation for decision-making. Ironically, however, this inevitability results in the use of some "quasi-transcendental" criteria for contingent judgment. For even as judgment takes place on a case-by-case basis, decisions must be made by some criteria. Lyotard's key distinction on this point is between the assumption of truth and unity (a linkage that forms the terror of totality) that underlies the Kantian Idea and the "opinion politics" that determine judgment in the pagan. Throughout Just Gaming, Lyotard attempts to "go beyond" Kant's formulation of the Idea, abandoning transcendent criteria for judgment. According to Lyotard, criteria are derived from "the discourse of truth and suppose a referent or a 'reality'" (98). Lyotard's revision uses some sense of the Idea, one that is not, however, tied to Kantian formulations of a priori truths or a sense of a metalinguistic positions; justice in the postmodern assumes that "there is no outside; there is no place from which one could photograph the whole" (43). In place of a Kantian normativity, the Idea is used to guide judgment, a "wayfinding" that operates as an ethic (Pile and Thrift 88). Ethics, then, are used as guides rather than transcendental imperatives. Judgment occurs when the horizon of the Idea--an ethic--is used to adjudicate. To this end, Lyotard discusses ethics in terms of the rules of language games, rules that can be changed as cases change. Once configured outside the game of prescriptives indicative of Kantian versions of judgment, ethics becomes narrativity, stories that require continued dispersal. Notably, Lyotard use spatial directives to orient judgment; a "guide" or "horizon" marks the way for judgment.

Plurality and dispersal are the key terms of Just Gaming. In fact, the imperative of plurality stands as Lyotard's ethic of judgment. What becomes evident in reading Lyotard's "difference" from Kant is the circularity that postmodern ethics struggles to move beyond. The irony of Thébaud's last remarks on the ethic of plurality is a reminder of how difficult it is to think an ethics that does not use some normative guide. 
One of Lyotard's major contributions in Just Gaming is the offering of a different genre of discourse than that of the prescriptive. In place of prescriptives, Lyotard fosters a rhetorical understanding of the construction of truth and rationality, one that assumes both a discursive model of ethics and the multiplication language games, each with its own set of rules. These games will assumedly be played by rules that keep excess and abuses in check. As Best and Kellner observe, "[j]ustice is playing by the rules" (my emphasis 161). What is left out of Lyotard's theory, however, is any guide for choosing one language game over another. The guides that direct judgment in the postmodern work internally: that is, they determine the rules of individual games and judgment in particular cases. They do not, however, give import to any particular discourse over another. The photographic stance is a space left inoperative in Lyotard.

In The Differend, Lyotard takes the question of ethics and judgment further, a move that produces an interesting discursive imperative. Whereas Just Gaming works with spatial concepts to direct judgment, The Differend works on an explicitly discursive level. It attempts to make operative a postmodern approach to philosophy, and as a result, falls prey to the confusion that such a task produces. While there many things going on in The Differend, namely what Auschwitz means for speculative philosophy, I am particularly interested in the discursive description and construction of posmodern justice as a rhetorical formation.

A differend is "a case of conflict between (at least) two parties, that cannot be equitably resolved for lack of a rule of judgment applicable to both arguments" (xi). Notably, the differend is a space in discourse, an impasse, when litigants cannot decide on an equitable judgment because both or all claims hold equal validity. The question of responsibility becomes central as Lyotard attempts to derive a sort of discourse ethic, but one that does not reinstate normativity. Rather, we have a necessity and responsibility of linking phrases, of finding idioms to represent differends. In spatial terms, we might read this as the necessity of finding discursive spaces for 
representation. Thus, discursive responsibility carries the imperative only of arriving at some representation to show that we have borne witness to a case of a differend. The moment of the differend is one of dissensus, as litigants are suspended in argumentation without judgment. And this is the problem in The Differend: the question of judgment is avoided altogether in favor of a radical skepticism. We only choose regimes of phrases, similar to the language games of Just Gaming, that carry their own rules that must be followed. Phrases, however, are not equivalent to our sense of a sentence or a grammatical unit of language. Phrases are akin to a rhetorical situation: "A phrase is defined by-as it, in fact, defines-the situating of its instances (addressor, addressee, referent, sense) with regard to one another. Rather than defining a grammatical or semantic unit, a phrase designates a particular constellation of instances, which is as contextual as it is textual--" (194). In Just Gaming, one could only look to the rules of individual language games as a guide. Our rhetorical responsibility as litigants or witnesses to the differend is to choose the best phrases, the best means, to represent cases of the differend.

In The Differend, new rules must be found to link phrases. Phrases exist within genres of discourse; cognitives, prescriptives, descriptives, and ostensives are but a few of the genres identified. Notably, what Lyotard outlines as the necessity of linking phrases by following the rules of a particular genre of discourse sounds like a sort of structuralism in the avoidance of singular instances of discourse in favor of achieving a totalizing system. Lyotard's inclusive and active definition of phrases, one that includes anything that signifies--from a wink to tachycardia--accounts implicitly for the contextual matrices that accompany a rhetorical conception of the phrase. In other words, each act of signification participates in a network of relationships between text, author, audience, all of which depend on each other and which assume particular stances in particular acts of discourse. 
Litigants' responsibilities or obligations refer to the imperative to find ways of linking phrases within specific discourse genres. Here, I think Lyotard means the imperative of finding a way to represent differends and competing discourses, to allow for the freedom of speech he alludes to in Just Gaming. Lyotard defines the unjust as the instance when dissensus is squelched under the silence of totality. To allow for differends, despite the desire to judge, is to allow for the representation of even "immoral" or "unethical" views. Thus, even ethics may be just another genre (117). The genre, rather than any meta-discursive criteria of judgment, brings forth the obligations (117); "[t]here is no genre whose hegemony over the others would be just" (158).

Therefore, the rules determined by a rhetorical context (or genre) issue the imperative. For example, a prescriptive genre would concern itself with the ethical and normative. Because of this, participants can issue further prescriptives, in the cause of linking and creating new phrases and representing differends, not in the pursuit of issuing universalist imperatives of behavior or action. In other words, what is produced within the genre cannot be used to judge others.

In some ways, however, Lyotard appears to be supplanting the discourse of truth, a master narrative assumedly external to language, with the transcendent rules of discourse genres, what I earlier called a sort of structuralism. Perhaps, though, this is the enactment of Just Gaming: that is, guides can be used and created in the pursuit of judgment, but these guides reflect the rules of a particular discourse, not the pretension to truth or the assumption of a metalanguage that would rule in all decisions of the ethical or the just. The Differend works as an attempt to disperse these narratives into their specific genres, a move that highlights the essentially rhetorical context of differends as well as the ethical imperative of "hearing" and "bearing witness" in cases when judgment cannot be determined for lack of any rule.

What Lyotard presents in both Just Gaming and The Differend is a localized, contingent approach to ethics. What remains unclear, however, is how we are to choose 
one genre over another, one phrase rather than another, for representing cases of the differend. This is, of course, the problem of relativism that plagues this "either" side of the ethical dichotomy. What Lyotard foregrounds, albeit unintentionally, is the inherently rhetorical dimension of his postmodern ethics of judgment. A counterstatement to universalist conceptions of truth and ethics, Lyotard offers a discursive alternative to the demand of the normative, or in his own terms, prescriptives. In so doing, Lyotard examines how the genres of discourse are connected, linked together to find the best means of "bearing witness" to arguments and dispute.

Furthermore, if we understand one central meaning of rhetoric as choice, then I think we can grant that Lyotard was working on something akin to offering discursive choices in the linking of phrases. If we also consider that the semantic base of ethical statements is based on the normative or prescriptive genre, then we need to consider if shifting this base to another genre by linking phrases will clear a path out of the universalist-relativist dichotomy. Lyotard attempts as much by supplanting the philosophical presuppositions that follow normative statements of "ought" and "should"-as well as the position from "outside" discourse that supports such statements--with the imperative of choice. Such a shift would offer "can" in place of discursive normativeness. ${ }^{6}$ In this revision, the spatial agent is free to choose plots or points of entry into ethical discourse and action. Nevertheless, the move from imperative to choice opens Lyotard to charges of ammoralism; in short, postmodern ethics does not provide a tenable position that allows for the ability to judge one discourse of truth over another, only the reduction of imperatives to decisions and choices, a semantic move that harbors serious ethical implications. In other words, a semantic move is not enough. As I will argue later, kairos provides a stronger foothold for rhetorical and ethical intervention.

Lyotard's work exemplifies the "groundlessness" of ethics in the postmodern. I fear, however, that his project "to philosophize" (The Differend xiii) results in an 
untenable ethical theory. One primary reason for this is that he does not consider subjectivity in relation to ethics. The subject is generally identified as the judge who must make contingent decisions about specific cases. Questions about what informs the subject's ability and authority to make these decisions go unasked. This is a significant space that threatens to dig up the foundations of Lyotard's "grounds" for ethics and judgment in the postmodern and serves as an important concern for my own attempt to bridge the either/or dichotomy.

\section{II. "Or" Habermas}

Unlike Lyotard, Jürgen Habermas works with a norm-driven basis of ethics. He defends the important tenets of the Enlightenment: progress, parity, and rationality are the important horizons of critical social theory. ${ }^{7}$ We might then read the work of Habermas as a counter-statement to the skepticism of postmodernism. Habermas focuses on the process of creating and testing ethical norms and maintains some universalist assumptions. Also, he appropriates a vision of discursive space in the employment of some model of discourse and community in his theory. Working with an ideal model of a democratic society, Habermas posits the importance of a public sphere or community in questions of ethics and moral communication. Despite the renewed emphasis on discourse and community, however, the discourse models presented by Habermas overlook the important rhetorical matrix that this project must inevitably contend with. In this section, I want to examine the limits, liabilities, and contributions of Habermas's work on the discourse ethics, especially the assumptions of space that support his ideal of the public sphere as well as what spaces are left inoperative and inbetween.

In Moral Consciousness and Communicative Action, Habermas observes the "performative contradiction" (80) of what he terms the "fallibalist" or skeptical position. The skeptic, as we know from the example of Lyotard, would assert that there 
are no grounds to moral principles. In the process of arguing against the possibility of normativeness, Habermas cleverly identifies that in the process of constructing an argument, a speaker must presuppose the structure of argument. Thus, when the skeptic claims that there are no valid universals, she uses a structure of argument that uses grounds, a rhetorical move that implicitly testifies to the possibility of establishing grounds. There is, then, a "common ground" that can be found in the structure of argument; that is, the skeptic assents to grounds by negating their possibility. The only alternative for the skeptic, in refusing a foundationalist position, is silence.

Habermas creates a procedure for testing the validity of ethical norms. He is quite adamant that his theory of the discourse ethic is not about generating ethical norms; rather, his goal is to find a means of testing them. "Practical discourse [communication about moral justification] is not a procedure for generating justified norms but a procedure for testing the validity of norms that are being proposed and hypothetically considered for adoption" (103). Judgment is possible in Habermas's moral universe because "effective communication" helps a community to achieve a criteria of some valid universals. Norms may be justified through a process of guided argumentation, but only when agreed upon by all affected by such norms. All participants of the discourse on norms are assumedly responsible and truthful (87).

In effect, the discourse ethics is a type of "conduct" to be observed in the discussion of ethical norms. Speakers are under contract, by virtue of their responsibility to the social whole under democracy, to maintain the process of a discourse ethics (163). The logic of argumentation is the rule by which consensus will be achieved; the logic of argumentation is proven as the "facts of reason" (95) that help in justifying norms because they assumedly pre-exist discourse by forming the formal structure for the proceedings. Thus, reasoned argument comprises the ideal speech situation of the discourse ethics in which each participant has the opportunity to speak and contribute to the matter under discussion toward the goal of consensus. Maxims 
generated by debate must be submitted to all others to be agreed upon and adopted for universal law (67). In this configuration, agreement is the first goal of argument, making consensus the goal of communicative action (134). Parodoxically, "the force of the better argument" must be unforced. Effective communication will eventually yield objectivity and impartiality as all possible objections and considerations are entertained. Habermas argues that "the proponents of discourse ethics rely on a type of argument that draws attention to the inescapability of the general presuppositions that always already underlie the communicative practice of everyday life and that cannot be picked or chosen like makes of cars or value postulates" (130). Argument, as a form of communicative action, "presuppose[s] those very relationships of reciprocity and mutual recognition around which all moral ideas revolve" (130). Argument, then, becomes both the practical enactment of communicative action and its foundational tenets. The "goods" inherent to argument transcend the subject of argumentation to serve as the process of negotiation as well as its goals. In other words, universal validity is found in argument, its rules, its presuppositions, and its rational conclusion of consensus.

Even while he offers the ideal speech situation as a model of the discourse ethics, Habermas concedes that as an ideal, it is--to employ a geographical marker-a "road," a guide or means to a better end of ethical justification. This is an interesting and necessary concession about the ideal speech situation. Nevertheless, it is somewhat counter-productive in that the discourse ethics only works productively in the ideal. In other words, Habermas defends the discourse ethic as a valid model of discourse, one with fundamentally pragmatic uses and applications. His concession about the ideal seems more a conciliatory address to critics who might notice the impossibility, and consequent invalidation, of a theory of communicative action than a considered opposition. In short, while professing pragmatics, Habermas's discourse ethic might prove to be hopelessly utopian when read rhetorically. 
What strikes me as particularly interesting is Habermas's reconfiguration of argument as a process of reaching consensus, one that relies on "good" reasons and evidence to support claims. The assumption that all involved can speak to the justification of norms in the respectful, turn-taking ideal speech situation seems to overlook the very nature of argument as an often combatative process. Underlying Habermas's theory of communicative action, furthermore, is the assumption of language as a transparent, non-ideological medium for transmitting ideas. This is not to suggest that Habermas is not aware of the ideological and rhetorical force of arguments; rather, he takes the political backing of arguments into consideration as he attempts to create an almost "rhetorically-free" theory of argumentation. While positing the validity of a theory of communicative action, he notes the negative appeal of a communication based on "strategic action," arguments that attempt to convince and persuade. In fact, Habermas is quite aware of argument as a rhetorical mode of discourse. He attempts to separate his sense of argument from Tugenhat's equation of "argument as will formation" (72). In so doing, Habermas avoids politics in creating the discourse ethics. His presuppositions of argument are based on an ideal of neutrality and rationality, and the consensus assumedly derived from argument remains equivalent to rationality. By virtue of their place in this implicit demarcation, arguments that attempt coercion and persuasion might be seen as irrational and unreasoned.

Habermas's ideal speech situation, wherein participants adhere to the principle of discourse ethics, does not identify speakers in any concrete way, a consideration that contemporary rhetoric takes into account as the location of subjects in relation to discourse and audience. Habermas assumes that all participants have the means of communicating in a fair and equal way. What Habermas overlooks are the very real conditions of very real speech situations. Real speech situations are peopled with subjects who are constrained by the material positions of race, class, gender, and sexuality, to name but a few of the vertiginous (em)placements subjects occupy. More 
importantly, Habermas does not account for the problematic of subjectivity and issues of authority that determine who speaks and who gets heard. Iris Young continues this critique of Habermas's blindness toward the rhetorical and material context of communicative action. She argues that dominant groups have exclusive access to interpretation and communication. The faceless mass that is the communicative society does not take this into consideration. Communicative action will, then, regardless of what is decided upon engagement, take on the values, norms, and ideologies of the dominant group. Their experience is thus presented as the norm and standard for humanity (Young 59). In terms of justifying norms, the norms derived from communicative action will merely reflect the values and assumptions of the authoritative group.

In rhetorical and spatial terms, Habermas overlooks ethos, the location of the subject within discourse (Reynolds). Furthermore, arguments do not always hold as their goal consensus, nor do they always take place with each participant taking their turn. Real speech situations often contend with many opposing views, many of which are voiced more loudly than others. In the case of argument, dissensus is often the end product of agonistic proceedings. With the neo-Kantian equation of rationality and consensus, Habermas overlooks the possibilities of growth and the productivity of exchange when outcomes only yield dissensus in the emotional and unreasonable meeting of opposing views. Indeed, the very definition of productivity in communicative action is the continued movement in the direction of objectivity and impartiality.

In my reading, I see Habermas risking the potential harm that the excesses of reason can produce in his reduction of a process of justification to the rules of logic. ${ }^{8}$ For example, Habermas, in refuting the performative contradiction of the skeptic who must use the rules of argument to argue against foundationalism, bases his refutation of this position on "petitio tollendi," a move in logic that "show[s] an opponent that he makes performative use of a tollendum, that is, of the very thing he wants to negate" (95). In 
the abstract, the performative contradiction of modus tollendum makes perfect, logical sense, but in the rhetorical dimension of argumentation, it falters as the basis for engaging the skeptic in argument. On this point, I am merely attempting to point out that Habermas depends upon a highly rational organization of the rules of discourse, a dependence that overlooks the often messy and "irrational" basis from which many disputants would argue. The separation of structure from the content of argument inevitably bypasses the important, symbiotic relationship these two aspects of discourse share. I am not entirely sure we can abstract discourse, itself a highly arbitrary and vague signification system, to the rules of formal logic. Indeed, a rhetorical reading would disallow this very prospect in the assumption of language as a transparent medium of signification.

Where Habermas succeeds is in his persistent attempts at placing questions of moral value and ethics within a social and communicative matrix as well as in the creation of a "logic of values" (Perelman 152). Both attempts desire to make of formerly "irrational" decisions of value the property of a democratic polity. ${ }^{9}$ From the point of view of a rhetorician, however, he elides important questions about the "substance" of language. In so doing, he treats language as an objective system whose genre of argumentation houses the essential formula for reasoned argument. To understand where this sense of language comes from, we need to consider how Habermas interprets the role of capitalism in postponing the ideal outcome of the ideal speech situation.

Mark Poster reads Habermas's Communication and the Evolution of Society as a critique of capitalism. Habermas envisions a space "beyond capitalism" (466) where communicative action will engender freedom and the deferred goal of the ideal speech situation. Further assumptions of this discursive space are that "[s]peaking is an effort to communicate and this implies ... that what the speaker says is comprehensible, that what the speaker says is true, that the speaker is sincere, and that the utterance fits into the normative context" (464-465). For Habermas, even in cases where the speaker 
intends to deceive, the goal for a participant in the discourse ethics is the ideal of truth (465). Even as he understands that the ideal speech situation is hardly ever met in real conversation, Habermas defends that the inability to reach this ideal provides proof of the "distortions introduced into speech by social modes of domination" (465). To facilitate this ideal, Habermas posits the public sphere in which the conditions for communication and exchange are encouraged.

In spatial terms, Habermas attempts the creation and management of a public sphere wherein communicative action can take place. As I have already unpacked, this space is created "in space," without an account of the legitimate constraints of real argument, not to mention the problematic assumptions of truth, rationality, and freedom that support such spatial practices. The "distortions" Habermas tries to weed out of communication ignore the socio-spatial dialectic that is culture. If we recall Edward Soja's articulation of the symbiotic relationship between the social and the spatial, we can find further evidence of Habermas's attempt to make of the public sphere-in separating social and rhetorical realities from the spaces in which they exist--an inert, apolitical, and ahistorical space. We might, then, read Habermas's lament for the public sphere as an attempt to move beyond the spatial problematic of capitalism. Soja identifies capitalism as the hierarchical management, fragmentation, and parceling of both work and class spaces (92). These spatial practices produce the networks favorable to "the penetration of state power into everyday life" (92). Even though he is attempting to recreate a liberal-democratic space of discourse, Habermas's spatial contribution to a viable discourse ethics avoids the material constraints of capitalism, those distortions that may provide ways of managing more operative and politicallyviable spaces.

What Habermas re-introduces to the debate on moral theory is the importance of the public sphere as a space for a discourse on ethics; "the public sphere is the crucial domain of interaction which mediates between the macropolitical institutions of a 
democratic polity and the private sphere" (Benhabib 12). It can be an important space for local politics, a launch for community involvement before it attempts to resist or enter the larger macro-political spheres. It is a space for organization, discourse, and foundation. For our understanding of rhetoric and ethics, the public sphere recalls the importance of community. Lawrence Kimmel argues that the framing of moral choices is not a search for absolute imperatives, but like the goal of the discourse ethics, is a search for as well as an understanding of communal and contingent values. Civic participation is crucial to discussions of ethics. "Community becomes the space and language, the connective tissue of ethics and rhetoric, thought and action" (Kimmel 2). Kimmel's rhetorical understanding of community and discourse leads him to argue for the reinstitution of an ancient public sphere, a place, like the Athenian polis, that would allow for open debate and discussion on ethics with the ethical practice of discourse that is rhetoric.

Although I will not be discussing the communitarian position in this chapter, what I want to emphasize is the important revival of community in ethical theory, a move that inevitably creates spaces and spatial practices that must be maintained and managed within the models of democratic society offered here. Also of importance are the political implications of spaces and their management in light of and in reaction to an increasingly global sense of community. While his sense of community is similar to Habermas's concept of the public sphere, Kimmel's is aligned more closely with that of another prominent position within contemporary ethical theory, that of the communitarians. Foremost, however, is Kimmel's understanding of rhetoric as the discursive foundation of community. In both the post-metaphysical universalist and communitarian positions, there is an important equation of discourse and community, a linkage that rhetoric, as Kimmel observes, has historically understood as fundamental in questions of justice and ethics. Communitarians wish to recall the Greek model of community in their theory of virtues. They find in the Enlightenment "the formalist, 
ahistorical, and individualistic legacies... which have led to the decline of community as a way of life" (25). In their recall of an ancient model of community, communitarians lament the rise of technology and capitalism that has led to the decline of civic participation and a splintering of foundational communities.

Furthermore, Habermas's vision of public discursive space assumes a fairly "public" agenda. In other words, discussions more often concern questions of civic virtue rather than more intimate investigations of personal and private ethics. Notably, the personal or private spaces of ethics are associated with "feminized" spaces of the home. While this point will be discussed further in Chapter Three, Benhabib's observation of this exclusion points to the need for the creation of another kind of space, one that includes both private and public concerns, and one that provides us with a general definition of the model of space most amenable to discussions of ethics. "Discursive space," a model I have used throughout this discussion, is not to be "understood agonistically as a space of competition for acclaim and immortality among a political elite" (Benhabib 105). Rather, this space must be "viewed democratically as the creation of procedures whereby those affected by general social norms and by collective political decisions can have a say in their formulation"--a procedure that also needs to include a way of discussing private associations of ethics in a public way (Benhabib 105). I want now to examine the implications of the spaces created by Lyotard and Habermas, respectively, as they highlight the need for a space-between a highly subjective relativism and a foundationalist position grounded too firmly and too confidently in assumptions of rational discourse.

\section{Habermas and Lyotard: The Rhetorical Implications of Ethical Space}

A consistent, implicit metaphor in the theories of Habermas and Lyotard is that of space; that is, the creation of ethical spaces for discursive exchange or the use of spatial directives that will guide judgment. Lyotard uses the "guide" as a means 
toward making ethical judgments, while Habermas's discourse ethics assumes a public space that will facilitate this kind of discourse. But as David Harvey argues in The Condition of Postmodernity: An Enquiry into the Origins of Cultural Change, the management of both space and time is a political act and must be understood in concert with the material changes and conditions that surround such management. While the management of space and time is subject to the hegemony of capitalism, spatial and temporal practices can reflect and aid in social practices, especially in the creation of more democratic practices and spaces for resistance. We need, then, to recognize that the meaning of space is contestable and that all attempts to stabilize and situate it must be addressed as ideological and political uses of space and the social life it attempts to manage. To this end, Doreen Massey understands the management of space as "attempts to stabilize the meaning of particular envelopes of space-time" (5). She comments that this impulse is "normal" for it betrays our need to deal with the "mobility and contingency of space-time" (5).

Even as he draws upon models of discursive rationality and ethics, Habermas separates time from his examples of discursive space. For Habermas, time is an assumption that goes without any examination in terms of how the discourse ethics will proceed. I do not want to suggest that Habermas is completely ahistorical; rather, his procedural rationality ignores temporal concerns of how public spaces are mediated by a logic of time. ${ }^{10}$ David Harvey observes this logic of time in terms of capitalism, noting shifts in commodity production as they reflect the rise of technology. Increased mechanization and technological advance bring with them a shift in our sense of time as the nature of commodity production, circulation, and appeal becomes instantaneous. The result is the simultaneous enactment of space-time. In the realm of ethics, such ephemera creates "'a temporariness in the structure of both public and personal value systems' which in turn provide a context for the 'crack-up of consensus' and the diversification of values within a fragmenting society" (Toffler as qtd. in Harvey 286). 
The crisis of modernity--accelerated by the postmodern turn--is, then, in what Harvey calls space-time compression. This crisis is experienced as the "shrinking" of world markets and communities into a "global village," coupled with a sense of having lost time in the rapid mechanization of contemporary culture. The continuous present of postmodern time results in a curious lack of history. Commodities are manufactured in an ahistorical matrix, a system of production and exchange that is far removed from the consumer. Ironically, Habermas, working clearly in the tradition of critical theory, "simulates" this ahistorical quality of the postmodern in his creation of discursive procedures "in space" that do not acknowledge historical and temporal context.

Habermas's remedy for this current situation is the study and re-valuation of the public sphere. This space operates on the socially agreed-upon concepts of consensus and rationality. At its root, his idea of a public sphere is a democratic discursive space. As Harvey observes, the modern goal of liberty and freedom, as evinced in the examples of Jefferson's Homestead Act and the architectural designs of Corbusier, find their enactment "through the construction of a highly ordered and rationalized space" (271). For critical theory, there is "the danger of confining the free flow of human experience and practice to rationalized configurations" (Harvey 253).

If social life is to be rationally planned and controlled so as to promote social equality and welfare of all, then how ... [can] social interaction be planned and efficiently organized except through the incorporation of the ideal abstractions of space and time as given in the map, the chronometer, and the calendar? (253)

In Habermas's ideal speech situation we meet "the ideal abstractions" of subjects, social spaces, and time. The equal distribution of time to each member of the discursive community, as well as the assumed equality of all who participate, results in the ahistoricism of rationalized space. In its ideal state, the ideal speech situation as a 
discursive space leads to a "pulverization" of totalized space into more democratic portions; that is, everyone gets a space in which to speak. Habermas's model of ideal speech is consequently an ahistorical model of discourse in its bureaucratic rationalization of discursive spaces. Nevertheless, Harvey confers that the goal of equal distribution and participation born of the Enlightenment also helped to forge the space of revolution. The concomitant rise of capitalism and liberalism did not engender such egalitarian results, however. Capitalism led to a commodification of space and, later, to the production of oppressive space, as in the extremes of rationality that organize and distribute space and spatial practices as well as the fundamental inequities in labor and production forged by capitalism. By insuring all an equal space in the ownership of space, capitalism mediates this democratic entitlement and forges inequities among apportioned spaces (Harvey 258); we need to think only of the spatial practice of ghettoization to find an example of this.

Harvey's reading of capitalism and liberalism offers a consequential, historicized, and material reading of the liberal discursive spaces created in Habermas. In effect, the totalizing tendencies of the public sphere, wherein the ideal speech situation can take place, fulfills the prophecy of inequity and oppression. A recall of Iris Young's critique of the hegemony of the elite in communicative action is useful here; those with the means of communication, and in an expanded reading, those with the ownership of space, will create the conditions for democratic polity, one that, of course, favors their maintenance of power.

The postmodern penchant for fragmentation and the dispersal of totalizing discourses might initially look like a remedy to the hyper-rationalization of social spaces. Lyotard's response to the latent terror of totalization is the increased fragmentation of dominant narratives. "Little narratives" must be allowed to speak; this is the ethical imperative of Just Gaming. The political implications here rally around the local and often marginalized narratives that are allowed to disrupt 
hegemony. As a discursive spatial practice, postmodernism further pulverizes space, but not into democratized and equally valid portions for a rational politics (Harvey). Rather, Lyotard's sense of space focuses on localized narratives as a reaction to the globalization and totalization of master narratives, including the homogenizing tendencies of ethical thought. In some sense, Lyotard does bring in the element of time in his rejection of ethics as a normative base that can stand "for all time." By dismantling the narrative of ahistorical, transcendent norms, he opts for the contingent cases of judgment that occur at certain moments in time. But while time--as the aleatory and contingent response to representing differends-is sensitive to the impossibility of ahistorical norms within the postmodern, Lyotard leaves out a vital consideration of history. Thus, Lyotard's contribution to ethics does not provide a description or strategy for when one must do more than represent differends, when one must, because of immediate temporal and historical circumstances, respond with action. Without this dual sense of time as the temporal and the historical, Lyotard leaves out the component of action for ethics. With the emphasis on local resistance in postmodernism, and the consequent invalidation of universal criteria for ethical judgment, the question still stands as to how can we achieve an ethics. Harvey observes that such a project becomes even more difficult in the postmodern, because of capitalism's persistent spatialization of time: "Time and space both get defined through the organization of social practices fundamental to commodity production" (239). The social struggles over the management of space and time are constantly destabilized in reaction and resistance to capitalism's equation of space and time. "As a consequence nobody quite knows what 'the right time and place for everything' might be" (239) because of a constant instability between the dialectic of capitalism and social practices.

Attempts to create an ethics that responds to both the perceived need of contemporary culture as well as the philosophical and historical considerations and reconsiderations of ethical theory have provided important models. These paradigms 
work to create spaces of discourse and community, and in so doing, employ discourse models that, while important for discussions of philosophy, do not consider the rhetorical and political matrices and implications of such projects. Furthermore, in "neither" Habermas "nor" Lyotard do we meet a consideration of subjectivity. In his emphasis on narrative and judgment, Lyotard never addresses or explains his own understanding of the subject in relationship to judgment. Habermas's ideal speech situation assumes that disembodied, equal participants have equal access to this discourse. Thus, a revision of kairos for rhetorical theory must not only consider space and time as simultaneous "events" but also the role of the subject in ethical rhetorical action. In both Lyotard and Habermas, the subject of ethics is either construed as a function of discourse in a universe void of legitimation, or as the agent who, with the aid of community, discourse, and consensus, can derive some universals to negotiate the relativism of modernity. In my revision, the subject who struggles with a vertigo created by the postmodern condition can find strategic points to enter conversation and argument and can make opportune uses of space and time.

\section{Toward a Kairotic Ethics}

Action involves character, which involves choice--and the form of choice attains its perfection in the distinction between Yes and No (shall and shall-not, will and will-not). Though the concept of sheer motion is non-ethical, action implies the ethical, the human personality.

Kenneth Burke, "The Rhetoric of Religion"

In a world where there are no absolute rights and wrongs and in which for every issue there are reasonable, contradictory positions, how can the rhetor and his 
audience arrive at the best probable judgment?

Michael Carter, "Stasis and Kairos: Principles of

Social Construction in Classical Rhetoric"

Kairos is an important concept that directs our attention to situational contexts for rhetorical action. In combination with my spatial reading of this concept, the temporal, historical, ethical, and rhetorical foundations of kairos provide another space to consider in forming an ethics of rhetoric.. "As the principle of timing or opportunity in rhetoric, kairos calls attention to the nature of discourse as event rather than object; it shows us how discourse is related to a historical moment; it alerts us to the constantly changing quality of appropriateness" (Miller 310). The dichotomy in ethical theory either overlooks or ahistoricizes time or offers models of discourse that do not provide the most effective or rhetorically viable means for ethical rhetorical action. My rhetorical response to the gap created by this dichotomy is the in-between space of kairos that provides some "horizon" for guiding ethical action in its original emphasis on time and history. That is, kairos traditionally concerns questions of when might be the best time to speak or enter discourse. It also focuses on historicizing its own normative basis while paradoxically maintaining a relativistic posture. Nevertheless, little has been done to continue and extricate this important and elusive concept. ${ }^{11}$

I think we can retain some normative foundation for ethics without adopting universalist or ahistorical positions. With the similar goal of an ethics in-between in mind, Best and Kellner argue for the importance of retaining some universal norms, such as human rights. However, they do not ground this norm philosophically; rather, they argue for historicizing important norms, offering a unique temporal foundation for some positive values. They also identify that ethics, as a discursively and socially constructed body of values, issue from specific struggles rather than assumed attributes of human essence (242). Kairos helps to negotiate this space-between the relativist- 
universalist dichotomy in its unique ethical foundation of the imperative to act and respond to both historical and temporal context. My use of temporal here refers to the moments in discursive context that demand response; historical retains kairos's sensitivity to socially-established and historically-located norms that must be recognized in decisive, discursive action. Thus, my use of kairos draws upon the crucial distinction that historicizing suggests: that is, our examination of how subjects are called upon to occupy certain ethical positions as well as how the subject must adjudicate among competing claims, must include how this process takes place at specific moments in time and in specific cultural spaces. In other words, the guide of "human rights" might operate as a normative horizon in ethical judgment, but we must understand this imperative historically rather than as a trans-historical truth.

The concept of kairos comes to us primarily from the Sophists. ${ }^{12}$ Kinneavy finds traces of it in Hesiod's proverbs, but credits Pythagoras with the development of its ethical complexity "linking it closely with the basis of all virtue, particularly justice, and consequently civic education" (81). Gorgias and later Sophists further developed its use and complex meanings. In a purely stylistic sense, kairos refers to improvisation. In its various uses, kairos generally refers to timing, and an oversimplified definition might place it as "saying or doing the right thing at the right time," but further studies have established the complicated implications and meanings of this term. For example, Tillich defines kairos as a moment of time approaching "fate and decision" (129). It is also "capacity and precept" (Untersteiner 197). Kairos marks the "ripeness or fitness of the occasion; it is a 'crisis situation' that demands decision" (Kinneavy and Eskin 137). Kinneavy adds further Plato's amendment to kairos as "proper measure and right time" (88). Dale Sullivan defines it in three ways: 1) "as poetic timing"; 2) "a point of indecision"; and 3) "an irrational power" (319). In brief, Sullivan identifies a kairos "of inspiration, of stasis, and of dynamis of power" (319). Kairos sometimes means "'a lethal place in the body'" (Race qtd. in Sullivan 320). While the term clearly operates 
under several nuances of meaning, it takes as its common denominator the emphasis on decision, occasion, and a sense of time. Sheard, adding a specifically ethical connotation to the term, finds that "kairos is akin to exigence and provides a method for deciding courses of action and for deriving probable truths in a relativistic world" (292).

Generally and historically associated with timing, as in the right time to speak or intervene in discourse, kairos also has a spatial dimension. The rhetorical concept of kairos introduces the crucial aspect of space/time into this discussion of ethics; it is "the sum of contexts, both spatial and temporal" (Sheard 29). Carolyn Miller identifies that kairos's spatial dimension comes from the root of opportunity, "in the Latin porta, 'entrance' or 'passage through' (313). The original Greek uses of kairos, in archery and weaving, refer to a 'penetrable opening, an aperture'" (Onians qtd. in Miller 313). Kairos is "a critical point in time and space" (Carter 102). Kairos allows us to look at the ethical situation and the subject who attempts to operate as an agent as an essentially ethico-rhetorical one. It also allows us to configure ethics spatially and temporally: that is, kairos is a response to problems that occur within specific historical moments and locations, that operate under moral and value assumptions of that context, and that come from the culture and moment from which they generate. In this way, considerations of time, of kairos, are inextricably bound up with questions and judgments of value (Sheard 296). Kairos may help to bridge a space-between the either/or dichotomy by initially positing the possibility of agency and a tenable ethics that resists the lure of relativism, and further, by disrupting the monologic vision of postmodern theory that sees the subject as political and ethical nomad. Furthermore, kairos provides the tactical and rhetorical exigencies to act in discursively opportune moments by creating spaces for intervention and critique.

In my reading, kairos is an essential component of ethics and justice. Aside from Sheard, however, the ethical implications and foundations of kairos have yet to be fully addressed and examined for what space-between they might provide. Because it 
depends upon recognizing situations and contexts, kairos is also an epistemological concept. James Baumlin sees kairos as the "epistemological counterpart of decorum" (179). Pythagorean doctrine developed the closely related concepts of the dissoi logoi and kairos. According to DeVogel, "kairos implied an ethical system based on the belief that certain types of conduct were by nature appropriate" (qtd. in Sullivan 318). As "an essential aspect of determining justice" (DeVogel qtd. in Sullivan 318), kairos takes on its ethical implications through Pythagoras who, drawing upon the dissoi logoi, made it the crucial moment of choosing a break in antithesis.

The dissoi logoi holds that "all things are composed of opposite qualities" (Untersteiner 304), of opposing logos. These opposing logos create a unity. Because neither logos of the antithesis can be an absolute claim of validity or truth, in the sense that both can be opposed and equally valid and true, choosing one logos over another is a rhetorical act (Carter 106). Untersteiner's reading identifies kairotic judgment as nonrational. According to Gorgias in the Funeral Oration, judgment is the crucial midpoint between thought and action which occurs not from a "logical law but from the persuasive force of logos which is released in the instant of the decision which has as its object ... the right thing at the right moment" (177). In another instance, Gorgias calls the antithesis between the chaos and order the tragic. The instant of decision creates a "third space" which describes the decision of choosing one of the antithesis "while knowing that opposite term is by no means destroyed" (176). While formerly conceived as a primarily temporal concept, kairos here takes a spatial turn by becoming a space in time when action creates a space between the dialectic. Thus, kairos is a lateral move toward the space of action. Because of its immediacy, it destabilizes temporal logic by carving a space for action, a move that collapses the space-time dialectic into a simultaneously enactment of space/time (Massey).

In terms of a kairotic ethics, Pythagorus gives further evidence of the irrational dimension of kairos by again referring to the dissoi logoi. The irrational lay in "the theory 
that good and bad coincide, 'so that for some it is good, for others bad, and for some persons, sometimes good, sometimes bad'" (Untersteiner 305). Kairos determines the good and bad as virtues, not their inherent truth as virtues. "'All is noble at the right moment" (306) exemplifies Gorgias's conviction that timing is what defines actions and words as virtuous. Furthermore, the opposites of good and bad are easily convertible into one another in Gorgian kairos. The result of such relativity is Gorgias's belief that virtue could not be taught, a position in opposition to that held by most of the Sophists; others felt that good and bad are different qualities which can be defined beyond their kairotically-constructed meanings. Gorgias attempted "to preach" an awareness of the moments when choosing virtue over excess would be fit and right, focusing on "practical training" of the means of arousing the desire for virtue (Untersteiner 182). Gorgias, according to Untersteiner, did not deny "supreme ethical law" but was attempting to question and weaken the supremacy of absolute ethics. If we follow Untersteiner's defense of Gorgias, we find that ultimately the philosopher's tenuous position as an ethical relativist has a pedagogical purpose. For Gorgias, kairos was "the epistemological function of stirring up those conflicts which made objective knowledge impossible" (239). Thus, we need to understand Gorgias's relativist position as one possible interpretation of the ethical in kairos, not as the only way of using it as a means of guiding ethical action. Appropriately, kairos should be viewed as an epistemological concept that changes its varied meanings depending upon historical context and rhetorical purpose.

Ethical kairos and the paradigm of the dissoi logoi, especially as developed by Gorgias, is open to charges of extreme relativism, not unlike those weak and somewhat untenable links evident in Lyotard's theory of judgment. Indeed, Gorgian kairos leads us to question what, then, is to guide our decisions besides the occasion, the historical moment, and subjective response. Furthermore, we encounter an ethical snag of basing justice and ethics upon the contingent circumstances of historical context and subjective 
opinion, a base that could engender an opinion politics, a problem observed in Lyotard. Nevertheless, Untersteiner defends a specifically Gorgian kairos by noting that Gorgias, unlike Isocrates, did not think that "for the purposes of persuasion, any means is good" (199).

But Gorgias does not go so far. Since he laid the emphasis on the 'tragedy' of things, on the eternal drama [between chaos and order], this imposed the responsibility of the irrational judgement of [kairos] without allowing any surrender during the duration of the tragic tension to an alternative chosen by following the utilitarian impulse, and released from the dialectic of the 'tragic.' But this dialectic cannot be overcome because it is rooted in Being (199).

Untersteiner suggests, albeit unclearly, that within the constant antithesis between chaos and order (justice and injustice, good and evil), the "irrational rupture" (Sullivan 320) in the conflict is the choice between conflicting opinions, and in the choice of one, "the opposite ... is by no means destroyed" (176). Consequently, the antithesis continues and a third term operates as the kairotic space of decision, the paradoxically rationally irrational moment of decision that is determined by the circumstances, and because choices are given value in specific circumstances, the negation of the other is by no means absolute. It is important that Gorgias sees kairos as a responsibility of judgment, an occasion for action that recognizes that the good in one circumstance may be evil in another, and in choosing one or the other, its opposite will still be valid. This "value contingency" describes the dialectical "tragedy of things," the awareness that both good and evil, justice and injustice can be defined as such within contextual spaces of time. The tragedy is that one must know how to use space/time and fulfill the responsibility to respond to the occasion with action and decision because there are no absolute values 
that can be universally defined. They can, however, be guided by historicized norms that can help in forming and informing ethical decision-making.

Notably, the charge of skepticism that so often follows Lyotard's advance toward an ethics of judgment mirrors that which follows Gorgian epistemology. I think Untersteiner's defense of Gorgias is worth another look as we attempt to construct an ethics in-between.

Gorgias is not a skeptic nor a relativist but a tragic philosopher and an irrationalist. Knowledge of the power possessed by the irrational constitutes the victory of the tragic. Man cannot resolve the antithesis. His thought discovers only the opposite poles in all propositions which try to explain reality philosophically. The reality reached by dialectic expresses only aporiai: this is the conclusion of Gorgias himself, who makes us feel above all the drama of the continual clash and counterclash of the extremes, into which every attempt to arrest the mobility of physis is resolved. In the increasing intensity of a close-locked struggle all human experiences, taking dramatic form, are brought to a standstill in the face of reason, which can no longer decide anything and therefore ends by denying on a rational basis every relationship between man and man, and finally all coherence within the individual himself. (160)

We find echoes of this very position in Lyotard's interrogation of claims to progress and rationality. What we do not find in Lyotard's relativist position is the importance of decision and action so central to kairos; suspending judgment in favor of representing differends--not unlike the Sophistic dissoi logoi--is the only discursive action taken in Lyotard's postmodern ethics. What is significant in Gorgian kairos, moreover, is the weight given to an epistemological basis for kairotic action. But even as he defines this 
action as irrational, Gorgian kairos has an underlying logic of its own in the process of rhetorical decision-making. What is "irrational" is the recognition that in choosing a space between the extremes, between two opposing logos, the" not chosen" is never negated. Unlike the speech situation proposed by Habermas, one that relies on rational beings and their commitment to the truth, kairotic speech situations are aware of this fundamental chaos of reality, what Gorgias calls the "tragedy of things," and in this awareness, do not assume a static truth underlying logos, but instead, heighten their consciousness of the historical and political moment to gauge the best opportunity for action.

In cases of judgment, particularly for the Pythagoreans, "[i]]ustice was defined as giving to each according to merit, that is, generously to those who had worked hard and parsimoniously to those who had shirked" (Kinneavy 87). Here, kairos concerns "merit" in distributional justice. While this example does not constitute a developed theory of ethics and justice, the criteria to be used for judgment--whether in a public court of law or in the everyday--depend, then, upon the criteria of judgment and must be derived from those situations. This latter point, however, leads us right back into the problem of criteria. We are still left to respond to the question of how we determine the grounds for judgment beyond highly localized and "hyper-spatial" guides for judgment. The solution to this problem is not necessarily in kairos, however, but in a more developed description of the subject's relationship to space and time.

\section{Kairos as Relative or Relational?}

Kairos is fundamentally a relative concept; that is, it works in response and relation to a specific context. But its "relativity" does not make it equivalent to relativism. "The relativity of kairos indicates that a circumstantial change can alter the evaluation of a rhetorical context" (Schwartzman 8). In other words, what is right at one time may not be in another; the rhetorical value of speaking at a particular time 
increases or decreases depending on when a speaker chooses to intervene. Ironically, Roy Schwartzman's "A Re-examination of Kairos: Implications for Moral Accountability and Rhetorical Criticism" argues for an enhancement of kairos's relativism, finding that most scholarship conflates two different senses of kairos as "the right time" and "just in time." Schwartzman attempts to tease out the more relativist implications of kairos, concluding that "the relativity of kairos raises some problems. If there exists no absolute standard for rhetorical timeliness, how can speakers be held accountable for their acts? Without clear standards for determining when to say what, there seems no way to judge a speech-act as just, unjust, appropriate, inappropriate" (10). Schwartzman is much more comfortable than I am with this prospect of radical contingent judgment. Because of this "discomfort," I want to work toward highlighting kairos as a principle that does retain some historicized normative foundations.

Schwartzman's emphasis on kairos as a relativist concept hinges upon distinguishing between eukairos which carries "normative overtones" of performing an action at the right time (2) as distinct from kairos which means "just in time" (3-4). It is also not to be confused with to prepon, a related concept which "represents the formal aspect of the epistemological context expressed in kairos" (Poulakos qtd. in Schwartzman 2). What Schwartzman does here is to suspend temporarily the epistemological grounding of kairos as "at the right time" to open up a more relativistic reading that is divorced from transhistorical rhetorical and ethical norms of "rightness." By separating the epistemological foundation of kairos from its discursive "effect," he creates a space for a relativistic reading of kairos, rather than focusing on the philosophical foundations that inform judgment. As a result, the ethical outcome of this reading invests rhetors, not the philosophical and epistemological foundation of kairotic decision-making, "with greater moral responsibility" (12). What Schwartzman implicitly does here is shift kairos from questions of ahistorical prescriptions for when a discursive act should be taken to that of the subject's role in making such choices and 
actions. In Schwartzman's interpretation, the rhetor is responsible for judging circumstances because she is ultimately responsible for discursive acts. Schwartzman makes this move in his reading of Nietzsche's very rhetorical understanding of the responsibility to respond and act in situations and at times which require moral courage. For Nietzsche, freedom is construed as a moral responsibility to recognize what a situation calls for as well as when the moment demands that an individual act (11-12). Thus, the recognition of the responsibility to respond is with the speaker for "Nietzsche asserts that such ... failures [to act at the proper time] result from waiting passively for permission to act" (12).

What Schwartzman brings to kairos is a focus on the subject's ability to "adapt" to a given context and act appropriately (4) because the "absence of absolute standards ... invests a speaker with great moral responsibility" (11). Thus, kairos is both the opportunity and the demand to speak, a space that must be seized to enter discourse; this interpretation of kairos highlights the importance of kairotic agency. It also serves to free ethical decision-making from the pure "determinism" of situations and contexts (16). The tacit assumption working in this configuration of kairos is that rhetorical time concerns choice and rhetorical space concerns action. Schwartzman's shift from situation to a rhetor's moral responsibility creates, however, an undifferentiated and somewhat unexplained vision of the subject and rhetorical agency. Since his understanding of kairos as a viable rhetorical concept hinges upon rhetorical and ethical agency-an emphasis I would like to retain for this discussion-his important reading of moral responsiblity needs a more developed understanding of the subject. Thus, in working toward a kairotic ethics, I think we need to understand kairos's relational capacity without leaning too heavily in favor of its relativist implications as well as to develop a description of the postmodern subject that does not assume an overdetermined position or oversimplify the subject's approach to agency. 


\section{Strategic Vertigo: (Re)Placing the Subject of Ethics}

For kairos to emerge as an important concept for contemporary rhetorical theory, especially theories that respond to the ethical demands of discourse, questions of subjectivity must also be addressed insofar as they include some consideration of how the subject is constructed in relation to the discursive agency suggested by kairos. Schwartzman's work makes clear that merely shifting the responsibility of decision and action to the subject to endorse a relativistic reading of kairos does not fully engage with the implications of subjectivity and ethical decision-making. For if, as Schwartzman argues, there are no absolute criteria for judgment, then what authorizes the subject to decide and act?

In my view, retaining kairos's important considerations of timeliness and historicization as well as its spatial implications for creating a relational but not relative theory of ethical rhetorical action also calls for some address of just how the subject works within this discursive matrix. Schwartzman's argument for the rhetor's moral responsibility does not consider the problematic descriptions of subjectivity provided by Foucault or other poststructuralist theorists who are suspicious of any theory of subjectivity that does not describe and account for how choice and intervention are to be understood. More importantly, Schwartman does not describe or clearly articulate how moral responsibility authorizes intervention into a relational kairos.

Foucault's work is useful for highlighting what adjustments must be made to a theory of ethical subjectivity. As I discussed in the introduction, Foucault's early thinking on subjectivity left out the transformative and congnizant moments that occur within subjectivity. His later work suggests something akin to agency in theorizing a transformative self, one who cannot escape moral subjectivization but who does not necessarily have to be determined by it. His analysis of the four modes of subjectivization-that is, the four means by which a subject is called upon to be an ethical subject--are an enactment of how ethical subjectivity is performed. This shift in 
thinking the subject opens up a range of possibilities for thinking an ethics that does not pretend to ahistorical or absolutist foundations. What Foucault's late interest in ethics brings to this discussion is an understanding of ethical subjectivity that is not merely determined or determining. In other words, his own struggle to articulate an ethical subject that is not merely a function of discourse opens up a discussion of the ways in which subjects are indeed determined by ethical discourses as well as how they resist the (em)placements created by these discourses. In many ways, Foucault's articulation of the construction and resistance of an ethical self offers a description of the subject's relation to kairos.

In my reading as well as my use of space/time, the subject, while not able to transcend historical circumstances for a photographic stance "outside" discourse, can choose discursive action at certain spaces in time using historicized norms as guides in ethical decision-making. The subject has the transformative potential of the agent, but only in terms of a revised concept of space and time in the kairotic action of choice. The ethical subject under absolutist ethical models creates agency by "transcending" time or drawing upon norms that stand "for all time"; space here is inert and relatively unimportant. The spatial moves of postmodern or relativist ethics situate ethics in the "ungrounded" spaces of the local and contingent without a full consideration of time and historicization of some valid and valuable norms. What the either/or dichotomy ignores is the creative and cognizant moments available to "vertiginous subjects," opportune uses of space and time that transform subjects into spatial agents. I want to admit, then, a description of ethical subjectivity that works in tandem with a kairotic ethics and one that helps to envision the possibility of temporal and tactical agency.

The subject, like kairotic ethics, can be understood spatially-as having an inside and an outside, a "fold" that has an inside preserved by notions of the individual and an outside created in the external world and the discourses that create subjectivity (Deleuze). The self operates as a boundary between these spaces. But neither the 
outside nor the inside is a monolithic space with uniform discourses and possibilities for agency. There is continual conflict between the inside and the outside that keeps their "fixity" or stability indeterminate. According to Kathleen M. Kirby, political and ethical commitments are determined by the material spaces of everyday life, "like bodies or countries, ghettos or suburbs, kitchens or boardrooms" (175). Discourses of agency are "spatial networks" (174) that offer many, sometimes conflicting "directions" for action and resistance. Building on the political possibilities of space offered in Adrienne Rich's "Notes Toward a Politics of Location," Kirby argues that the spatial orientations between the inside and the outside should not be strengthened or 'naturalized' as boundaries because this reification suggests inclusion and exclusion as well as an idea of the subject as an effect of the outside. She argues that "[w]e must neither collapse the distinctions between all the forms of space that shape our being nor entirely disengage them; rather, we need to work towards describing occasions on which they converge and reasons for why they diverge" (189).

Kairos descibes, then, both those "occasions" when speakers enter discourse and the way subjects choose one discourse over another as a result of negotiating the spacesbetween the inside and the outside of subjectivity. The intersections, overlap, and tensions between spaces may prove disconcerting, however, for the subject who, through the process of rhetorically investigating ethical choices, finds competing claims on subjectivity, such as those made between the "kitchen [and] boardroom." So while there is no way of "firming up" the ground beneath subjectivity, there is a way of situating subjectivity in relation to kairos. My use of "strategic vertigo" describes an approach to the competing and often contradictory demands made on subjects. "Strategic" suggests action and planning; vertigo is the ongoing travel that occurs within the spaces of subjectivity, between the inside and the outside. In relation to kairos, strategic vertigo enacts the subject's position to a discursive situation and demands a strategic intervention, a moment in time when discursive action is demanded or needs to be 
constructed. It offers a description of the subject in relation to kairos, a consideration that has not been made in reconceiving kairos for rhetorical and ethical theory. Thus, I am not asserting a theory of subjectivity, rather a way of illustrating a speaker or writer's response to rhetorical situations. Strategic vertigo characterizes the spatial directive available in a relational approach to kairotic ethics. I want now to consider how to create strategies for adjudicating among competing ethical claims and what normative grounds can tentatively "stand firm" for a kairotic ethics.

\section{Ethics and The Space-Between}

As a principle for guiding ethical decision-making, kairos maintains the norm of "demanding" some kind of discursive response, even that of silence; it is also contingent, presenting itself as an "opportunity" of a particular situation (Miller 314). But kairos is not merely responding to cirucumstances. Carolyn Miller's reading of kairos reminds us that kairos is not just a response to context; "we should remember that an opening can be constructed as well as discovered" (313). Thus kairos is not just a response to a situation; it can be a logical, timed intervention of "taking a space" or a stance. For example, Miller draws upon John Swales's model of scientific research papers wherein writers use the "create-a-research-space' model" that demonstrates a creative kairos (319). This model involves finding "a gap" or "a space" in the current research and then using that space as the exigence of one's discussion or research. While this is a model that is used across the disciplines, the "create a space" model provides a means of authorizing entry into a discussion.

Notably, what authorizes an intervention into discourse--in either an academic article or an "unjust" rhetorical context--is not only the responsibility of "bearing witness" to other voices in the debate, but also choosing and constructing a rhetorical space that demands recognition and response. Authorization comes from knowledge of the issue or the context that a speaker or writer is attempting to enter. Thus, the 
possibility of action and choice is negotiated within the rhetorical context and may be created on occasions when someone must speak; this retains the relativistic notion of kairos. However, unlike the positions created in the either/or ethical arguments examined earlier, kairos does not merely describe differends--arguments upon which no decision can be made for lack of an agreed upon rule of judgment. Unlike a differend, kairos demands action and response in either choosing a side in the differend or by creating another space that will allow for a break in the antithesis. Kairos allows for this space by appealing to a historicized norm to guide judgment and decision. In contrast to the discourse ethics and its transparent, hyper-logical sense of langauge, kairos is rhetorical context, and as such, demands recognition of both the logical and irrational basis used to organize and authorize other voices. But similar to Habermas's emphasis on the communicative procedure of testing ethical norms, kairos is social and responsive to discursive demands and draws upon temporally located or historicized norms to guide when might be the best time to intervene or create a space. Because of the way in which it creates a space-between the either/or dichotomy as well as its rhetorical and ethical emphasis, kairos works to fill in the topos left between these extremes.

What Habermas and Lyotard each share is the desire for an ethical (re)turn in contemporary culture as well as a means of conducting a discussion of ethics in a social, political, and public sphere. While their attempts have wrestled with finding a rational and democratic means of achieving this goal, rhetoric has been offering "irrational" strategies to deal with the problem of ethics, the subject, and discourse. Ultimately, a kairotic ethics unfolds a map for a discussion of an ethical subject, one situated in a space-between the entrenched poles of universalism and relativism. The difference here, I think, is that kairos puts us closer to a more viable ethical horizon by offering a means of adjudicating that relies foremost on the imperative, not to philosophize, but to act.

Considering that my project attempts to work the space-between the relativist and universalist dichotomy, we need to return briefly to the historical uses of kairos to 
reach a more tenable theory of discourse and ethical action. For the Sophists, there exists an important link between being and knowing. Since both ontology and epistemology were considered relativistic in nature, their concept and use of kairos reflect this. The basis of a Sophistic ethic, one grounded in the awareness of antithesis, the constant agon between opinions, beliefs, and truths, also includes the attempt to deal with a relativistic universe in the best means possible. While he sets out to defend Gorgian kairos and ethics as an irrationalist philosophy, Untersteiner does not attend effectively to the problem of relativism that plagues a practical enactment of this sense of kairos.

Michael Carter's work on kairos is important to re-establishing the link between kairos and balance, a link he makes in drawing on the work of Richard Enos. Kairos, in Carter's essay, is "the principle of conflict and resolution" in Gorgian rhetoric (102). The antithesis of the dissoi logoi is not, then, merely a struggle between opposing forces, the conclusion forcing the prominence of one over the other; rather, it forms a synthesis, a static harmony of inextricably bound opposites, the existence of which defines the other. Carter's review of the historical traces of kairos highlights the influence of Protagoras who "suggests that despite the inevitably contingent nature of knowledge, it is possible for the rhetor to achieve orthon, a kind of knowledge that approaches universal truth. The object of rhetoric... is to determine which argument most closely achieves orthon, that is, which has the greater probability of truth within a community of listeners" (103). Selecting the best argument, the most probable, is not an easy task, one that relies on the rhetorical concept of kairos, "a harmony of the conflicting elements" (Untersteiner 72). "It is the role of the rhetor, then to guide the auditor toward discovering which one of these alternatives is the more probable ... kairos keeps this decision from being completely arbitrary by providing an ethical basis for the decision" (104). The ethical basis is in finding a means of acting on the stasis of the antithesis. It also relies on the imperative of a response to the arguments, "to break up the opposing 
elements that form a rhetorical situation" (Kinneavy cited in Carter 104). The emphasis here is on the ethic of action, of the force with which the rhetor will choose a stand, a position from the antithesis (Carter 104). Thus, the "guide" toward judgment is both the rhetor who directs and the "harmony of resolution" that comes from decision--one that is further guided by a relational understanding of historical and rhetorical context-and that focuses on the argument that bears the greater probability of truth.

The active component of kairos is developed by Carter's reading of the Pythagorean doctrine that made of the antithetical forces the generative paradigm of the universe (102). Another perspective worth entertaining is that of Plato; even as he criticized the Sophists for what he read as a dangerous ethical relativism, he employed kairos in the development of his own ethics (Kinneavy 88). "Plato used the concept of proper measure and right time... [to] construct the doctrine of virtue as the mean between two extremes (excess and deficiency)" (Kinneavy 88). Despite the major philosophical differences between the Sophists and Plato, the development of the mean comes from the Pythagorean doctrine of balance between antithesis, and one that is continued in Aristotle's ethics. What remains significant, however, is the continued development of kairos in classical rhetoric as well as its implications for deriving a kairotic ethics within the postmodern.

To adopt kairos as a way of mediating and adjudicating competing ethical claims is to foreground, to use a well-worn phrase, "a politics of location" (Rich). In my configuration, kairos is a space in time, an irrationally rational aperture created by a logic and ethic of action. We cannot avoid that the spaces that prove opportune and the actions to intervene in a moment of ethical suspension are rhetorical as well as political contexts. These contexts bring with them the risks of choosing one ethic over another, and in so doing, actively place oneself within or without a particular group or identification that shares the same values. Consequently, ethical stances may involve social exile, the result of taking a stand or operating outside of an accepted ethic and the 
group that supports it. There is, then, a politics of ethics that must be considered in using kairos to determine questions of action and value, a point I will consider further in Chapters Two and Three.

If kairos is a means of adjudicating among competing ethical claims, then the ethical imperative of rhetoric is in creating spaces, spaces of action and decision informed by the better of probabilistic arguments. A kairotic ethics is about finding and creating spaces in time, about determining what should be done in the face of a given controversy. Kairos is thus a tactical exigency, one that has important implications for a theory of ethical resistance. As Michel deCerteau outlines, spaces are the operative, creative loci where people negotiate the fixed, inert categories of place. Strategies concern the operative ways individuals manipulate place; tactics, the means of the weak, involve space. Subjects take "narrative actions" to organize space (116); they act productively in the management and narrating of new spaces as a reaction to the institutional determination of places. Tactics of space deal with time and opportunity. Like the dissoi logoi that demands resolution of the antithesis, tactics "boldly juxtapose diverse elements in order suddenly to produce a flash shedding a different light on the language of a place and to strike the hearer" (37). Like kairos, tactics are, then, a means of dealing with time and opportunity as well as a means of resisting the political impositions of place.

I think deCerteau's configuration of space and place has important implications for kairos, especially in developing kairos as a tactic for ethical decision. What I want briefly to emphasize here is the fundamentally, and overlooked, political dimension of kairos as well as the tactical management of spaces in time that create an ethics of resistance. Notably, David Harvey recalls the revolutionary potential of space as it was organized by democratic thinkers. Quoting Ozouf, Harvey notes the transgression of exlusionary spaces in the creation of revolutionary space during the French and American Revolutions: "the revolutionaries 'saw space and time as an occasion' to 
construct a ceremonial space that was the equivalent of the "time of the Revolution'" (257). Harvey blames capitalism for exploiting and de-politicizing these democratic spaces, but his description of those opportune moments and spaces relies on a kairos of action. Furthermore, Harvey brings to kairos the important political potential that revolutionary and even impudent uses of kairos develop. The following chapter will examine the ethics and tactics of resistance embraced by the ancient Cynics, a nomadic group of philosophers who provide an example of how a kairotic ethics works within a political framework.

Kairos recognizes that ethical choice and action occur at specific moments--as rhetorical time. Kairos focuses less on the rational account of deriving an ahistorical or universalist ethics and more on the discursive spaces available at moments when a speaker or writer might best intervene. Rhetoric, as both the method and the context of discourse, and kairos, as the concept of creating spaces in time, offer tactics to negotiate the space-between an either/or dichotomy for thinking ethics. The latter in its awareness of qualitative time and action, and the former in its political, discursive, and social foundations, provide a working context for a theory of an ethical subject. In this configuration, the subject-as-agent makes use of spaces in time to create moments of exigence. Guided by the ethical and juridical backbone of kairos, the subject looks for "signposts" of the mean and the resolution of decision among vertiginous positions. In so doing, the subject asserts a location, a space that while active and contradictory, provides some ground from which to act--even if for the moment. 


\title{
Chapter Two
}

\section{Cynic Rhetoric: The Ethics and Tactics of Resistance}

\begin{abstract}
I will not serve that in which I no longer believe whether it call itself my home, my fatherland, or my church: and I will try to express myself in some mode of life or art as freely as I can and as wholly as I can, using for my defence the only arms I allow myself to use--silence, exile, and cunning.
\end{abstract}

Stephen Daedalus,

A Portrait of the Artist as a Young Man

Like his mythical namesake, Stephen Daedalus chooses "other" arms that will free him from the conventions of a politically and artistically suffocating Ireland, opting for the hostile position of one who either chooses or is forced into taking a position on the outside, an exile, one who must use "cunning" arts for expression. In this way, Stephen shares a discursive position with the Cynic philosophers of fourth-century Greece. And like the Cynics, he chooses weapons that place him in the paradoxical position of one who struggles with the very culture from which he attempts escape. In choosing the position of exile, the artist as well as the philosopher reconciles herself to a place outside the familiarity and safety of home, city, country, and national affiliation. Exile, however, can be an operative space. In the case of the Cynic and his philosophy, this location--beyond the safety of citizenship and its attendant rights and privileges in the polis-offered freedom for resistance. Through recovery of the examples and tactical rhetorics practiced by the ancient Cynics, we can understand their philosophical and political tenets, a project that will yield a number strategic positions for both rhetoric and ethics. 
This chapter is an attempt to recuperate Cynic rhetoric and ethics, an investigation that points to the historical linkage between these terms. My purpose in highlighting this connection is not to transplant this linkage to our own historical period as a remedy for the gradual divorce of rhetoric and ethics, a topic I dealt with more thoroughly in Chapter One. Rather, my purpose is to understand better and historically how ethics, politics, and rhetoric functioned in Cynicism as interrelated poles rather than, as in the contemporary case of our culture, as distinct, competing concepts. To do so means that I will also be reading how the ethics and politics translated into rhetorical tactics. The Cynics provide a model, although not necessarily one we can fashion for our contemporary needs, of a public discourse on ethics. In particular, a rereading of the Cynics provides an important but overlooked history that harbors some strategic ethical positions for rhetoric. In the Cynics, we find the possibilities of rhetorical resistance as well as spaces and places from which speakers and writers who remain at the margins can launch critique, those minority voices that get subsumed and silenced under the monolith of majority "conversation." This is an important "tradition" of Cynic rhetoric; it operates always from the margins, taking its model from their forced or chosen exile. It foregrounds the political by calling attention to the inequity in both speech and discursive situations. Cynic tactics are impolite and disruptive, for, as Hodge and Mansfield confer, "if you are a minority, you have to shout to be heard" (199). It disperses the centrality of logic in philosophy and rhetoric by operating by a logic of its own, one that uses parody and satire to question accepted norms. It uses the body and accounts for desire in constructing its ethics; it is, as Edward P. J. Corbett describes, a "muscular" or a "body" rhetoric (105). It is a "closed fist" rhetoric that is at once persuasive and potentially coercive in its "ethos of action" (99).

The Cynics' remains survive in the the anecdotal history of Diogenes Laertius. While they did write prolifically in various genres, only the Cynic epistles remain available, and even these are of questionable authorship..$^{13}$ In a figurative sense, the 
letters form a palimpsest over which later Cynics left their signature, until the possibility of identifying "single" or "true" authors becomes impossible. Consequently, with only the trace of earlier writings and a predominantly oral tradition, assembling a definitive history of Cynicism becomes nearly impossible. For earlier scholars, this proved to be a weak point in ascertaining the legitimacy of Cynicism as a philosophical school.

A.A. Long places Cynicism under under the historical rubric of Hellenistic philosophy and considers it the minor forerunner of Stoic and Epicurean schools. Long suggests that Cynicism is the foundation of Stoic philosophy into organized principles (8). Such critics as Dudley discuss Cynicism as an anarchic array of contradictory tenets, and for this incongruity, cannot be taken "seriously" as a Hellenistic philosophy. In terms of Cynic rhetoric, the same omissions apply. George Kennedy's A New History of Classical Rhetoric contains a chapter specifically on Hellenistic rhetoric with discussions of Stoic and Epicurean branches; he does not mention a specifically Cynic rhetoric. I attribute this omission to the lack of extant manuscripts to corroborate a definitive rhetorical doctrine. Since Cynicism is not generally considered a philosophical or rhetorical "school," such omissions are inevitable.

Nevertheless, the advent of poststructuralism and the recuperation of Nietzsche have recently brought philosophers "back" to the Cynic legacy of negation and their quest to enact "the transvaluation of all values." Leif E. Vaage and Horst Hutter examine Cynic practices with a contemporary understanding and appreciation of the subversive potential of this legacy, especially as it provides an alternative voice in the philosophical tradition. R. Bracht Branham's “Defacing the Currency: Diogenes's Rhetoric and the Invention of Cynicism" is the most fully articulated, serious engagement with Cynic rhetoric. Consequently, I will be drawing upon his identification of Cynic tropes and strategies. Unlike Branham, though, I will attempt a more integrated discussion of Cynic rhetoric and the attendant political and ethical motives that underscore their rhetorical repertoire. I want to note here, however, that the subversive 
qualities of Cynic rhetoric--its experiment with exile, its tactics of parody, play, and diatribe--share some ground with radical literary strategies associated with postmodernism. Because of this and the critical trend to celebrate the relationship between Cynicism and postmodernism, I will be examining these tactics guardedly to avoid celebrating rhetorical tactics that must be read with a keen eye to the specific historical, political, and rhetorical contexts in which they surfaced.

Cynicism is, however, a recuperable tradition, one that with closer scrutiny offers the contemporary reader creative links with an ethical past as well as important legacies of rhetorical tactics. The Hellenistic period has often been bypassed as a period meriting little scholarly inquiry because classical rhetoric and philosophy look to Plato and Aristotle as the touchstones of tradition (Long). Cynicism is also often read as the precursor of modern Christianity, a move that further occludes some of its singular contributions, but one that paradoxically provides evidence of its emerging importance. With their emphasis on the ethical practice of askesis or acesticism, the Cynics could quite easily be (mis)read as early Christians. Indeed, the image of the exiled philosopher, preaching to those who would listen, wearing the pauper's garb of a single cloak and carrying a staff, recalls descriptions of Jesus Christ and the first apostles. While both share some philosophical ground, the association of the Cynicism and Christianity--in the facile description of Cynicism as a model for Christianity--overlooks the layers of historical and cultural change that find their way into the (re)writing of the narrative of Cynicism, especially after the arrival of Christianity in the ancient world. For example, we find in Epictetus's Discourses of the first century AD an interpretation of the Cynic way of life that is clearly influenced by Christianity. "For this too is a very pleasant strand woven into the Cynic's patterns of life; he must needs be flogged like an ass, and while he is being flogged he must love the men who flog him, as though he were the father or brother of them all" (Book III, 50-55; 149). The Christian imperative to forgive one's persecutors is not a distinguishable tenet of Cynicism of the fourth and 
third centuries BC. However, some of the basic tenets of Cynicism are analagous to a Christian ethic of suffering and redemption. Antisthenes, the "first" Cynic, considered "painful effort and sturdily borne vicissitudes ... [to be] a path to arete (virtue)" (Rankin 134). Antisthenes, unlike the early Christians, concerned himself with virtue in an ethical sense for its own end, as opposed to the Christian emphasis on forgiveness for redemption and salvation in the afterlife.

In tracing the relationship of Cynicism to other philosophical and rhetorical schools, we can identify some interesting and important legacies. In my view, the Cynics present us with an interesting merger between the historically-opposed fields of rhetoric and philosophy in their enactment of theoretical principles. Theoretically, they merge the Socratic emphasis on ethics with the Sophistic emphasis on action (Jarratt 50). H.D. Rankin identifies further influences of the Sophists in the Cynic endorsement of "naturalism" and their support of pan-Hellenism (183;187). Notably, Antisthenes was a student of Gorgias and later of Socrates. The figure of Diogenes of Sinope stands, however, as the key figure of Cynicism. Other notable Cynics include Crates, Menippus, Bion, and Hipparchia, the subject of Chapter Three.

At their best, the Cynics are a model of Benhabib's "social critic" (227) whose critical stance requires "a necessary distantiation of oneself from one's everyday certitudes" (227). The process of "distantiation," of finding a space and a means of challenging "the certitude of [the critic's] own way of life" will yield alternative tradition(s), culture(s), and societies because, like the Cynic's impudent stance, these traditions cannot form "without interaction, collaboration, confrontation and exchange" (my emphasis, Benhabib 227). And like the exile and expatriate, the social critic has a vocation to continually "leave home" to find the distance, the space, to learn and to teach, but this distance is always in relation to a perceived interior; there is ultimately, and paradoxically, no "pure" space of exile. 
By virtue of the ethical imperative of discursive agency, Cynicism negotiates multiple rhetorical spaces, and in so doing, fashions an arsenal of "hit and run" tactics. Positioned on the outskirts of culture, the Cynic parrhesiast---one who speaks openly and at great risk-creates the space to speak out. Coupled with their emphasis on ethics and action, Cynic tactics, along with others of their repertoire, have a transformative effect. Diogenes of Sinope is the most famous embodiment of the ethical and rhetorical imperative to find a space on the "outside" of the polis and speak out (of turn).

\section{Hounding the Polis: Diogenes of Sinope}

On being asked by somebody, 'What sort of man do you consider

Diogenes to be?'

'A Socrates gone mad,' said he.

\section{Diogenes Laertius}

Above all, Cynicism, as embodied in the example of Diogenes, was the enactment of tenets of action, of ways of living. Using Diogenes of Sinope as a singular representative of Cynicism, I want to trace some of the beliefs and motives behind Cynic action in the rhetorical repertoire employed by them. To understand it fully in its history and its implications for rhetoric, we must "read Cynicism off" the anecdotes, practices, tactics, and insights unearthed through excavation. Unlike their predecessors the Sophists, nothing remains of their philosophy of language, although their tactical rhetoric, as well as their connection to the Sophists, provides some reliable clues. Furthermore, since much of the extant work on the Cynics attempts a stable, coherent set of philosophical and rhetorical principles, many historians and philosophers have either minimized their significance or homogenized their theory of action into a neat bundle of easily identifiable and over-simplified tenets. However, the creativity and contradiction endemic to historiography affords us multiple readings and uses of Cynicism rather than 
attempting a positivist reading of a strange and divergent history. Foremost in my reading, as well as in the school of Cynicism itself, is the importance of contradiction and how antithesis can provide productive tensions in any rhetorical dicta.

Born in and later exiled from Sinope, a coastal city of the Black Sea, Diogenes (404-323 BC) remains the most notable, and in many readings, the most infamous Cynic. In fact, it is mostly through what little survives of him and his life that we know about Cynicism. While the details of his exile remain somewhat occluded, either Diogenes or his father was found guilty of theft in "adulterating the coinage" (Lipsey 52). Most accounts corroborate that a crime did take place; whether Diogenes or his father was found guilty of the crime remains unclear. Roger Lipsey suggests that Diogenes's crime was a "misinterpretation of the Delphic oracle that urged him to make his reputation by 'giving a new stamp to the common currency'--advice that in later years he would vigorously follow but in his youth may have taken materially" (52). In his later years, Diogenes would intepret the oracle's advice to the imperative of "reminting the coinage." In its figural enactment, "reminting the coinage" became the mantra of Diogenes and his followers as they attempted the transvaluation of values. Tied to their almost complete emphasis on the ethical, changing the value of cultural currency through the public indictment of corruption and excess became one of the central tenets of Cynicism. "Remint the coinage" became the Cynic slogan, and it meant an open attack on accepted ideas and conventions.

The result of Diogenes's crime, however, was exile from Sinope, and exile in fourth-century Greece meant that the privileges of citizenship--the right to vote and to speak freely on politics--were stripped from the citizen. Notably, relatively few persons held full citizenship in ancient Greece. While the requirements varied between them, most individual city-states mandated that a citizen had to be a free-born, propertied male; women, slaves, and exiles were excluded from the political polis. Consequently, without the rights of citizenship, the exile became a political pariah. This point will 
become increasingly important as I trace the tactical rhetorics adopted by the Cynics later in this chapter; for now, though, it is important to note that political stature--at least in conventional terms-was not available to the exile, whether that position was chosen or imposed. Nevertheless, Diogenes used the stance of exile to launch the invective of cultural critique for which he is remembered. Although he wandered freely throughout Greece, he spent most of his time in Athens, where he found an audience for his caustic diatribes against the excesses of wealth and the hypocrisy of political leaders.

After demanding to work as a student of Antisthenes, Diogenes coined this branch of "Socratic sophistry" after kynos/kyon--or the dog. Diogenes gained renown for his public displays of Cynic naturalism in shameless exercise of his bodily functions which enacted the "doglike" lifestyle to which he and his followers had professed allegiance. Laertius provides numerous examples of Diogenes's shamelessness as well as accounts of his witty repartee with outraged Athenians who recoiled from these displays. Once, when observed masturbating in the marketplace, he wished "it were as easy to banish hunger by rubbing the belly" (71). He lived in the agora, using only a tub for shelter. For possessions, he had but few: a worn cloak, a staff, a small wallet, and if needed, a few eating utensils. He relied only on the generosity of the Athenians for his daily bread, who, in return, appeared to maintain a benevolent tolerance for his antics, the way a community will simultaneously abhor and protect its mad: Laertius recalls Athenian courtesy in replacing Diogenes's tub when a group of students destroyed it.

Because their philosophical tenets were part of a larger topoi of action, Cynicism operates more as a motivated rhetoric than a philosophical school. In short, it is because their philosophical principles rested upon action rather than abstraction that an organized body or philosophical school becomes difficult to organize and study. In one memorable example of this, Diogenes, in response to the stated impossibility of motion, proceeded to stand up and walk to oppose such theoretical argumentation (Dudley 21). 
Thus, foremost in Cynic thought is the commitment to "the shortcut to philosophy," whereby all who were interested in discoursing and acting upon philosophical principles were invited to do so. This shortcut could be accessed through action rather than philosophical doctrine. In another connection with the Sophists, Branham observes that Isocrates "also shunned theory as remote from the exigencies of moral experience" (338). Thus a second tenet of Cynic thought is the principle of action and living. The emphasis on action rather than dialectic and introspection, publicized an ethos of the individual, one that was open to every weakness of hypocrisy. Branham reiterates the active imperative that underscores the Cynic's skepticism of abstract argument for "the test of truth is less a matter of logical finesse than of the philosopher's ability to practice persuasively what he teaches" (337).

In addition to maintaining the importance of an ethos of speaking and action, the Cynics's free distribution of practice was an attempt to democratize "the good life" that might be demonstrated by Cynic practice. Foremost they held the belief that virtue could be taught, mirroring the trend of Hellenistic philosophy to appeal to a group beyond those enclaves of classical philosophical schools (Long 6). At the same time, this "open admissions" policy toward philosophy helped to democratize education to all who were interested, men and women alike. They argued that the excesses of materialism in wealth and gluttony were social evils to be avoided. The stark examples of an unequal polis, one wherein the slave and freeborn could not share a common sense of freedom and justice, were used in reasoning for a skeptical view of civic participation. The Cynic political stance attempted to operate on the fringe of political culture rather than in its center to highlight the exclusions of the polis and the rewards given the corrupt. Unlike Aristotle, Diogenes "attacked the city-state as an institution by advocating an ascetic life based upon 'human nature,' the rationality of which was at variance ... with the practice of Greek society" (Long 4). As a consequence, Diogenes positioned himself in antithesis to civic conventions of democracy, a move that 
indirectly drew attention to the contradictions of democracy that existed within the polis, even in the example of the exile himself. Cynic action and asceticism was an attempt to balance inequities and to provide an example of the ethical life. Freedom, the supreme "good" of Cynicism, was from the possessions of nation, material excess, and social convention. On the level of the everyday, the Cynic rejected the standards of propriety that banned him from eating or bathing in public, to name but two of the often exercised liberties of the Cynic way of life.

In the Cynics, and more specifically in the characters of Diogenes, and later, Crates and Hipparchia, we find a radical ethic of the political put into rhetorical practice to test the limits of a philosophy of action. As Donald Dudley indicates, Diogenes's ideal state is one in which weapons would be considered useless and coinage was to be abolished in favor of bone currency (36). This ideal community would rely further on the good and virtuous. Other systems of exchange would also be transformed; women were to hold equal status with that of men. While this may seem a gratuitous admission on the part of the Cynics, they were one of the only philosophical schools that allowed women to participate. As Dudley qualifies,

It seems almost certain that the Republic of Diogenes, like that of Plato, dealt with the position of women. They were to wear the same dress as men, and to exercise nude in public, as at Sparta; they were to be held in common. The only marriage he recognized was the union of the man who persuades with the women who lets herself be persuaded. And for this reason he thought that children should be held in common. If Philodemus is throughout drawing on the writings of Diogenes, we gather that intercourse was to be permitted without restriction of place, person, or sex. It goes without saying that all distinctions of rank and birth were to be abolished. Such appears to have been the 'ideal state' of Diogenes. That it might be realized he carried on a violent opposition, not merely to 
the customs and conventions, but to the ordinary business of existing communities. (Dudley 37)

Diogenes's ideal community upholds the eradication of economic privilege and the support of communal culture. His goals of economic and class emancipation struck right to the root cause of basic inequity: to end equality alter the economy of exchange. Furthermore, and perhaps most strategic for my purpose of excavating an ethics and practice of resistance, the Cynics demonstrated a public exercise of resistance to social conventions. In flouting the norms of acceptable conduct, Diogenes and his followers sought not only to shock members of the polis from complacency and acceptance, but also to force a critique of accepted norms.

As a wandering band of philosophers, the Cynics rejected firmly-entrenched notions of nation and allegiance to city-state, exploiting their positions as exiles by endorsing a cosmopolitanism reminiscent of the Sophists. Laertius recalls Diogenes's idea of commonwealth: "[t]he only true commonwealth was, [Diogenes] said, that which is as wide as the universe" (75). In this way, their work, while masquerading as a benign philosophy and chronicled in history as an aberrant philosophical school, was a highly political movement against the abuses of social and economic excess as well as a critique of Greek life and its governance. "This was the gist of his [Diogenes's] conversation; and it was plain that he acted accordingly, adulterating currency in very truth, allowing convention no such authority as he allowed to natural right, and asserting that the manner of life he lived was the same as that of Heracles when he preferred liberty to everything" (73).

Dudley calls the Cynics and their radical practices of resistance, at their best, a form of "benevolent anarchy" (37), but clearly not a viable political system (37). What we cannot overlook is the potential of such "anarchic" practices, albeit within certain constraints. We need also to consider the political climate in which such practices begin to take place. Cynicism finds its exigence in Antisthenes and Diogenes, the latter of 
whom was born shortly after the Peloponnesian War. With the increasing complexity of everyday life and the negotiation and emergence of democratic communities, a post-war Greece saw the gradual divergence of politics, philosophy, and economics, three poles that were once intricately connected in public life (Botsford 415). Also at this time, Periclean law afforded citizenship only to those having Athenian parents (416). With Alexander's expansion of the empire later in the fourth century, we find a gradual decline of city-states and local politics. Such a shift gave some influence to an increasing focus on the individual, rather than the individual's responsibilities to the polis, one who needed to replace a democracy built on genial humanism with a practical philosophy to negotiate a hostile world. In my reading, Cynicism is situated within this change, especially in its practical attempts to draw attention to the increasingly isolated poles of the economic, political, and philosophical-or in the terminology with which I began, the ethical and political. And while my historical sketch is an oversimplification of the political changes of the fourth century, I am attempting to give some account of the rhetorico-political contexts Cynicism had to negotiate. Furthermore, the historical narrative of this century is not nearly as tidy as I am making it; Greek governments, which varied among city-states, balanced between oligarchy and democracy, and at different times, weighed heavily in favor of one or the other. What becomes most strategic in this political philosophy, however, is the rhetorical legacy left by the Cynics. As R. Bracht Branham asserts, the sheer legacy left by the Cynics is demonstrated proof of their rhetorical force (127).

Nevertheless, in the example of the Cynics, and in particular, Diogenes's rather "mad" refusal to conform, we confront the limits of valorizing the kind of behavior that we would today classify as simply socially unacceptable, not politically radical. Because of this, we should keep in mind both the structure of the Athenian polis and the historical context in which these behaviors appear. In other words, we would not now endorse public masturbation as a radical rhetoric or an ethical stance. Invoking the 
obscene has limited, although practically useful, potential; I think we need to consider always the kairotic opportunities within which these tactics may be useful and when they may be labeled obscene or insane gestures that are disregarded as such. Therefore, I present these anecdotes about Diogenes to show to what extent his sociallyunacceptable behavior was the performance of philosophical doctrine by a man we would generally consider quite sane. At the same time, I do not want to discount the models of moral courage they provide for our contemporary scene. I think a legacy of Cynic ethics and tactics circulate in contemporary life, but they take more sociallyacceptable, less "scatalogical" forms. To give evidence of this, I conclude this chapter by providing one example of how the Cynic tactic of silence is appropriated by a marginalized group to give a more productive, less easily-dismissed example of Cynic rhetoric.

\section{Resistant Rhetorics}

The Cynics used a wide range of rhetorical tactics in their political practice. Parrhesia, diatribe, chreia, satire, and parody and schema (skhema) are the predominant modes employed in Cynic rhetoric. Branham adds that they also used epistolary forms, memoirs, lectures, treatises, and symposia in their repertoire, not unlike most philosophical schools of the day, as well as adding new, hybrid forms.

[T]he Cynics struck out in new directions both by transforming the traditional material of myth in burlesques and parodies and by renovating traditional forms such as the proverb (or gnome), to which they gave a Cynic stamp that would remain a permanent feature of aphoristic writing. But they didn't stop there; they also developed new or marginal forms in both prose and verse as well as the peculiarly Cynic mixture of the two 
associated with Menippus (and Lucian) .... turning low or extraliterary genres such as the will or the diary into full-scale literary productions with satiric motives. (333)

For my purposes, I would like to read rhetorically what Branham identifies as "literary." What both Branham and Vaage skirt in their analysis of Cynicism and its attendant tactics is the inherently rhetorical and political purposes of the Cynic repertoire. Even though both are discussing Cynic rhetoric, the implications garnered from such analyses remain "textual," in the sense that the possibilities of transgression stay within an economy of genre; I want to locate the possibilities of transgression and resistance textually and culturally-to take the rhetorics they read a bit further. However, I do not want to suggest that neither addresses the political matrix of Cynicism. In fact, both argue Cynicism and its tactics are transgressive modes of engaging with popular audiences to question and critique social norms. To this end, I want to take their initial, and quite engaging, analyses of Cynicism to the next level of rhetorico-ethical strategy, especially in terms of what rhetoric and composition can gain from studying these "tactical rhetorics" as we wander through our classrooms, much like the fourth-century Cynics, and attempt to give students some range of operative political stances from which to speak, write, and critique. To focus only, then, on the transgressive literary practice evinced in Cynic rhetoric elides what I see as a more expansive, lateral move toward the rhetorical and ethical.

It is in the pairing of their verbal and visual tactics that the Cynics find their rhetorical efficacy. In effect, their rhetorical practices as well as their corporeal enactment of their political stances foreground what Elspeth Probyn discusses as the "the politics of articulation ... the articulation of where we speak from" (510). By engaging in the "rhetorical rights" available to only freeborn male citizens (Flynn 103), the Cynics transgressed the limits of their assigned places in the polis as exiles, articulating an identity of exile in the discursive act of speaking "out of place." 
Parrhesia, the practice of free and open discourse, is of the highest order in Cynic rhetoric. Coupled with Diogenes's philosophical belief that "'the most beautiful thing in the world. . .[is] [f]reedom of speech" (Laertius 71), parrhesia was the tactic that forced the possibilities of agency and resistance.

\section{Parrhesia}

Despite its multiple uses and changing contexts, ${ }^{14}$ parrhesia generally means freedom of speech, the practice of frank and open discourse. In a negative sense, it means a license of tongue or "loose-tongued" (Isocrates Busiris). It is often used to implore students and speakers to speak openly and without reserve during discussions of philosophy (Isocrates Antidosis). While they employed parrhesia in a pedagogical sense of constructing an environment wherein all would feel free to speak, without ideological impediment to silence or constrain speech, the Cynics more often used this tactic in an overtly political sense to speak openly to leaders and others with power to note their hypocrisies and excesses in government, especially when deeds did not conform to the stated goals of the democratic city-state. For example, several stories circulate concerning the meeting of Alexander and Diogenes and help to illustrate political parrhesia. As Laertius relates, "When he was sunning himself in the Craneum, Alexander came and stood over him and said, 'Ask of me any boon you like' To which he replied, 'Stand out of my light.'" (41). In this example, we meet the Diogenes who is not afraid to banter with the likes of Alexander, opposing power with courage. In this way, parrhesia becomes a political practice used to question and critique not only social injustices and unethical practices but the political authority of leaders. It is, then, a more politically and rhetorically situated practice than Vaage would have us read. He asserts that in its multiple uses, parrhesia was either "tasteless talk" (28), and at its best, "highly spiced [talk] . . .with wit and denunciatory verve" (29). 
Thomas Flynn, in "Foucault as Parrhesiast: His Last Course at the College de France," observes that parrhesia was the right of every Greek citizen; for the exile, the loss of this right proved to be a painful exclusion from democratic politics (Flynn 105). In effect, exile stripped an individual of his political rights within a democracy; I use the masculine pronoun exclusively here because citizenship rights, such as voting and parrhesia, did not extend to women, slaves, and exiles. These exclusions carefully sidestepped the concerns and voices of those a patriarchal majority did not consult in distributing power in the polis. Thus, the advantages of citizenship were available largely to the wealthy, educated-male elite. As the basis for power increasingly weighed in favor of wealth in the later fifth and early fourth centuries, power within the polis became increasingly negotiable. Those who were formerly excluded now, because of the commensurate rise of democracy and an emerging capitalism, were allowed positions of power. With the shift from birth to capital, came the emerging Greek democracy. Nevertheless, as Flynn observes, "democratic parrhesia was criticized by the aristocracy in fourth-century Athens because it gave freedom speech to the masses" (106). This contradiction between the goals of the democracy and the desires of those with power was "not only an expression of class interest; it revealed a perceived structural incompatibility between parrhesia and democracy that challenged Greek political thought for generations" (Flynn 105). Appropriately, however, the Cynic ignored the constraints of this speech situation by exercising his right to parrhesia.

Thus, the right of parrhesia becomes more and more valuable as the Greek world moved from a democracy back to an autocracy in the Hellenistic period. First with Philip and then with Alexander, the freedoms afforded to a democratic polis withered under the expansion and consequent colonization of the empire. While the study and use of rhetoric did not wane during the Hellenistic period, George Kennedy notes the opportunities for deliberative rhetoric were scarce (81). With the rise of autocracy came the consequent decline of democratic venues for rhetoric. This change marks an 
important break with a previous tradition of rhetoric that had its origins in the democratic government. Notably, the public discursive space of parrhesia transformed into the spaces of law courts as forensic rhetoric grew in popularity and practice (Kennedy 81-82). As a result of such social and political change, parrhesia was exercised under increasing censure. Greece's changing political context only drew attention to restrictions on speech and civic participation. Nevertheless, the Cynic practice of parrhesia continued to outrage and incite throughout the Hellenistic period and was carried on through such notable Cynics as Crates, Hipparchia, and Bion.

Thomas Flynn's chapter in The Final Foucault stands as one of the few investigations of parrhesia. In it, Flynn examines parrhesia as a philosophical practice of truth-telling, whereby a speaker had to meet specific rhetorical conditions for parrhesia. These included belief in the truth being stated and the fear of violence due to speaking (103). Moreover, Flynn's work attempts to explain the influence of Cynicism on Foucault's late turn to the aestheticization of the self. Because of this focus, Flynn's account addresses the philosophical imperative to live a true life by practicing parrhesia as a means of accounting for oneself and telling the truth of this self. In my view, Flynn's work is necessary to understanding Foucault's appropriation of Cynic doctrines, like parrhesia, as well as his turn to the self in and as a result of discourse.

According to Flynn, with Plato's influence, parrhesia, as a political virtue available to all, became more and more the property of philosophy, and under this rubric, carried an assumed air of the "apolitical." Flynn is not suggesting that Plato ignored the politics of parrhesia in appropriating it for philosophical reflection and use. Rather, Plato was quite aware of the problems and vicissitudes of allowing all to speak in a democratic forum. Indeed, Plato's ideal state differed greatly from that of Diogenes: A sort of eugenic policy of the Republic replaces Diogenes's rejection of rank and birth in assigning social roles. Where freedom is the greatest good for the Cynic, efficient management of the polis according to those best suited for specific positions is the goal 
of the Platonic state. ${ }^{15}$ Plato feared that the masses would not think in terms of "what was best for the polis" (Flynn 105) but of "the desires of the crowd" (105). In paternalistic fashion, he attempted to appropriate the cultural and political agency afforded to citizens--the wealthy as well as the poor--by taking parrhesia under the wing of philosophy. As Foucault suggests in his reading of the Republic (Book VIII), parrhesia took on the cast of an ethical rather than political virtue, a process that invariably takes freedom of speech out of the realm of public property to the private word of philosophy, one contained by either free or pay schools. Such a move diffuses some of the political charge of parrhesia by putting it indirectly in the service of autocracy.

But the transitional position lies in his [Plato's] continued respect for parrhesia as a personal attribute of character despite a basic distrust of 'democratic' parrhesia. The focus of parrhesia is no longer the citizens or even the politeia but the soul (psyche), especially that of the prince, which, because it is educable, is capable of moral transformation to the benefit of all. The objective of parrhesia is the formation of a certain way of acting, of an ethos of the individual. (Flynn 106)

By erecting this dichotomy--between ethical and political parrhesia--Plato redefines parrhesia as a metaphysical pursuit, one that concerns itself with the soul. Foucault's identification of this split develops the association of the ethical parrhesiast as a truthteller, but one who is concerned with the confession of philosophical truths, rather than, or in place of, the political, "in that [he] is concerned with practical reason (phronesis), with the truth and with the soul" (108). Foucault then draws a Platonic "aesthetic of existence" (109), the life lived by the ethical parrhesiast who must live according to the imperative of giving "an account of oneself so as to lead to care for oneself" (108). "The art of existence [then becomes] ... truth-telling" (109), an ongoing process of "giving 
account" of the self. This move deepens the rift between a "private" ethic of parrhesia and a public ethic of political agency in parrhesiatic discourse.

Although he does not examine the power-knowledge connection in creating the schism between ethical and political parrhesia, Foucault does provide us with an important understanding of what Plato infuses to the parrhesiatic tradition. What I am arguing, however, is the inherently rhetorical formation that this split undertakes. What we gain from Plato's use of parrhesia is an "aesthetic vision of truth" (Flynn 113). "The Socratic parrhesia of harmony between one's logos and one's bios exemplifies such an aesthetic vision of truth. It is a truth one does or lives rather than says. And the living realizes a certain style, not a general rule or norm" (113). This is an important qualification of the ethical turn for parrhesia-a Socratic legacy of the ethical tied to action-and one that is clearly operative in the Cynic development of the ethical life. Nevertheless, the emphasis on the private and aesthetic experience of truth (re)constitutes "the (moral) subject" (Flynn 107) and its relation to truth-telling. On the surface, this practice avoids the political matrix of risking all to speak out in the polis; instead, it highlights the possibilities of parrhesia in the transformation from public to private.

As Foucault argues, separating knowledges and discourses helps to create and maintain systems of exclusion and control. In the case of parrhesia, we have this dynamic working on multiple levels. In the successful attempt to move parrhesia from the democratic forum by appropriating it to a privatized sense of an individual ethics, the ethical imperative to speak out within a public forum is diffused, especially as this demand comes more and more under the purview of a highly centralized government and a wealthy ruling class. Flynn suggests that this is exactly what Plato wanted to do in his fear of what "the desires of the crowd" would give life to. Foucault's interpretation, moreover, erases the public sphere by "privatizing" parrhesia. 
Nevertheless, I agree that Flynn's reading is an important and necessary one in coupling a theory of the agent--whether that is in an aesthetics of existence or in a political imperative to exercise freedom of speech or silence--with an ethical imperative to act, either within the polis or in the experience of living an ethical life. Foucault's oeuvre can be read as the assumptions that underlie the creation of subjectivity and the problems inherent in devising any theory of an ethical subject. His work is, then, the theoretical precursor to a theory of agency that is sensitive to the construction of the subject within discourse. As Flynn notes of his final remarks in the College de France lectures, Foucault was attempting to historicize and construct "a freedom of resistance" (116) based on a belief in (retreat to?) "individual responsibility" (114). However, as I have argued throughout, the separation of the ethical and political has not been satisfactorily (re)joined in discussions of rhetoric, especially in the sense of finding a range of tactics that can be used to confront dominant discourses. Foucault's reading of the Cynics leaves out an important aspect of political parrhesia, especially because the Cynics attempted to join the political and ethical in their "social" work. The following works as an attempt to heal this rift.

It should not be any surprise that Diogenes was the most outspoken of the Cynics in his formal and public denunciations of political leaders and what he assumed were their inherent abuses of power. An example from Laertius relays that when brought before Philip and asked who he was, Diogenes replied, "'A spy upon your insatiable greed"" (45). Laertius notes that for this act "he was admired and set free'" (45). And when witness to a thief being dragged away by officials of a temple, he yelled out to them, "The great thieves are leading away the little thief" (47). This impudence was originally the practiced privilege of the select group of Athenian citizens who used this right when necessary to denounce political leaders and their practices. It appears, however, that Diogenes was beyond retribution for "speaking out of turn" in his blatant use of a right that was not available to the exile. Moreover, his critiques centered on 
political figures of the day; Laertius tells us that far from being persecuted for speaking out against leaders such as Alexander and Philip, he was rewarded with his life by escaping their wrath. Most likely Diogenes remained unscathed by political leaders because in his role as a public spectacle, he escaped punishments, the same way that children and the insane were exempt from legal and political responsibility.

Cynic opposition works rhetorically as an "impudent kairos," one whereby a context demands the continued opposition to accepted norms. In use by the Cynics, kairos becomes the power to create situations wherein the Cynic could speak. By devising an almost "violent" set of tactics with which to critique culture and its icons, Cynic parrhesia distinguishes itself as an consistent ethical imperative to take a side in an argument, not as a statement of beliefs, but rather as an uncomfortable reminder of opposing views. As Vaage confers in "Like Dogs Barking: Cynic Parresia and Shameless Asceticism," "Cynic parresia [sic] was distinguished less by its specific content and more by its relation to the socio-rhetorical situation in which a given statement was uttered. In the mouth of the Cynic, parresia meant saying whatever whenever in such a way as to provoke the consistent sensation of 'boldness.'" (27). While I think that both content and form were important to the Cynic method, the Cynics are remembered for the rhetorical tactics that grabbed the attention of audiences and converted some into taking up staff and cloak. Like the Sophists, they demonstrated that truth was the sum of contingencies, and that ethics had to be defined in particular situations under specific constraints. Flynn argues that "parrhesia seeks the political conditions and the ethical differences at work in the question of true discourse" (106). A qualification must be made here, however, for Cynic kairos: "true discourse" is not dependent upon a Platonic sense of truth. Rather, a Cynic kairos seeks frankness and freedom rather than truth in its search for the opportunity to speak effectively. This qualification highlights the rhetorical nature of Cynic exchange by foregrounding freedom rather than truth. In effect, the Cynic took inventory of the rhetorical situation and 
rejected any and all constraints, including political ones, spurned onward by an ethical imperative to speak, to remain visible in the polis. Moreover, parrhesia called attention to unjust rhetorical contexts by highlighting those who were not invited to speak and then speaking in these spaces. Because it "stole" rhetorical situations, parrhesia demanded concomitant tactics that met its insurgent potential; diatribe was one of these.

\section{Diatribe}

The ethical imperative of Cynicism is discursive agency, those rhetorical strategies that "interfere" with hegemonic discourse and attempt to disrupt the oppressive constraints of determined and determining discourses. One recent example of these strategies is Julia M. Allen and Lester Faigley's article, "Discursive Strategies for Social Change: An Alternative Rhetoric of Argument," wherein the authors identify the ways excluded groups have created discursive strategies for social change, moves that seek some sort of agency from dominant discourses. They contend that writing instructors misrepresent the "real speech situations" to and of which marginalized speakers are subjects by identifying argument as the legitimate and recognized means of harnessing agency in "unjust" rhetorical contexts. In response, they examine the successful and strategic ways that speakers and writers have either subverted rhetorical norms or created new languages as a means of achieving agency, and by extension, political and rhetorical purchase in and against dominant discourses. Whereas parrhesia seeks the conditions for a contestory discourse, diatribe is a specific tactic that intervenes in the real speech situations of everyday life. Kennedy identifies diatribe as "informal preaching" whereby the Stoics (after the example of the Cynics) "lived in poverty and wandered from city to city inveighing against the stupidity of social conventions" (92). In particular, diatribe was one of the ways the Cynics spoke in the polis. 
In my reading, diatribe works in two ways: as a description of the "real speech situations" that speakers must negotiate and a tactic that is used to "break into" a conversation or argument that does not allow certain participants to enter. Ironically, the very foundations of democratic discourse in the ancient Greek public sphere precluded the possibility for many speakers to participate because of the requirements necessary for political participation. As a result, the Cynics, as an example of those who were not invited to participate, "broke into" the political conversation in impolite ways. Diatribe is an argumentative tactic that calls attention to the inevitable exclusions of critical democratic discourse and responds to its exemption in disruptive ways. Nevertheless, I do not want to suggest that their voices were either listened to or heard. In contrast to Hodge and Mansfield's claim that "if you are a minority, you have to shout to be heard," there is also the possibility that shouting will make you "not heard," and thereby diffuse the political efficacy of diatribe. I turn now to Jürgen Habermas's proposal of critical democratic discourse for a better sense of how both the democratic polis of the fourth century and our contemporary public sphere are supposed to operate, to situate the effects of this tactic within a rhetorical and political matrix.

In Moral Consciousness and Communicative Action, Jürgen Habermas outlines a procedural approach to communicative rationality and its uses for testing ethical norms. In doing so, he advises a rule of conduct, also known as the discourse ethics, for testing the validity of normative claims. The model of argument advocated is the ideal speech situation. In general, the ideal speech situation moves toward the goal of consensus. In basing its practice on mutual respect, the ideal speech situation emphasizes rational argument and turn-taking in discussion. In many ways, the ideal speech situation holds the same goals as the Greek polis-even though Habermas is not taking ancient Greece as his model--the ideal speech situation engenders the conditions for democratic, discursive participation. Even though the Greek polis assumed that its approach to democracy 
allowed for fair and rational debate on matters of civic importance, the Cynics testify to the inevitable omissions that occurred.

Aside from the contradictions and shortcomings that survive in any attempt at democratic discourse, the premises and practices of this ideal speech situation point to a critical omission of democracy in general: By making all voices equal, differences are erased; dissent is streamlined into the "larger" goal of consensus. In terms of producing social transformation and agency through reasoned argument, Allen and Faigley assert, "we do our students and ourselves a disservice by pretending that facility in the construction of logical argument is all that will be necessary to shift entrenched social structures" (168). As is evident in the ideal speech situation, agency is available only to those who are skilled in argument. What the conduct of ideal speech and its democratic foundations forget is that not all participants, even in the insurance of voice, will be listened to and heard.

In his "neutralization of differences," Habermas ignores what Seyla Benhabib calls "the concrete others" in discourse, those disputants whose race, class, gender, or sexuality can be "read off" of them and given "use-value" in the current discussion as they attempt to enter conversation. Furthermore, the ideal speech situation takes place in the public sphere that, while a potentially transformative space for civic participation, works to maintain "the political regulation of civil society" (Landes 95). This "regulation" can be read in a variety of ways. But within a sphere where consensus and rationality are the rule, there is reason to believe that "political regulation" will merely replicate existing power structures, rather than upset or transform them. As Iris Marion Young identifies, the means of communication are always held by dominant groups (59); any consensus reached by this group will inevitably reflect dominant views and power positions. Her point is well taken; for if the ideal speech situation leads to a just outcome, then what conclusions can be drawn from real speech situations, such as 
those that often occur in a democratic culture--in both the fourth century and the present moment?

The Cynics adopted what Michael Walzer calls "insurgency tactics" to deal with the inequities fostered by political and economic systems. According to Walzer, insurgency is "the acting out of a new dialectic, which denies conventional definitions of good behavior and seeks to make the 'helpfulness' of ... bureaucracy the starting point of a new politics of popular resistance and self-government" (152). Insurgency is not revolution, however. It is more limited and more immediate "precisely in that it seeks no more unity, but calls instead for the multiplication of diverse and independent unities. And it begins this process with a modest but urgent demand for a share right now in the management of this community" (152).

Diatribe is thus an insurgency tactic that in its disruptive and misbehaved way highlights the political dimensions of exclusionary speech situations by making agency available through "bad" discursive behavior. According to Demosthenes, in using diatribe, a speaker should employ "abrupt and pungent" (13) diction, as well as dramatic expressions of "puzzlement" (13). Its success at directing attention to the speaker and her message comes from its "habit of indignation" (13). It is tactical because it works by surprise and "spontaneity by never preparing the reader [or listener] for what is coming; it expresses pity, conviction, disbelief, distress" (13). As George L. Kustas discusses in Diatribe in Ancient Rhetorical Theory, diatribe resists one complete definition, as it changes form throughout history. It is also a multi-dimensional genre that describes both the subject matter and the means of presenting it. In its early uses, diatribe concerned a single speaker or writer who responded to a moral or ethical subject, much like a sermon or lecture. As Demosthenes defines, "Diatribe is an extension of a moral sentiment so that the ethos of the speaker may abide in the mind of the listener" (7). Diatribe is also a hybrid genre, employing several features to illustrate its indignant tone. It often makes use of a "fictitious interlocutor who raises objections 
and is answered" (11), what in more formal terms is called asyndeton. In the process, "... it makes provisional concession of an opponent's point and uses techniques of invective and innuendo to discredit [others]" (13).

Because it responds to the intensity of feeling created by ethical themes, diatribe does not operate by formal rules of logical argument. "We are not asked to follow a train of argument which will end by including us within its syllogistic embrace" (Kustas 15). Instead, it works to reveal the "logic of emotion" (15), making use not of formal rules of composition but a repertoire of disruptive tactics. Ultimately, ethos is its driving force, relying almost entirely on the rhetorical space available and authorized through sincere indignation and outrage on a moral question. Nevertheless, diatribe cannot be reduced to an emotional outburst. Rather, it gains character by appearing improvised in its emotional foundations; in reality, it carefully calculates the opportune time to launch an impudent statement or reaction. Thus, we can distinguish diatribe by its concern for ethical issues and questions of "ethical behavior" (14), as well as its disruptive, rhetorical management of a logic of emotion in the use of hybrid genres. And while its forms and contexts change in the history of rhetoric, I want to retain its specifically Cynic uses as "a discourse of an especially invective manner" (16), what we might also call "a rant" in its tendency to "engage people's feelings and change their lives" (38). While we should consider the Cynics's impudent statements examples of diatribe, I find more immediate, compelling examples of this tactic in contemporary political life. Benjamin DeMott's "Seduced by Civility: Political Manners and The Crisis of Democratic Values" provides an excellent case in point. In response to the call for civil, "polite" public discourse by what he deems "the leader class"-from Supreme Court Justices to Law Professors to President Clinton-DeMott observes the trend of incivility in public discourse as an aggressive, angry response to "leader class" power and moral decay. According to the privileged, "Citizens are shouting too much, as on Geraldo and talk-radio. They've forgotten how to listen and respect and defer" (11). 
DeMott argues that the new incivility needs to be recognized as "a flat-out, justified rejection of leader-class claims to respect, a demand that leader-class types start looking hard at themselves" (14). DeMott also sees the "civility boom" as an indicator of a "rising establishment impatience with the notion that, on these shores, class interests stand in ever sharper conflict" (116).

In some ways, the cry for a more civil discourse is not far from Habermas's hopes for communicative rationality in the public sphere. Even though he--and I--would defend the value of real argumentation rather than rant, Habermas's assumptions of equal access, equal entry, and following the conventions of turn-taking resemble the "civil sphere" described by DeMott and assumed by the "leader class." However, the "leader class" emphasis on civility overlooks the importance of "fairness, justice or decency among the privileged" in favor of "getting along," and thereby parting company with Habermas on this emphasis (16). That is, civility is upheld at the expense of real argumentation and justice. DeMott's examples of incivility range from the tactical use of the talk-show to changing voter opinions of government officials' perceived ethical integrity. Citing a University of Michigan study of voter opinion, DeMott finds that with each notification of both government and corporate excess and abuse at the expense of "persons of modest means or inferior coiffure," voter faith in the elected is on a rapid decline (14).

I read DeMott's descriptions of incivility as timely examples of diatribe. Like the Cynic's refusal to remain quiet and orderly in public discourse, Americans's impudence is read by DeMott "as a protest by Americans outside the ranks of the publicly articulate against the conduct of their presumed betters" (12). Notably, and to refute those examples of incivility used by the leader class, DeMott interprets examples of incivility provided by the leader class-Farrakhan, Buchanan, and domestic terrorismas examples of arguing off the point. DeMott reads these examples as part of a larger, seductive ploy by the civil to align incivility with the un-American and aberrant. His 
citation of voter response and talk-show rage show a very different picture of those "outside the ranks of the publicly articulate" who comprise a steadily growing "uncivil" public (12). In addition, the theme of uncivil protest shares its habit of ethical indignation with diatribe. In the polls DeMott studies for evidence of voter incivility, the questions asked of respondents deal implicitly with moral and ethical concerns. Finally, diatribe and incivility are both rude "attitudes" adopted by the excluded who develop tactics as a means of protection against the deceptive claims of "the leader class" (14).

Thus, crucial to our understanding of diatribe is its essentially political character. In the discussion that follows George L. Kustas' Diatribe in Ancient Rhetorical Theory, the participants attempt to define exactly what a diatribe might be as it includes so many genres, almost expanding it beyond definition. In the process, they rest on diatribe's social and political distinctions that make it something separate from mere literary strategy. As Kustas notes, "[b]ecause of the plasticity of the form, any definition would have to include the speech of the lower class" (36), those "others" who are generally denied agency and access to the public sphere. Notably, he alludes to the Cynics as "street speakers" who used diatribe to enter political discourse from their position as exiles. Another respondent clarifies that diatribe might be understood as "the emotional expression of a counterculture" (37) attempting to express "a sense of conflict, struggle, tension that would result from and reflect actual political crises and class conflicts" (37). Because of this connection to the social and political context of its production and circulation, diatribe concerns the formation of identity in its emphasis on foregrounding conflicts. In effect, diatribe is about the struggle for recognition (Walzer 153). In this way, diatribe also involves the search for agency, one that accesses a discursive "way out" for marginal members of culture.

My endorsement of diatribe does advocate the kairotic use of "bad" rhetorical behavior. My point in excavating this concept is that diatribe may offer a way of being seen and heard to those voices that are erased by the goal of an ideal speech situation. 
DeMott's observation of leader class contempt for the "rant" of the excluded is one effective enactment of diatribe. Michael Walzer remarks that the promise of such tactics insure "a kind of permanent insurgency, generating marginal but never major disturbances" (152). This, I think, is the strength of Cynic diatribe: It does not pretend to some universal concept of revolution or collapse into liberal notions of equal voice because it recognizes that speakers are located differently and in relative positions of power. Therefore, it sustains its insurgent potential by staging brief "hit-and-run" tactical advances. For the Cynics, diatribe works in the rhetorical and political exercise of parody, "feigned dialogue" with real and imagined opponents, and the use of anecdote to illustrate the consequences of political views and ethical behaviors.

Cynic diatribe provides us with a name for the insurgent political practices that generate from the ethical imperative to speak and be heard. Moreover, it recognizes that minority voices often get subsumed under the monolith of majority conversation. In its recognition of the contradictions latent in the democratic society and its speech situations, diatribe describes the real speech situation of silence, exclusion, or noise. At the same time, it provides the rhetorical approval to enter this conversation by temporarily authorizing a particular style, a way of attempting agency and resistance, even in the realistic promise that it may not be heard.

\section{III. "Serious Laughter"}

Laughter and humor can temporarily destabilize traditional genres and rhetorical situations by opening up the possibilities of inversion and critique. Such tactics undermine the rather straight-faced, logocentric norms of classical philosophy. Disruptive and misbehaved, the Cynic rhetor, using not only a bag of tricks that include rhetorical tactics--such as parrhesia and diatribe--but also a parody of philosophy, 
makes the audience laugh at him, in the hopes, perhaps, that they may come to laugh at themselves and their artificial reliance on social customs and conventions.

Branham argues for Diogenes's attempts to subvert traditional philosophy by infusing it with laughter, parody, and a mocking use of the syllogism: "jokes--a parody and a pun-are decked out in the trappings of formal argumentation" (344). Further examples abound in Laertius: when answering the arguments against doing everything, including breakfasting, in public, Diogenes responded with the witty inversion of syllogistic logic. "If to breakfast be not absurd, neither is it absurd in the market-place; but to breakfast is not absurd, therefore it is not absurd to breakfast in the marketplace'" (Laertius 71). Drawing upon the work of Bahktin and Mary Daly, Branham cleverly associates the Cynic penchant for hilarity and outrageousness in jokes and laughter with their resistance to "the authority of society to dictate thought and behavior ... [by] resistance to the social control of cognition" (Utopian Laughter" 342).

Diogenes begins his critique of Plato and, by extension, philosophy, using it, in effect, as a "straight man" for Cynic laughter. Laertius recalls a humorous example. "Plato had defined Man as an animal, biped and featherless, and was applauded. Diogenes plucked a fowl and brought it into the lecture-room with the words, 'Here is Plato's man.' (43). Inverting the causal logic inspired by cognitive custom, Plato addressed Diogenes as he was washing lettuces and said to him, "'Had you paid court to Dionysus, you wouldn't now be washing lettuces,' and that with equal calmness made answer, 'If you had washed lettuces, you wouldn't have paid court to Dionysus'" (60-61). And like their philosophical cousins the Sophists, the Cynics employed eristic reasoning in arguments against social conventions, focusing on witty inversions of syllogistic logic to win an argument rather than attempting to support a particular truth (Dudley 29). In the clearest example of Diogenes's departure from Plato's metaphysics, we encounter Diogenes' skepticism in the debate of ideal essences. "As Plato was 
conversing about Ideas and using the nouns 'tablehood' and 'cuphood,' [Diogenes] said, 'Table and cup I see; but your tablehood and cuphood, Plato, I can nowise see.' 'That's readily accounted for,' said Plato, 'for you have the eyes to see the visible table and cup; but not the understanding by which ideal tablehood and cuphood are discerned" (Laertius 55). Lacking the intellectual faculties needed to comprehend essences, Diogenes must bear the insult to his drive for the practical and earthly. While these examples do not translate easily into a statement of Cynic ethics, they do, however, identify a departure from Plato's metaphysics which, in turn, would presume transcendental moral and ethical essences. What we get here, rather, is a gleaning of Cynic principles, ones located firmly in the material conditions, those drapings of the everyday that demand ethical action. I will return to Cynic ethics later, but for now it is important to note the dichotomy between Plato and Diogenes, as well as the development of a Cynic imperative, an ethic, of application.

Jokes, parody, satire, and laughter are the tactics of Cynic rhetoric. Irony also works to make jokes effective, especially when joking and humor are used to temper or disguise political critique. This tactic is called spoudogeloion--or "serious laughter." Hodge and Mansfield have written on the use of humor as a tactic of resistance. While they are concerned mainly with humor's "tactical value" (197) in the anti-nuclear movement, their work offers important insights on reading the Cynics' contribution to a rhetoric of laughter. The Cynics also make operative Elspeth Probyn's search for a transformative theory of the self, one that puts "oneself to work discursively without taking oneself too seriously" (505).

According to Hodge and Mansfield, humor serves several purposes: to form solidarity; to work as "a shield that protects critics from being punished for their truths"; and to facilitate the acceptance of ideas (197). Seldom do any of these purposes work singularly; they tend to work simultaneously. The joke, in any of its various genres, multiplies its success in the effectiveness of irony; in other words, how 
well the rhetor has juxtaposed competing meanings. Similarly, jokes are when a "public level of meaning is yoked to and opposed or subverted by another set of meanings that are excluded from the surface of the text, repressed" (200). Like the subtext of Cynic laughter, the joke works at the moment when its "repressed" text(s) come through (as) the opposition to "public" meanings. The body also plays a role in creating laughter, mediating between verbal and visual texts (199), the "opposing [or complementing] discourse" (199) that works in tandem with the body. In their reading of Freud, Hodge and Mansfield extract the "libidinal depths" (208) evinced in the joke. Notably, the Cynics, and especially Diogenes, expressed libidinal desire in public ways, making, at the same moment, a joke of himself, his actions, and the conventions that govern appropriate behavior. What is laughable here is the subversion of cultural norms that work in opposition to the repressed subtext of libidinal desire. This appropriation of humor has obvious political overtones. Hodge and Mansfield coin the intersection of the body, laughter, tension, and resistance a "political somatics" (200). This is an important term for its expansive understanding of the political matrix of tactical rhetorics and the use of the body, and one I will return to in Chapter Three.

Political somatics describes the operative stances taken in cultural critique. When we throw this "political body" into the "body politic," we find several connections between Bakhtin's carnival and the Cynic's radical parody, connections that reveal an ethical foundation for the Cynic's use of humor as a rhetorical tactic. Carnival and parody serve as transgressive modes that degrade "the prevailing hierarchies and institutions [and] its dominant forms of expression" (Platter 202). In his work on Rabelais, Bakhtin identifies the genres that allow for the critical upheaval that is carnival. The heteroglossia of the novel provides a "self-consciousness" that engenders parody (Platter 204). Menippian satire is named as an ancient precursor to the work of Rabelais as well as a "tradition of laughter" (204). 
Notably, Menippus of Gadara (third century BC) was a Cynic who wrote scathing political satires. Laertius tells us that "[t]here was no seriousness in him; but his books overflow with laughter" (103). The genre for which he is named admits "a variety of different voices to produce a text that is polyphonic" (Platter 209). In this way, the Cynics provide an historical legacy of laughter coupled with an ethico-political imperative that foreshadows Bakhtin's theory of carnival, providing an important critique of not only fixed genres, but also of political hierarchy. As Branhham notes, Menippus's works are lost, but his legacy as a "parodic elaboration" (Unruly 14) in Lucian's satires survives as the legacy of Cynic laughter. Lucian is responsible for "publicizing" Cynic satire through the literary stereotype of the "unruly jester" (14). The jester is, like his predecessor the Cynic, an agent of critique, one who is often beyond punishment because his words are conveyed with humor. As a clown, the Cynic is permitted license that ordinary citizens are not allowed. As Platter suggests, satire employs "the language of carnival in a manner that simultaneously destabilizes the ruling hierarchies and can be co-opted by individual citizens in their pursuit of individual distinction" (207).

Joel C. Relihan's Ancient Menippean Satire discusses the legacy of the genre in predominantly literary terms. Essentially, satire, as well as the other parodic genres, works to undermine the artifice of genre and to expose the "ridiculousness of speaking or writing in verse" (20). He also discusses the philosophical project at work in the use of satire by noting the genre's confrontation with language. Relihan finds in the satire a mode that denies claims to knowledge and truth, while also maintaining the inadequacy of language to adequately convey either of these things $(20 ; 28)$. I disagree, however, with Relihan's assertion that the genre "keeps rhetoric and persuasion at a minimum"(35); that is, satire is fundamentally a persuasive genre. In both form and content, satire questions authority, but not just literary authority. In the case of the Cynics, satire goes even further to undermine and indict popular values and blind 
adherence to convention, including political, ethical, and philosophical convention. By operating in the "double" meanings contained by the parodic, Menippean satire relies on the logical and creative work of the audience to complete its message. With wit and humor, the Cynic persuaded his audience to imperatives of action.

Parody is the larger category that houses Menippean satire, diatribe, and chreia. ${ }^{16}$ Satire, however, is not as explicitly in the service of ethical and moral ends as other genres.

Menippean satire, like verse satire, has origins in diatribe. The genre teaches commonsense values (the horror of pride and presumption, the folly of dogma and theory, the joys of the simple life), but only through the example of the embarrassment of the preacher who tries to establish such common sense logically as ultimate truth. Menippean satire parodies the diatribist; in it, the catechizer is catechized. (184)

Satire, then, parodies the instructive genre of diatribe in a larger attempt to "dethrone" philosophy and philosophers (Relihan $45 ; 185$ ). Early satire of the Hellenistic period often took the form of dialogue; many were in parodic imitation of the serious philosophy of Socratic dialogue. Relihan notes that Menippean satire was greatly influenced by Plato's "literary forms and techniques of persuasion as its interest in the question of literature to convey philosophical truths grows" (185). But as Plato's place as the font of Western thought became more entrenched, he became the "butt" of satiric attack (185).

Menippean satire is a hybrid genre that made use of seemingly disparate genres; fiction, nonfiction, verse, and prose were all drawn upon in the creation of satire. Plots often followed a pattern of fantastic journeys to another world, but with hyperbolic allusion to contemporary myths (Relihan 180-183). Highly ironic, satire operates through the juxtaposition of genres and themes; notably, "the combination of the moral 
and the erotic" found a mode of representation here (34). This is an important facet of Cynic rhetoric: their ethic of the body; we need only to consider Diogenes's masturbating in the marketplace in resistance to standards of propriety to find the mixing of didacticism and sexual function, perhaps even a reduction of "the moral and erotic." Furthermore, satire destabilizes traditional notions of authorship by offering "no consistent point of view" (23); in fact, the author/narrator was himself often the object of parody. Replacing erudite arguments about truth with phronesis (practical wisdom), diatribe "thumbs its nose at pretenders to the truth by a denial that anything other than common sense is valuable or applicable" (29).

Platter's discussion of Bakhtinian carnival in Aristophanes points to some interesting parallels between the root-level uses of laughter and the comedic in both Bakhtin's configuration and the Cynics'. Parody, furthermore, is the genre that provides polyphony, or in my terminology, the "self-consciousness" to undermine its claims to authority. Parody, according to Platter, "doubles" as it takes something being parodied from one context to another;" "the parodic stand[s] in dialogic relationship" (210) to the other. "It is therefore no longer possible to consider the original as existing unconditionally and its claim to absolute authority is seriously undermined" (210). We see the disruption of parody at work in Diogenes's example of Plato's man. Using this rhetorical trope to "turn" Plato's philosophical project toward the face of Diogenes's laughter, Diogenes sets the dialogic in motion, and at the same time, attempts to undermine the absolute authority of Plato's metaphysical suppositions. The language of parody suspends the carefully reasoned arguments of philosophy. "When it [satire] begins, the ordinary requirements of reason are suspended in favor of parodic fantasy, satiric conceits, and the mock logic of the mobile jester" (Branham, Unruly 16). But the jester is a paradoxical figure for he is a "seriocomic ... who, while comic and amusing on the surface, frequently emerges as, in some sense, earnest, with a claim to our serious attention" (Unruly 27). The Cynic clown is simultaneously attempting a pedagogical 
purpose within the tension of the serious and comic (Unruly 27). Comedy and laughter are not, then, somehow "anti-logical" in their disruption of established modes of reasoning and argumentation. They are, rather, very logical, requiring the cognitive engagement of audiences. In effect, such a tactic works by surprise and cunning to rupture the terms of argument and critique, dressing them in the jester's language. Branham adds further that

[a]ll true humor has an enthymematic character: it requires the audience to perform an act of mental collaboration that can be variously described as bridging a logical gap; moving between alien codes, frames of reference, or universes of discourse; or, in Koestler's classic formulation, bisociating divergent matrices of meaning. (Unruly 54)

Nevertheless, and as I mentioned at the beginning of this chapter, parody has another side to it, one that does not always insure that the jester will make his point as he intends. That is to say, parody does not necessarily result in destabilizing hierarchy or making a political disruption. In the case of the Cynics, we can only rely on Laertius to confirm that Diogenes, in particular, was effective in his parodic imitation of Platonic thought. Consequently, Diogenes, and by extension, the philosophy and history of Cynicism, has not been taken seriously, at least not until the recent recovery of Cynicism. We might then argue that the use of satire and parody for which Diogenes and the Cynics are remembered is also the basis for their dismissal--for disrupting the "straightfaced," logocentric norms of philosophical discourse. My point here is not to diffuse the political potential of parody, but to warn against a facile association of parody and humor with political transgression. Diogenes and the Cynics are examples of the successful use of these tactics, but such tactical rhetorics must be read carefully and in tandem with historical context. 
Politically, such tactics attempt to wrest philosophy and rhetoric from the "seriousness" of Socratic and Platonic schools. The Cynics democratized philosophy and rhetoric in both their use of parrhesia and the medium of laughter, the latter which comes under attack by Plato because it is to be performed only by "slaves and 'foreigners' (xenoi) for the purpose of showing citizens how not to conduct themselves.. .. Citizens should not give it serious attention" (Laws 816 as qtd. in Branham, Unruly 48). Branham also notes Aristotle's dismissal of comedy because of its lack of seriousness and its focus on "less worthy objects" (49). The realm of the comedic, then, lands by default into the realm of the popular because it does not abide by the aristocratic emphasis on seriousness in philosophy and literature. Thus, the Cynic provided a location from which to speak and launch critique in the spaces outside of citizenship--to the slaves, women, and exiles of the polis. Cynic tactics offered, at least in their example if not in their exercise, the possibility of resistance. Vaage aptly identifies the democratic nature of Cynicism: "Cynic discourse as parresia opposed the 'refined' speech of the educated. The Cynics spoke 'street' Greek" (Vaage 28). In the marketplace, on street corners, at festivals and public baths, the parrhesiast took great risks in speaking out of place and out of turn.

\section{Ethical Bodies}

Throughout this chapter, I have been discussing tactics of Cynic rhetoric as they work in formulating a cultural critique. The Cynics offer models of resistance in their chosen rhetorical tactics as well as the dramatic use of the body, both as a complement to their tactics and a dialogic text to their asceticism. But the body is not merely a textone inscribed with cultural scripts of gender, race, class, and sexuality, to name but a few of the discourses that make their way into the formation of subjectivity--or a "prop" in the drama of Cynic rhetoric. The body is the locus of drives and desires that speak themselves into visibility and legibility. If we follow Cynic dicta, the importance 
of the body, coupled with the an endorsement of naturalism, become important sites for reading an ethic of the body; for in defining arete or virtue, the Cynics held that all that is natural is considered good. The tactics that derive from such a belief endorse a philosophical and political connection between the corporeal body and the body politic.

Foremost in Cynic thought is the importance of ethics; physics and logic are secondary pursuits. While they took their cue from the questions of virtue posed by Socrates, the Cynics expanded their discussion of ethics to include questions of public action. They attempted to redefine philosophy as a way of life from its Socratic emphasis as a "scientific system" (Hutter 117). This attempt to rejoin ethos and bios is part of the Cynic belief in enacting the practice suggested by theory. We need to recall the examples of Diogenes' contempt for the erudite and impractical arguments of Platonists to find evidence of this.

On another level, joining theory and practice in ethical action finds a conclusion in the joining of the body-mind demarcation erected in Socratic-Platonic thought. Horst Hutter argues for a Nietzschean view of Socratic values, observing that the Cynics were responsible for the attempt to reverse the first transvaluation of values enacted by Socrates.

Socrates and his followers... originated a transvaluation of values under which 'counternature' gradually assumed the force of instincts and initiated the reign of lies and priestly representatives of the life. Socratism then achieved its full expression in Christianity which has since then dominated human evolution. The original transvaluation, effected by decadent weaklings who successfully turned their resentment against life into morality, has since led to that total corruption of life in which all values are upside down. (120) 
The second transvaluation in Cynicism, then, was an attempt to recover the "lost body, a problem arising from the attempt to house all value in the 'immortal' soul at the expense of the mortal body" (Hutter 118). In doing so, questions of the ethical life were asked in conjunction with and in terms of the body. We see this at work in the distinction between the Cynic affront to "material" pleasure--one that further severs the body and mind--and the importance of "natural" desire. ${ }^{17}$ They contradicted some of the assumptions of askesis, their professed and practiced asceticism, in allowing for a body. The work of the fourth-century Cynic, Monimus, in his OnImpulses, supports this belief in asserting that "truths" were to be found in "impulses" or what we would call "instincts" (Dudley 41). Naturalism and the shameless exercise of the body in public were the inevitable consequences of this belief. Both the tenets of their thought and the tactics of their rhetoric testify to the Cynics's use of the body as a "political somatics" (Hodge and Mansfield 209). If only in the possibility of political resistance, the Cynic chooses strategic positions and desperate measures to bring about a crisis of conventions.

This political body advanced, and in some instances, worked against, the discursive ethics erected by Aristotle as well as the intellectual domain of ethics practiced by Socrates, not only in the "unreasonable" outbursts of Cynic rhetoric and the rupture of Cynic laughter, but also in the shameless influence of the body and its desire. The body and its attendant discourses become, then, visible agents of resistance. For Socrates, the development of the intellect led to moral virtue; in Aristotle, we find development of this education into ethical action. Action and reflection work in concert to form ethos, which is ultimately supported by reason. Like the example given in Phaedrus, Plato divides the soul into two parts: reason and irrational desire; pure reason will always temper the emotively-based drive of desire. Unlike Plato's demarcation, however, Aristotle offers some value and rationality to the "appetitive part of the soul" (Nichomachean Ethics $1102 b, 6-28 ; 89-90$ ). This part of the soul may 
be further subdivided into rational desire and an aberrant but obedient drive, that "other in the sense that a child pays attention to his father" (90). Thus for Aristotle reason is of the highest order in the discussion of ethics and rhetoric, especially as this pairing relies on a strong sense of civic participation. Notably, however, Aristotle, unlike later Cynics, did not live to see the end of a democratic Greece. Furthermore, Aristotle's polis was severely limited by virtue of who could participate in ethical and political discourse. The Cynics, as a counter-statement to the imperative of reason and the education of desire, attempt to transvalue values while simultaneously developing a tactic of the margins. In the echo of the imperative of civic participation that is so important to Aristotle's understanding of rhetoric, Cynic laughter can be heard. Their opposition "laughed" at the role of logical argument by employing parody and other satiric genres. "Against their [Aristotelians] pretensions of civic friendship, and their interest-laden 'good reasons,' it [impious rhetoric] would oppose with paradox, burlesque, and ribaldry" (Charland 341). Thus, the Cynic always operates in the space of antitheses, offering arguments against any form of cultural monologism and restraint. In the relentless critique of cultural norms and mores, the Cynic exists in that vertiginous space that proves strategic.

As practitioners of the seriocomic (Branham, Unruly 27), the Cynics offered serious ethical and political themes under the disguise of the comedic. Their revision of the body in their way of life is set in dialogic fashion against its erasure in other cultural discourses. In place of "pure" reason, they offered only phronesis informed by wit and cunning. In Aristotle we also find the emphasis on cognition, reason, and phronesis, but the body and its desires appear only in moderation--Aristotle's theory of the mean--and must be checked by the strength of reason. Aristotle, after Plato, finds that the comic is a vice; therefore, it should not be pursued unless it takes the better of two forms, that of "dramatizing [the] ludicrous rather than satiric material" (Branham, Unruly 49). Branham notes that heavy qualifications follow the use of comedy in both Aristotle and 
Plato, testifying to its potential to rupture the stasis of both the political text and the "right" uses of literary and dramatic genres.

Freud's work on jokes and the unconscious supports the subversive potential of the comic, in addition to suggesting that jokes release internal inhibitions (105). In the case of the Cynics, this release would appear as an account of the body and its desire. Freud adds further that satire or "hostile" jokes are the modes used in attacking those in positions of power, noting that this is a special case of the comedic that is particularly useful in revealing relationships of power (105). The comic, and especially in the case of the joke, always has something forbidden to say (Freud 106). At the same time, laughter destabilizes rationality for "a joke is derived from play with words or from the liberation of nonsense, and that the meaning of the joke is merely intended to protect that pleasure [desire] from being done away with by criticism" (Freud 131).

Both Aristotle and the Cynics weighed the importance of phronesis in transforming rhetoric into ethical action. In its emphasis on practicality, the Cynics dealt with the "conduct of everyday affairs" (Charland 52). At their root, the Cynics focused on questions of agency and ethical life. Even with the proto-Cynic, Antisthenes, we find this relationship between virtue and self-transformation. Hakkert notes that for Antisthenes, "philosophy is especially concerned with the individual as agent, active in struggling to attain arete" (101). In their emphasis on practice, they maintained a discourse ethic that offered rhetorical tactics. As I discussed earlier, the memory of their presence--despite its anecdotal orgins-testifies to the inequity of real speech situations and the tactics that must be drawn and created when "in exile."

In word and action, the Cynics "went public" not only with the exercise of personal desires, but also with their critique of social and political inequity. As Seyla Benhabib observes, "the struggle to make something public is the struggle for justice" (94). In doing so, they attempted to create a counter-discourse to the pretense of a just and virtuous polis. Not only did they offer discursive spaces from which to launch 
critique, they blurred the boundaries that define the private and public. Their "shameless" private behaviors became public spectacle in what reads as an attempt to transvalue private and public spheres. In doing so, the Cynics take questions of virtue and morality out of the darkness of private decision-making to the light of public judgment and scrutiny. Jeffrey Minson names this private/public demarcation as the conflict between foundationalist and personalist views of ethics (149). Foundationalist views are couched in the language of rights and the law, while personalist views rely on intensely intimate and private determinations of ethical problems (152). Minson sees an almost complete privatization of ethical questions at the expense of dialogue and important, public ethical questions sequestered by the demand for individual decision making. I think Minson is right in noting an historical split between these divergent views of ethics, one we can also see in the changing uses of parrhesia; such a split effects an almost complete privatization of ethics, a move that potentially "silences" ethical discourse as well as the bodies it attempts to control. What I find in the Cynics is an attempt to keep ethics in the public sphere, including normally private experiences of desire and the body. Their practiced and professed naturalism testifies to this. Furthermore, their attempt to collapse this public-private boundary highlights "the common antithesis between principles and tactical exigencies in politics" (157).

Foremost in Cynic philosophy was the imperative to join the contradictions of theory and practice. Their idea of a "short cut to philosophy" creates a renewed importance on practice and action. Exiled-as women, slaves, or non-citizens-the Cynic used his position on the margins of culture to intervene. Exile, then, becomes yet another possibly operative stance for social and political critique. ${ }^{18} \mathrm{~A}$ literal and rhetorical space, exile offers a starting point for creating "sorties," ways out that glean the possibilities of agency. Nevertheless, the exiled are often those who are without power in society. They are the minority that is always excluded from creating the very power structures that dominate them. Consequently, I am not suggesting that we should simply 
re-value the space of exile to make it operative. Rather, exile for the social critic, the Cynic, can be used as an operative stance. As Benhabib offers, "[t]he social critic who is in exile does not adopt the 'view from nowhere' but the 'view from outside the walls of the city,' wherever those walls and those boundaries might be" (228). As a strategic place for resistance, exile offers the perspective that more entrenched positions might not offer. It is also the position that results because of ethical choices. As I have been arguing, we have much to gain from reading the rhetorics created in and from this space. In the singular example of the Cynics we find that it can generate radical tactics for ethical challenge. As Robert Edwards finds of exile and literature, exile forces literary transformations (23). The exiled attempts to create a parallel society through such transformations. In a very real sense, the transformative potential of exile mirrors the ethical in the emphasis on change and transformation. In the Cynics, we see this working in the creation of rhetorics of resistance. Transformations are indeed at work in the generation of Cynic tactics, as well as the alternative worlds created in Menippean satire, a genre that finds its legacy in the Cynics.

In some cases, exile offers only silence as the speech of resistance, as in the contemporary examples of resistance from the Huairou conference that preceded the United Nations Fourth World Conference on Women in September of 1995. In this article from Newsweek nine exiled Tibetan women are photographed wearing gags in protest of the repression of their homeland (42). According to the report, such a demonstration must have escaped Chinese censors who did as much as possible to impose "rules to restrict the expression of unwelcome opinions" (42). Like the example of the fourth-century parrhesiast, these women, already oppressed and exiled, choose their arms wisely, opting for the "loudest" expression they can create to speak out. In this and many other examples of women's resistance, we will find exile an uncomfortable and, at best, potentially operative position for marginalized speakers. In the next chapter, I will examine the location of exile in its relationship to feminism. 
Beginning with the figure of Hipparchia, the next chapter will address her "double" exile for being at once a Cynic and a woman philosopher. Using her example as a starting point, I will discuss the development of a feminist ethic, one that draws upon the political tactics offered in Cynicism. 


\title{
Chapter 3
}

\section{Hipparchia the Cynic: Feminist Rhetoric and the Ethics of Embodiment}

\author{
I admire you for your eagerness in that, although you are \\ a woman, you yearned for philosophy and have become \\ one of our school, which has struck even men with awe for \\ its austerity.
}

A letter to Hipparchia from Diogenes of Sinope,

\section{The Cynic Epistles}

Stand fast, therefore, and live the Cynic life with us (for you are not by nature inferior to us, for female dogs are not by nature inferior to male dogs)

A letter addressed to Hipparchia from her husband Crates, The Cynic Epistles

Little remains of the early Cynics; even less is known about Hipparchia of Maroneia (ca. 300 BC) whom Ethel Kersey identifies as the "first feminist" (132). What does remain is hidden within the history of Cynicism. From these traces emerges the legend of Hipparchia, the story of an outspoken woman who flouted convention, took up staff and cloak, and joined her husband Crates in the streets of various Greek cities to show the masses how they had fallen under the spell of false gods, shirking the virtues of a democratic polis for the comfort of easy wealth. In this way, Hipparchia participated in and continued the Cynic ethics and tactics of resistance.

The most detailed account of her outrageous behavior is provided by Diogenes Laertius who tells the story of her engagement to Crates of Thebes, a follower of Diogenes of Sinope. A woman of high-birth, aware of the attendant expectations that 
she would marry a wealthy man of the same class, Hipparchia rejected these expectations, as well as her parents' arguments, by her intention to marry Crates who had neither station nor wealth to offer her, save the few belongings he carried with him. Following the wishes of her parents, Crates tried to dissuade Hipparchia from her intention to marry him. But after all arguments went to waste on her, Crates finally took off his clothes, and standing naked before her said "This is the bridegroom, here are his possessions; make your choice accordingly; for you will be no helpmeet of mine, unless you share my pursuits" (Laertius 101). By accepting Crates's offer of marriage, Hipparchia also embraced the Cynic way of life, a life that demanded she give up not only her domestic tasks, but also the comfort and stability of high social class. Living in the agora and openly questioning convention, Hipparchia and Crates exemplified the Cynic doctrine "to live a true life."

The Cynics were one of the few sects that allowed and even encouraged the participation of women, observing no intellectual differences between men and women. Others were not so progressive. As Laertius relays, at a banquet given by Lysimachus, Hipparchia argued with the atheist, Theodorus. Laertius relays the encounter:

'Any action which would be not called wrong if done by Theodorus, would not be called wrong if done by Hipparchia. Now Theodorus does no wrong when he strikes himself: therefore neither does Hipparchia do wrong when she strikes Theodorus.' He had no reply wherewith to meet the argument, but tried to strip her of her cloak. But Hipparchia showed no sign of alarm or of the perturbation natural in a woman. And when he said to her: 'Is this she/Who quitting woof and warp and comb and loom?' she replied, 'It is I, Theodorus,--but do you suppose that I have been ill advised about myself, if instead of wasting further time upon the loom I spent it in education?' (101) 
In her essay on women and philosophy, Michele Le Doeuff observes that Hipparchia's reproach of Theodorus's insults concerns how she uses her time, in particular, her life-time, for the improvement of her mind rather than "wasting" her time confined to the home (205). For Hipparchia, time spent away from the loom and on "the getting of knowledge" (206) provides her with "a better life, but [in the process] she wins exile" (206). Nevertheless, Hipparchia preferred her exile to traditional feminine pursuits.

I, Hipparchia, have not followed the habits of the female sex, but with manly courage, the strong dogs [Cynics]. I have not wanted the jewel or the cloak nor bindings for my feet, no headties scented with ointment; rather a stick, barefeet and whatever coverings cling to my limbs, and hard ground instead of a bed. A life such as mine is preferable to that of the Menalian maid, since hunting is not as worthwhile as seeking wisdom. (208) As I concluded in Chapter Two, the Cynic operated from a position of exile-sometimes chosen, sometimes forced--and while the causes of exile require specific and responsible address in terms of what critical stances they offer, exile did provide a rhetorical space for the Cynic rhetor. In addition, the idea of exile assumes a spatial understanding of the political subject in her relation to the polis. That is, the literal and figurative space of exile assumes "an outside," a sense of (dis)placement that affectively situates the exile in relation to a perceived "inside." In some cases, exile is the spatial movement of the body over time and space to a place outside a city, a nation, a place. Thus, exile--in both literal and figurative terms--involves the body and its relationship to both space, as a figurative concept, and place, as a lived or "real" environment.

Central to Cynic ethics was the performed function of ethical critique, and exile provided an important discursive space for this rhetorical practice. A philosopher of action rather than discussion, the Cynic is one who "receive[s] virtues for toils" 
(Malherbe 65). "For the way that leads to happiness through words is long, but that which leads through daily deeds is a shortened regimen" (Malherbe 7). In addition, the Cynic imperative to create spaces to speak through parrhesia and to critique through "serious laughter" maintains the Cynic ethics of resistance. Thus, Cynic rhetoric--in its emphasis on critique as well as the inclusion of women--took an ethical stance toward giving discursive spaces to "those who are not already located in speaking positions within dominant discourses" (Allen and Faigley 142).

In this chapter, I want to develop the critical space of exile for the Cynic tactical repertoire. In the case of Hipparchia, we meet an almost "double exile"--as a woman excluded from political citizenship ${ }^{19}$ and as a Cynic. In this sense, her exile is simultaneously forced and chosen, a move that further complicates the position of exile. Moreover, Hipparchia--as the woman rhetor-tells a different story as the gendered site of ethical and rhetorical enactment of Cynic tactics. As I will argue, Hipparchia highlights the problem for ethics, rhetoric, and embodiment because both ethics and rhetoric have historically assumed a male body and its corporeal experience. Women's bodies are positioned as "other" to men's centrality and the standard of their corporeality. Because of this, as well as her commitment to Cynic ethics, Hipparchia forces us to consider important issues of gender, sexual difference, and embodiment in ethical rhetorical practice. As I will discuss later in this chapter, her absence in the history of both rhetoric and philosophy and her present recovery as "the exception" in these traditions, speaks to the gendered assumptions that underwrite the writing of history.

What Hipparchia addresses in both her bodily specificity as the woman rhetor and in her role as a Cynic are the important and overlooked connections between rhetoric, feminism, embodiment, and ethics. Moreover, as histories of women and rhetoric have and continue to evolve in the field, we need to consider how these recoveries work toward the development of feminist rhetorics. Related disciplines have 
been considering the role of ethics for feminism, just as rhetoric has and continues to examine the possibilities of a feminist rhetoric. To this end, feminist philosophers have recently renewed their interest in ethics. Claudia Card, Iris Young, Seyla Benhabib, and Rosalyn Diprose are but a few feminist philosophers who are working to redefine ethics outside of or in resistance to masculinist or patriarchal accounts of ethical theory. Within rhetoric and composition studies, feminist rhetoric has been an important locus for generating inquiry, critique, and new histories of women in rhetoric; Patricia Bizzell, Susan Jarratt, Sharon Crowley, and Andrea Lunsford are a few names associated with this project. However, a specifically feminist ethics of rhetoric has yet to be addressed. ${ }^{20}$ While I am concerned with the reasons for this "omission," if it can even be called that, I am more interested in reviving the ethical within rhetoric, especially as rhetoric needs to confront feminist rephrasings of gender and new, spatial definitions of ethics that will, in turn, help to create new discursive combinations and contributions. In short, this inquiry seeks to reveal the occluded links between rhetoric, ethics, and feminism, a move that will initially force us to consider the unexamined ethic(s) that supports much of feministrhetoric.

\section{Playing with the Big Dogs: Hipparchia the Cynic}

The enormity of Hipparchia's break with cultural and gendered norms can only be fully understood if we consider the historical context in which she lived. For an aristocratic woman of the fourth century, few freedoms were available. Subject to the rules of family and excluded from participation in the polis, women were not a visible presence in the public sphere. Periclean law certainly gave more importance to tracing and recording women's history and their familial legacies, but it did not translate into significant political purchase (Biesecker 104). Because she lived during the first century of the Hellenistic age (323-30 BC), Hipparchia enjoyed the few, limited extensions of social freedoms. I am not suggesting that there was any major shift in the status of 
women during this time; however, there were subtle changes that expanded women's movement, and thus their spatial mobility, in the political polis. According to Eva Cantarella, women enjoyed more legal and social freedoms than ever before as a result of larger shifts from the city-state back to monarchies with women rulers. In addition, the affront to classical values demonstrated in the Cynic philosophers marked the changes that were taking place (90).

Moreover, the changes were contradictory. Although they could "buy and sell goods and property, mortgage their own goods, give and obtain loans, assume obligations of work, make wills, be named heirs and inherit legacies" (Cantarella 91), women were still subject to apheresis, the right of a father to interrupt a daughter's marriage (91). Infanticide of female children and rampant illiteracy were still status quo for women in the Hellenistic age. Within this context, Hipparchia's refusal to follow the demands of her parents is all the more significant. Consider also that patrilineage, law, and social custom all considered marriage a financial arrangement. Hipparchia rejected these injunctions in choosing to marry for love, not the. insurance of familial wealth and relations. Socially, Hipparchia assumed two roles: a wife and hetaira.

The hetairai were often educated women who shared in the social, sexual, and intellectual life of men. As Cantarella outlines, Greek men of position often had other important relationships with women other than their wives, such as prostitutes, concubines, and hetairai (49-49). According to Pomeroy, the hetairai were euphemistically referred to as companions, similar to prostitutes for their paid service, but different in their education and social training. She also accompanied men where wives and concubines could not go, such as professional meetings and academic discussions (48). Highly unusual was the woman who held more than one role, as in the case of Hipparchia. One of the more famous hetairai was Aspasia whose controversial position as mistress, advisor, and teacher to Pericles alludes to the problem of classifying a woman who held more than one social role. 
While Canterella paints a more positive picture of women in the Hellenistic period, Sarah B. Pomeroy looks at the ambivalent messages given to and about women during this time of cultural change. Furthermore, Pomeroy makes important distinctions between the different areas of Greece that held more liberal attitudes toward womenthan others. Pomeroy seconds the existence of legal and economic participation of women during this period, noting, however, that even though they were conducting legal and financial transactions, women were always attended by a male guardian to insure the proper management of business (127). Despite these gains, little changed in the political realm for women; they still held no right to vote, and Athens still remained the most conservative of the Greek world in its economic and legal privileges for women.

Pomeroy credits the minor changes in women's status to several factors, namely the reinstatement of monarchies, as well as the exchange of culture and cosmopolitanism that characterize the Hellenistic period from the Classical. Important for understanding Cynic philosophy and Hipparchia's position in relationship to this school, is the gradual move from the communal ideals of the Classical period to "the goal of individual selfsatisfaction" of the Hellenistic (Pomeroy, Women 132). Pomeroy suggests that these changing values reflected the increasing gap between wealthy and poor. In seeking their livelihoods elsewhere, many men left their homes for colonies which held a more peaceful alternative than the fear of attack from warring monarchs at home (132). Ironically, however, with the loosening of social and familial responsibility for men and the focus on individual happiness, there were ambivalent messages sent to women about these changing mores. Pomeroy provides an example of the numerous treatises written on maintaining the virtues of feminine behavior, in particular, the behavior of free-born aristocratic women (134).

As I have alluded to already, the sexual lives of men were expected to be active; consider the many "service" positions women could occupy in the life of a man. Wives were not legally or socially expected to have sexual relationships with anyone other than 
their husbands, or in the case of slaves, their masters and his friends. Perhaps in response to these changing mores, women were engaging in more "unrestrained" sexual behavior. While this fact is impossible to prove, female representation in art and literature reflected changing attitudes toward the body and female sexuality, allowing for more equitable and understanding views of sexual pleasure in women (Pomeroy, Women 142-148). The existence and importance of educating female desire becomes more marked, then, in contrast to general social and cultural trends, especially as writers of treatises appear to be making gendered amendments to the larger emphasis on following individual desire. The case of educating female desire was, indeed, a special case, one deserving of careful interpretation.

\section{The Ethics of Exile}

In this section, I want to concentrate on how exile works both as a rhetorical and ethical space for women. This reading maintains a critical reappraisal of the position of woman as subordinate other by reevaluating the position of marginality. But the purpose here is not to reinvent marginality or to celebrate it; rather, it is to complicate exile and to foreground a rhetorical reading of such a stance. As Rosalyn Diprose outlines in The Bodies of Women: Ethics, Embodiment, and Sexual Difference,

Even if we grant that ethics is about moral principles and moral judgment, it is also about location, position, and place. It is about being positioned by, and taking a position in relation to, others. Being positioned and locating others requires embodiment and some assumptions about the nature of the place from which one moves toward others. (19) ${ }^{21}$

Notably, Diprose calls upon the etymological relationship between ethos as location and habit and ethics as practice to redefine ethics as "the study and practice of that which constitutes one's habitat, or as the problematic constitution of one's embodied place in 
the world" (19). Her account highlights a contextual account of ethics and the real, sexed bodies that inhabit discursive locations. Furthermore, by tracing the importance of habit and location, she reiterates the emphasis on action and practice that I want to extend in Cynic rhetoric. Diprose's work is central for concentrating on how discourses determine, evaluate, and regulate sexual difference. Foremost, however, is her contribution of how place--or in my configuration space--plays a vital role in a feminist ethics of rhetoric.

Exile calls up the cognates of colonization and territorialization. We are, then, speaking once again in spatial terms. Moreover, employing spatial modes of understanding and historicizing allows us to collapse the facile insider/outsider distinctions of binary thinking. In other words, binary positions used to describe the position of exile remove the mobility available to the one who has chosen exile as a critical rhetorical space. Nevertheless, I want to reinvoke Jane Marcus's warning for an "ethics of elsewhereness" in our thinking through new rhetorical spaces recovered through exile. We must beware of what Caren Kaplan observes as a "form of theoretical tourism ... where the margin becomes a linguistic or critical vacation, a new poetics of the exotic" (361). Kaplan also makes extended, important amendments to chosen and forced exile. "For if I choose deterritorialization, I go into literary/linguistic exile with all my cultural baggage intact. If deterritorialization has chosen me--that is, if I have been cast out of home or language without forethought or permission, then my point of view will be more complicated" (361). I would argue, however, that in the case of Hipparchia, and in full consideration of historical and political context, she operated in both complicated positions of chosen and forced exile, highlighting the problem of binary and exclusionary terms for thinking exile. That is, the very terms that Kaplan uses to structure a complicated and assumedly less complicated exile exclude the possibility of occupying both positions of exile simultaneously. What Kaplan does make explicit, 
however, is the creativity engendered by a practice of "leaving home," of finding exile. Yet, she reminds us that there is no "pure space" (264) of exile.

The move to the spatial allows for a remapping of critical rhetorical spaces that are not rigidly maintained by exclusionary fantasies of complete and permanent overthrow of the negative binary "other." As Cheryl Glenn confers, "[e]ach time we encourage such remappings and reconceptualize basic assumptions, whether in our theories or our practices, we are redrawing the boundaries of rhetoric to include new practitioners and new practices" (300). The space of exile provides us with another way of thinking through a practice of critique, one that demands an exterior position is taken and a critical space is assumed. Kaplan adds to this assertion in her reading of Minnie Bruce Pratt's work on location that traveling away from home engenders a feminist practice of "deconstruct[ing] the terms of social privilege and power" (363). There is an ethics to this position of exile, an imperative to take up this position of critical consciousness. Chela Sandoval argues that this position produces an "'oppositional consciousness'"(as qtd. in Kaplan 357) for those "men and women who move between the cultures, languages, and the various configurations of power and meaning in complex colonial situations" (357).

Much like the fourth-century Cynic, the exile feels an outsider and is often considered an eccentric. Furthermore, the Cynic's need for mobility requires that she live without material comfort and stability, those objects and attachments that would serve to anchor her too tightly to a fixed place. Edward Said seconds the creative consequences of exile, while also carefully noting the differences between real exile from home and country and the self-imposed exile of the expatriate. He observes that leaving home--under either guise--results in a new and important critical space. Said's "Reflections on Exile" observes the compensation for the "disorienting loss" (448) that results in the creation of fictional worlds for the exile. As a future novelist or political activist, the exile finds an occupation that "requires minimal investment in objects and 
places a great premium on mobility and skill" (448). Said's description of the exile's characteristics shares many similarities with a Cynic rhetoric.

Wilfulness, exaggeration, overstatement: these are characteristic styles of being an exile, methods for compelling the world to accept your vision--which you make more unacceptable because you are in fact unwilling to have it accepted. (448)

As the nomadic presence in "other" lands, the exile is disruptive in maintaining a position always at odds with his adopted home. For Said, there is an ethos, or in my configuration, an ethics of exile that results in the edification of the exterior, the "other" place the exile inhabits only temporarily. Said uses the more immediate examples of the struggle in Palestine and Israel to illustrate the task of maintaining this "exterior" ground in the face of oppression and "the threat of extinction" (450), but his point still has resonance for this discussion: the exile has to work to maintain a sense of self and connection despite the constant, and perhaps sometimes welcoming, attempt to assimilate, to let down the critical stance, and to steady the vertigo produced by an oppositional consciousness-to find rest in what Said calls the "contrapuntal" existence of exile; that is the "plurality of vision" (450) that, while engendering original, creative visions of the world, can prove exhausting to maintain.

What Said adds to an understanding of exile as a rhetorical space comes in his discussion of Theodor Adorno's Cynical view of mass culture. Said looks to Adorno as an example of what a productive sense of exile can do for the critic. According to Adorno, the intellectual's mission is to maintain an exile that refuses the commodity status of everyday life--a life that exists in all homes and all nations. Said's paraphrase is particularly apt in articulating a rhetorical space of exile.

Adorno's reflections are informed by the belief that the only home truly available now, though fragile and vulnerable, is in writing. Elsewhere, 'the house is past. The bombings of 
European cities, as well as the labour and concentration camps, merely precedes as executors, with what the immanent development of technology had long decided was to be the fate of houses. These are now good only to be thrown away like old food cans.' In short, Adorno says with grave irony, 'it is part of morality to not be at home in one's home.' (450).

Hipparchia opens the rhetorical space of exile as a valid and necessary stance. Indeed, it was one space, if not the only, that would allow for a woman rhetor. As the Cynic exile, Hipparchia made other philosophers uncomfortable by her presence in their discourses. Within the polis, she was seen as more shameful than her husband because she flouted the convention of the cloistering of women. But in adopting the Cynic ethic of exile, Hipparchia tells a different story of Cynic rhetoric and points to important considerations for a feminist rhetoric. Because of the role of the body in Cynic asceticism, Hipparchia reminds us to consider embodiment in conceiving a feminist rhetoric. In particular, she reminds us of the absence of a feminist ethics of rhetoric in contemporary debates that calls attention to the ethical problems involved in predicating a feminism based on "essential" or embodied differences. She provides a point of departure for what I see as the ethical problem for feminist rhetoric.

\section{The Rhetoric of Feminist Ethics}

If not the body, then the functions derived from or associated with the cultural construction of the female body serve as the basis of many strains of feminist ethics. The field of rhetoric and composition has borrowed heavily from the findings of Carol Gilligan and Nel Noddings in the development of feminist rhetoric and pedagogy. Revaluing feminine, maternal characteristics of care and nurturance as well as women's ways of knowing have come--if not directly--then implicitly from the epistemological bases of their work. Feminist rhetoricians ranging from Starhawk ${ }^{22}$ to Sally Gearhart ${ }^{23}$ 
to Elizabeth Flynn ${ }^{24}$ take up the development of feminist rhetoric by drawing upon a distinctly feminine consciousness that provides the foundation for feminist discursive and pedagogical practice. As I will discuss later, many feminist rhetoricians have questioned the essentialist foundations of Gilligan's and Noddings's work as well as how their models of femininity are imported for feminist rhetoric. Nevertheless, we are still responding to their work and the traces of it that have found their way into pedagogy and discourse theory--as we rightly should. However, such focused attention on critiquing these models leaves us little time to consider a foundation for feminist ethics of rhetoric. Ironically, I will also "spend time" doing the same, but with a different purpose in mind: 1) to examine the epistemological and ethical bases of feminist rhetorics and; 2 ) to point to and partially respond to the need for a viable feminist ethics of rhetoric. My second goal here addresses the need for a revised understanding of rhetoric's attention to embodiment as an ethical concern without reproducing essentialist or ahistorical foundations of woman upon which to build such a revision. I think we have overlooked the essentially ethical foundations of feminism and feminist theory, perhaps because as feminist rhetoricians, we, like Aristotle, assume the fundamental link between ethics and rhetoric. Thus, we feel no need to examine these foundations, as if we all tacitly agree that there is an ethics to feminism, even while it remains unarticulated. But this silence approaches deception. For much of what suspends feminist rhetoric harbors important, ethical assumptions that need to be addressed in the ethical project of developing a feminist rhetoric.

An extensive body of scholarship responds to the problems and contradictions of Gilligan's work. Nevertheless, and despite endless theoretical challenges to the assumptions and consequences of her work for feminism, Gilligan still stands as an important figure in the development of a feminist rhetoric. Because of this, her appropriation for a feminist rhetoric needs to be examined in developing a feminist ethics of rhetoric that does not replicate stereotypically feminine, and by implication, 
essentialist, theories of discourse. For, if as I contend at the outset, that a feminist ethics of rhetoric is about finding spaces to speak, then long-standing theoretical bases need to be examined for the spaces they cover up in "finding a space for all." As I argue in this section, the ethic of care as developed by Gilligan has been linked to an essential, feminine capacity for care in many appropriations of her work. An effect of this has been the confusion of feminist and feminine approaches in the development of a feminist rhetoric.

Carol Gilligan's In a Different Voice: Psychological Theory and Women's Development is a landmark on the map of feminist theory. In it, Gilligan refutes Lawrence Kohlberg's five stages of moral development for its biases toward a masculinist ethic of rights. In brief, Kohlberg's stages of moral reasoning value a gradual development of differentiating self from others, freeing thought from contextual constraints, and moving toward rational abstraction. The final stage of moral reasoning is thus equated with adulthood. This model progresses from egoistic to social to the highest stage of using universal, ethical principles to judge ethical dilemmas. According to Kohlberg's data, men generally operate by an ethic of rights, one "geared to arriving at an objectively fair or just resolution to moral dilemmas upon which all rational persons could agree" (Gilligan 22). In contrast, women tended to place lower on the developmental scale than men which was, in turn, used to support the claim that women's moral reasoning was undeveloped.

Gilligan criticizes Kohlberg's stages not only because they favor masculine approaches to ethical decision-making, but also because Kohlberg created his stages and the value given to high order moral reasoning before sampling the responses of men and women. That is, Kohlberg's paradigm of moral development, and the value it gives to abstract reasoning, was itself a gendered model used to plot responses rather than letting responses determine the stages (Ainely). Taking her cue from this built-in bias, Gilligan studies women's responses and finds that unlike men, women tend to operate 
by an ethic of care, one that values relationship and responsibility rather than duty and rights. "Thus the logic underlying an ethic of care is a psychological logic of relationships, which contrasts with the formal logic of fairness that informs the justice approach" (73). Care, for women, is equivalent to moral responsibility. A fully developed ethic of care "that remains psychological in its concern with relationships and response but becomes universal in its condemnation of exploitation and hurt... This ethic, which reflects a cumulative knowledge of human relationships, evolves around a central insight, that self and other are interdependent" (74). Thus, women see moral dilemmas in terms of conflicting responsibilities, and this is what needs to be added to developmental theory, an account of "feminine voice" (105). Because of women's moral capacity and willingness for care and sacrifice, of affect rather than extreme rationality and impartiality, they are provided by Gilligan as valuable models of moral reasoning. At no point does Gilligan advocate replacing a masculinist ethic of rights with that of care. Rather, her work seeks to valorize women's unique relationship to others and their development of moral reasoning.

I think it is easy to see how and in what ways Gilligan's assessment of women's moral development has been used to substantiate feminist theories of difference. Within rhetoric and composition, her distinction of an ethic of care and an ethic of rights has served to entrench a particular view of feminist ethics that favors relational models of discourse: dialogue over argument, shared rather than absolute authority, affect instead of, or in addition to, the rationality of argument, and collaboration and consensus as opposed to individual voices. Despite the positive models of change provided by her work, too often Gilligan, as well as appropriations of her work, celebrates a specifically feminine ethic of care, a move that does little to dismantle Kohlberg's theory of moral reasoning. But my quarrel is not so much with Gilligan, for hers was and is groundbreaking, necessary work on women and moral theory. My problem stems, rather, from the unexamined foundations of the ethic of care and rights, as well as the 
explanations given to build these differences upon two gendered categories. Moreover, though, I am concerned with the way in which an ethic of care has been used to ground feminist rhetoric in the field, and it is to these appropriations that I wish to speak.

Gilligan uses men and women's primary differentiation from the mother as the grounds for differences in moral reasoning. According to Gilligan, women desire connection and relationship because of their initial connection to their mothers; their need for individuation comes later and is less threatening to ego boundaries. Thus, femininity is defined by relationship with another and is not threatened by intimacy. Boys, on the other hand, need to individuate from primary identification with the mother to assert their masculinity. Thus, intimacy and relationship are threatening to the strict maintenance of male ego boundaries (8). In this way, the ethic of rights operates by separation, not connection (19).

Women's voice is located in their knowledge of connection and interrelatedness which is derived from their initial relationship with the mother. However, neither Gilligan nor Kohlberg ever substantially question the role of culture and social construction in the development of an ethic of care and rights. What is worthy of further note, however, is Gilligan's response to critics in the preface to the 1993 edition of In a Different Voice:

I find the question of whether gender differences are biologically determined or socially constructed to be deeply disturbing. This way of posing the question implies that people, women and men alike, are either genetically determined or a product of socialization--that there is no voice--and without voice, there is no possibility for resistance, for creativity, or for a change whose wellsprings are psychological. [This combination] prepares the way ... [for] the suffocation of voice and the deadening of language which ripen the conditions for fascism and totalitarian rule(xix). 
Gilligan's oversimplification of social construction aside, she neglects to examine the essentialist tendencies in her own work. In other words, to locate the base of an ethic of rights and care in psychological theories of individuation and connection to the mother falls just short of--if not directly on top of--biological essentialism by locating the source of gender polarization in pre-existing and an assumedly unchanging psychological dynamic with the mother. Thus her categories can be read as the reduction of the complex foundation of ethics to predetermined premises about how and why women and men tend toward different characteristics in their moral reasoning. Because neither consider the cultural matrix that constructs values and rationality in each gender, Gilligan and Kohlberg neglect the integral component of culture in the formation of ethics. What I am objecting to here is not so much the ethical categories that Gilligan provides; indeed, they are still useful, operative terms in both ethical and rhetorical theory. But I have serious reservations about the very uncritical way stereotypically feminine characteristics are established as the means by which women respond ethically. However, Gilligan does address embodiment; an ethic of care that "takes inventory" of those affected by moral decisions and opens itself up to contingent circumstances is designed to consider the problematic of embodiment in ethics. Nevertheless, as her critics have argued, she extrapolates an ethic of care from a relatively homogenous group of middle- to upper-class white women students, a move that denies Gaten's claims that we consider "an ethics of difference" (104). Moreover, I question how the ethic of care has occluded other modes of discourse in advocating a feminist rhetoric of care. In other words, the easy polarizations of masculine rights and feminine care have closed off alternatives to this traditional binary by speaking in primarily essentialist, ahistorical terms.

What a feminist ethics of rhetoric can provide for this impasse is an emphasis on those alternative discursive spaces that need to be generated from this static binary. Furthermore, a feminine ethics of care is predicated upon the characteristics associated 
with maternal care and nurturing. This dimension of an ethic of care is not so pronounced in Gilligan, and in all fairness, it may even be partially refuted by her study of women, choice, and abortion; it is, however, in the work of Nel Noddings, who, like many feminists working through Gilligan's work, have appropriated the ethic of care to develop those "positive" qualities associated with the mother.

Nel Noddings' work on ethical theory and education in Caring: A Feminine Approach to Ethics \& Moral Education is an example of the problems of essentializing masculine and feminine approaches to ethics. Taking her cue from Gilligan's identification of an ethic of care, Noddings explores and develops the possibilities of caring that reject principles and rules and the notion of universalizability in ethics, opting instead for a theory that "is not [about] judgment and not on the particular acts we perform but on how we meet the other morally" (5). Associating care, much like Gilligan, with the feminine assumedly in all of us, Noddings establishes a link with the mother previously ignored or subordinated to the paternal language of rights and justice in moral theory. Notably, she tries to maintain a sense of masculine and feminine that is fluid and not bound to essential differences between men and women (6).

The ethical self in Noddings' ethic of care is an ideal, a picture of the "onecaring" (the feminine) and the "cared-for" (the masculine) established in a pattern of reciprocity. "It is born of the fundamental recognition of relatedness; that which connects me naturally to the other, reconnects me through the other to myself" (49). Despite Noddings' initial disclaimer of wresting airtight masculine and feminine categories from "real persons," most of her examples are drawn from either a motherchild dyad, a student-teacher relationship, or a therapist and patient. The most prevalent examples, and those used as the basis for developing an ethic of care, are drawn from a mother's reaction and relationship with a child (59-64). While the examples are too numerous and too lengthy to give here, the effect of making these choices in establishing evidence for her claims is the infantilization of the "cared-for" in 
all relationships of care. As Sarah Hoagland observes, the contradictory practice of using a mothering model of care to argue for an independent, relational paradigm only provides examples of "unequal, authorized relations" that have no check on power, especially of an authority "promoted in the name of benevolence" (251).

Like David Hume, Noddings predicates an ethic of care on an assumedly universal "sentiment of natural caring" (77). While ethical caring is not the same as natural caring of a mother for a child, it is built from a desire to maintain natural caring, one that can be extended to others not considered within the boundaries of those for whom there is natural caring (81). This approach-the "memory" of natural caring in situations where care is not automatic but must be summoned-is sustained by the predisposition to care that is "latent in each of us... .In caring, we accept the natural impulse to act on behalf of the present other" (83). The desire to be ethical, then, comes from the desire "to remain related" (83). Thus when I do not naturally care for the cared-for, I must respond because of my obligation to care, one not rooted in contract theory, but an obligation from the emotion of care and the importance I place on caring (84). Thus, ethical caring is contingent, not based upon principles of duty, is relative to unique situations, and depends upon an ideal caring self as well as our commitment to and capacity for care and the protection of a caring society.

While I like Noddings's very rhetorical description of ethical caring, and I think that contingency and compassion are effective ways of viewing ethical decision-makingespecially when circumstance may call upon us to act when it is not easy to do so-I have problems accepting the epistemological grounding of her theory. In particular, Noddings neglects the politics of memory in arguing for ethical caring that could be summoned by "memory" of natural care and applied to those who are not our natural "cared-for's" but who require our caring response. In plain terms, she assumes that an indvidual has positive memories of natural care that can be commuted to a present other. Moreover, the other here is an unmarked figure, one who may not-because of 
race, social class, gender, or sexuality--trigger the propensity of care because of the "onecaring's" personal and political bias. Therefore, I see her creation of self and other as rooted very firmly in a liberal notion of the individual who can assumedly transcend existing circumstances to care for a very unproblematic other. Read in this way, Noddings's seemingly rhetorical sense of care "works" because it avoids particularities of real ethical situations.

Noddings's ethical caring assumes a nurturing basis for care, an assumption that harbors certain class implications. The liberal notion of transcendence that grounds Noddings's work also implicitly ahistoricizes a latent propensity for caring, a move that Teresa Ebert associates with strains of ludic feminism. Teresa L. Ebert's "For a Red Pedagogy: Feminism, Desire, and Need" takes further the critique of liberal humanism that so defines what she calls ludic feminism. Ebert's essay brings an important and overlooked concern to the feminisms deployed by Noddings and Gilligan, especially because she examines the seldom-discussed issue of class relations in contemporary feminisms. For this discussion, her critique offers further evidence that the epistemological bases for feminist ethics in rhetoric have yet to develop a viable, critical approach that is sensitive to the class implications of embodiment.

Ebert argues against both the liberalist assumptions of ludic feminist theory as well as its reproduction and "normalizing [of] the very logic of late capitalism and its class politics" (804). At issue for Ebert is how this popular strain of feminist theory informs a pedagogy of desire, one that draws its liberatory energies from an ahistorical celebration of desire, "sensuous corporeality; erotic seduction, and nurturing" (799). Ebert associates the pedagogies of desire in a causal link: pedagogy of pleasure, pedagogy of congeniality, pedagogy of nurturing, pedagogy of the body" (796). In so doing, she illustrates the other side of the binary she is working to maintain, a pedagogy of critique, a "pedagogy of labor and materialism" (796). The problem with these feminisms and their pedagogies is that they do not go far enough, and in some cases, do 
more harm than good; in positing liberation rather than emancipation as their goals, they merely reinscribe bourgeois concepts of the self as well as the conditions of class oppression (798). Thus ludic feminism is an "accomplice of capitalism" (804) by positing a market mentality of social relations in classroom, ones whereby "individuals are 'free' to negotiate in an unequal space that always privileges the owners [teachers]" (804).

While most of her argument criticizes erotic pedagogy, Ebert's critique implicitly, and at times explicitly, addresses the ethic of care that structures both Gilligan's and Noddings's work. "The other side of this erotic pedagogy... is a pedagogy in which pleasure is not so much erotic as maternal: a nurturing pedagogy that seeks to create a safe space, a compassionate place for the pursuit of feelings and desire" (805). "Desire, feelings, pleasure are all understood as the fundamental, immanent, essential, and defining attributes of an identity as a person, and the person is understood as an isolated, contingent, bourgeois monad-free from economic necessity and historical determinacy" (806). By arguing for a red pedagogy--the pedagogy of critique--Ebert makes economic conditions, institutional practices, and class key terms in repudiating an ethic of care as a basis for feminist ethics and pedagogy. The maternal body and its affective domain of care and nurturance replicates not only the liberal self of Enlightenment thought, but also the unfettered desire so important to the maintainence of late capitalism. What Ebert also brings to a discussion of feminist ethics is a material concern for the bodies on which feminism is built, in all their difference and need as well as the literal and figurative spaces they occupy relative to the "authorizing" bourgeois voices that articulate most feminist theory. She illustrates the inviability of ludic feminism by drawing a direct contrast between the desiring body of ludic pedagogy and that of "Indian women who sell their kidneys to feed their children" (805). The point here is obviously to debunk any notions of eroticized social relations or nurturing care as 
the basis for radical femininst theory, a critique that can equally be applied to the ethic of care.

In contrast to Ebert, both Gilligan and Noddings assume a stable discourse of woman and the feminine, one that goes continually uncontested in both of their texts. Noddings, in particular, assumes female embodiment in the position of the mother. This assumedly stable base of woman as the eternally feminine "I-caring" is opposed to a model of abstract, masculine rationality. What both overlook is the logic established by their gender dichotomies that foreclose on the possibilities of other ways of mediating and meeting ethical agency. That is to say, if we agree that the maternal body--as it is deployed in dominant culture--is used to maintain social relations, then we can see how an ethic of care maintains the position of the woman-as-mother rather than challenging it or finding new combinations for woman in "the body politic." In short, both Gilligan and Noddings speak to the risks of embodiment in theorizing female difference. I will return to this point in a moment. For now, it is important to note the discursive foothold that their theories create.

This discursive category of woman-as-mother, furthermore, is modeled after a psychologically and socially healthy, heterosexual female who brings no risk of abuse or neglect to her literal or metaphorical "cared-fors" (Hoagland 254). Noddings, in particular, adds nothing new to the maternal paradigm by establishing a "unidirectional, not mutual" model for care (Hoagland 254). As Hoagland notes "[t]o pursue the feminine is (a part of whose essence is agape and unconditional loving), to pursue this sense of female agency, is to pursue oppression. The masculine and feminine are not significantly different in what they engender" (Hoagland 259). Hoagland here testifies, albeit indirectly, to the need for a re-enunciation of a viable ethics. Thus, the discursive construction of an entrenched maternal, feminine model of an ethic of care and its opposite, a paternal, masculine ethic of rights, does little to disturb these gender categories or to offer a more political and rhetorical understanding of ethics. 
We are now at a point when gender categories--whether essentially or culturally derived--need to be refashioned to create new, viable, ethical combinations. "A truly radical ethics will challenge not only the masculine but also the feminine, for the feminine is born of the masculinist framework and so does not, at a deep level, represent any change" (Hoagland 259). As Hoagland aptly suggests, there needs to be another paradigm. In my configuration, this need is for discursive combinations beyond our gender dichotomies, those that can account for embodiment(s) and that can enable us to configure feminist ethics of rhetoric. This movement does not pretend to dispense with feminism or the goal of a feminist ethics-even an ethics of care. Rather, it diverges from a specifically feminine ethics of care for a rhetorical and ethical understanding of feminism as a discourse on ethics. As Joy Kroeger-Mappes confers:

Identifying two ethics and labeling one masculine and one feminine is not new, nor is it helpful. There is no reason to believe that the feminine ethic would or should be adopted as the ethic for everyone. Although discerning the male bias in the dominant ethic and the resulting implications for women and men is important..., we need now to move away from a system that has generated so much destruction. (125)

Rhetoric is well-poised to continue tactical exigencies for feminist ethics that account for bodies and the spaces they occupy, for rhetoric provides important intersections of the body, the political field, discourse, and constraints. For example, exile is a space that complicates gender assumptions by speaking through a "colonial" framework. And while exile does not eradicate the problem of gender-that is not the goal here--it does provide another space for critique that does not rely on a discourse of woman. Indeed, the exiled carries with her a certain gender--if only in being feminized by one's position in relation to the "inside." 


\section{A Feminist Ethics of Rhetoric}

While I do not think we can dispense entirely with the category of woman for a feminist ethics of rhetoric, we need to keep in mind the ethical dimension of "speaking by proxy" (Probyn) that often occurs in feminist theorizing, a move that so often homogenizes women into Woman. Nor do I think a sort of feminist pluralism is the remedy for breaking the dichotomy between liberal feminism and essentialist theories (Looser 66), or between the feminine and masculine as Kroeger-Mappes outlines. We do need to recognize rigorously the differences among feminisms, but we can also, as I will argue, maintain a certain gender skepticism in the attempt to maintain a politically efficacious feminist ethics of rhetoric. The project of grounding a feminist theory beyond a single category of woman-that is, with an eye to embodiment--is thus an ethical one, especially as we maintain the responsibility to create operative rhetorical spaces in theory and practice for speaking and in finding ways to respond in situations of silence and exclusion. As Devoney Looser asks in "Composing as an 'Essentialist?: New Directions for Feminist Composition Theories," "'Can there be a thing called feminism (or a feminist composition theory) without a presupposed-if only strategically constructed-category of 'women'?" (66). Her question is an important one for this discussion, for I also question the ethical assumptions of feminist rhetorics that are predicated upon essentialist notions of a female self. Furthermore, and as I discussed in the previous section, we need to ask how and to what extent an ethic of care has served as the guiding ethic for a feminist rhetoric. Looser's article goes on to investigate the very issues surrounding identity politics in the field and the essentialist base of much feminist work in the field, observing that there still remains resistance to the ways in which poststructuralism has challenged feminist rhetoric and politics.

Notably, most forays into historicizing and theorizing a feminist rhetoric have become what I earlier called "textualizations" of classroom practice. That is, whatever discursive tactics or models are recovered or proposed for a feminist rhetoric are often 
translated into feminist pedagogy or "read off" the classroom. Indeed, feminist discursive practice is easily translated into pedagogy, and I am not suggesting that this should not be the case. Feminist rhetoric and pedagogy has, to a great extent, inadvertently replicated the same maternal-feminine paradigm of the ethics of care. In response, I want to invoke a feminist ethics of rhetoric in managing the multiple discourses of feminist critique. For it is important that we learn lessons from poststructuralism in that we cannot take down one feminism and merely supplant it with another, nor can we welcome the validity of all in a benign attempt at pluralism or celebrations of difference. The project, then, is a contradictory one: to interrogate feminist theories so that no theory creates an epistemological space for all; at the same time, this interrogation must authorize some space from which to speak. This inquiry finds that rather than answering Looser's question about what epistemological definition of woman authorizes feminist theory, there is only the continual renewal of critique, an obligatory ethos in linking and creating phrasings of and for feminism. However, one provisional answer is the rhetorical positioning of woman and/in exile in addition to an ethics of embodiment. As Ebert's work identifies, there is also a strong political possibility in the class positions occupied-and shared-by women.

Always in search of a discursive enactment of feminist politics, feminist rhetoric looked to French feminism and écriture feminine for its possibility of resistance in offering a different language, a feminine one, that ruptures the logocentric systems that exclude this distinctly feminine language from presence. But there are problems with the French theories--as with the ethic of care--because much of their arguments rest upon "biological bedrock" (Bammer 248), especially the call to write the (female) body into visibility. Cixous, Irigaray, and to some extent, Kristeva, are a few of the major authorizing voices of French feminism. While each has distinct differences in theorizing women's libidinal difference from men, all confer that a revolution of phallogocentric language is possible in alternative forms of writing-as-resistance. In short, French feminism targets the 
history of binary thinking, patriarchal systems of inclusion and exclusion, and the position of language in maintaining patriarchal hegemony. By now, most readers are quite familiar with French feminism, its theoretical tenets, and its linguistic possibilities (see Junker; Jones; Worsham), so I will avoid lengthy descriptions and explanations of key theorists' work.

There are some startling intersections between an ethic of care and the way in which French feminism has been proposed for a feminist rhetoric. The "will to pedagogy" (Worsham 96) that drives composition to "practice" a possible feminist rhetoric results in an ethic of care in the classroom. For example, Clara Junker's "Writing (with) Cixous" is one important example of an attempt to absorb the theories of French feminism for the composition classroom. Junker extracts from Cixous for composition an emphasis on prewriting and revision to show students that texts are always being written. Cixous positions women as subjects who do not speak; they are designated in positions of lack. Écriture feminine--like Gilligan's "different voice"--tries to locate a feminine self in absence to make it speak. Because of primary difference--conceived in either libidinal or psychological terms--Cixous in the writing classroom can "allow women writers ... to speak foreign tongues" (431) by expanding and experimenting with writing. Junker adds that we need to encourage experimentation, lack of closure, invention and "reception rather than [the] aggression" (433) of academic argument.

While feminine écriture has been valuable for feminist rhetoric, it does not offer the kind of rhetorical spaces I want to advocate. Furthermore, I have ethical concerns about this model for "real world" writing situations. For if women writers are encouraged to break these rules by joining in the free play of the signifier released from symbolic law, aren't they at a disadvantage when it comes time to "write like a man," adhering to the logocentric, formal rules of argumentation? Feminine écriture still positions women writers in terms of--or in opposition to-men and masculine symbolic discourse. Furthermore, and as I argued against an ethic of care, I have problems with a 
theory that capitalizes on feminine behavior by advocating "reception rather than aggression". (Junker 433) for female students. "Reception" is associated with essentialist qualities of the feminine. And much like the need for relationship and understanding in an ethics of care, feminine écriture conflates aggression with the inversion of "true" femininity.

The ethic of care also shares many similarities with feminist pedagogies that use expressivist paradigms in the classroom. Autobiographical and personal writing are often the chosen modes in these caring, sharing, and "womb-like" classrooms that have opted for squelching argument and difference in the hope of providing a more nurturant, supportive environment for students. This particular strain of feminist pedagogy attempts to rewrite the cultural script of banking models of education (Weiler) by acting as a guide rather than a depositor of knowledge; favors collaborative learning and inclass group activities; uses one-on-one an personalized correspondence with students; and attempts to share and decenter authority in the classroom. Ideally, consensus learning and problem solving in a sharing, caring environment provide the setting for this comfortable practice of learning. Moreover, many expressivist pedagogies rely on assumptions of woman, femininity, and the alignment of "woman-as-mother," in addition to a focus on highly personal, private experience. Susan Jarratt argues that, while they allow students personal and unlimited expression, expressivism does not turn personal experience outward into public issues and public voices (121). Jarratt goes on to critique a trend among feminists to see argument, and by extension, rhetoric as a non-feminist mode of expression, an assumedly violent and phallocentric drive for masculinist models of discourse. Notably, argument provides a model for using private experience in a public way, a means of mediating both spheres, and if we follow through on the gendered connotations of these spaces, negotiating the private and public allows both men and women to integrate and occupy traditionally feminine and masculine space, a move that helps to question gender categories. 
Noddings' chapter on moral education in Caring shares the same means and goals of feminist rhetoric as I have described in it pedagogical translations. The ethic of care operates between student and teacher in an emphasis on "working together" (178). She "encourage[s] [the student] to stand personally related to what he says and does. He is not just part of the lesson.... He is a human being responsible for his words and acts" (178). The teacher in this classroom negotiates rules and even bends them to students' needs because these rules "are not sacred to her" (178). Instead, the teacher engages the student in dialogue to show him caring relations. To this end, smaller, collaborative classrooms foster the kind of dialogue necessary to meeting the other morally (181). Until this point in her chapter on moral education, I agree with the ethic of care in the classroom. However, Noddings is most concerned with "making the voice of the mother heard in both ethics and education" (182). The rules of argument, objectivity, and abstraction foster "detachment and loss of relation" (182). In contrast, the assumedly more valuable ethic of care fosters a more humane dialogue of relatedness.

There is, then, an obligatory ethos associated with feminist rhetoric and pedagogy: The message for feminists is that rhetorical strategies should be translated into classroom practices to further the goal of liberatory pedagogy. In the process of doing so, feminist rhetoric has inadvertently re-voiced Gilligan's initial findings about women and ethics. By predicating moral theories of difference upon quasi-essentialist foundations that do little to provide alternative rhetorics, Gilligan and Noddings attend to only one form of embodiment and help to establish a limited foundation for feminist theory. In addition, the liberatory goals of feminist rhetoric attempt to make public women's discourse and ways of knowing. Ironically, these attempts, in the limited "bodies" assumed in their appropriations of an ethic of care, privatize rather than publicize the difference of women's experience and embodiment. Thus, to deal with embodiment is to contend with politics; it means to go public. 


\section{Gendered Spaces for a Feminist Ethics of Rhetoric}

If we agree with Meaghan Morris that creating positions is the business of rhetoric, of forming what she calls "enunciative strategies" (86), then it is our business as teachers and academics concerned with ethics, rhetoric, and feminism to create these spaces of and in discourse. Rosalyn Diprose makes the connectedness of the body, discourse, and ethics apparent in linking these three coordinates in a spatio-temporal framework. "Taking up a position, presenting oneself, therefore requires a non-thematic awareness of temporality and location. And, the intrinsic reference point for temporality, spatial orientation and, therefore, difference is one's own body. That location and position are concepts easily interchangeable, illustrates the co-incidence of embodiment and ethics which necessarily come together by virtue of our spatio-temporal being-in-the-world" (The Bodies of Women 65). Diprose provides an important understanding of ethics in terms of "bodily specificity" (65), where the body is a site of subjectivity, a space "where the body is constituted by a dynamic relation with other bodies in a social context of power, desire, and knowledge" (66). Moira Gatens seconds the corporeal dimension of ethics in arguing for an embodied ethics, an ethics built from specific corporeal reactions and spaces. She qualifies, and quite rightly, that even while we accept the body as a site for an ethics, we cannot tacitly assume an essential female body upon which to predicate this ethics. She amends an "ethics of difference" (104) to attend to the "different forms of embodiment [that] are themselves historical and open to change" (104).

Politically, that is, within a male "body politic," Hipparchia's appearance as a public philosopher and rhetor disturbs what Iris Young calls "the moral division of labor" (100) that characterizes men's and women's roles in performing ethics. While Young sees this split emerging with the rise of the public sphere and Enlightenment philosophy, I would argue that her characterization extends to other historical periods 
as well. For even in the Hellenistic age, middle- and upper-class women remained in the home, schooled in little more than domestic virtues. Manuals for the well-bred, literate woman advised a passive and patient demeanor in the face of marital infidelity, the handling of slaves, and the ideal social behavior of a virtuous woman. Generally, passivity and silence were the favored virtues of respectable women of the polis. Indeed, while the central organizing principles of Greek society differed greatly from Enlightenment Germany, the role of women in maintaining private morality versus male participation in legislating public ethics remains a comparable distinction. With Hipparchia, we find the woman philosopher-the exiled parrhesiast--breaking into male territory. Furthermore, Cynic "shameless asceticism" in the use of the body as an enactment of ethics is further problematized when "woman" is thrown into the "body politic." In this way, Hipparchia uses the excluded spaces of Cynic rhetoric to engage the public sphere.

We need only consider the spatial separation of the sexes in ancient Greece to realize the significance of Hipparchia living and speaking in public (Pomeroy 78). According to Sarah Pomeroy, "respectable women" of the upper classes were secluded in the home, even the living quarters of the home were separated by sex. Men usually lived on the lower levels of the house, with the women, including a wife, living on the upper level to shield them from the public distractions of the street (Goddesses 80). These arrangements were normally maintained to prevent slaves from breeding and to keep upper-class women from the eyes of other men. Lower-class women and slaves were not as restricted for their work demanded that they leave the home to fetch water and do errands (80-81).

In literal spatial terms alone, women were annexed to the private rooms of the home, as they were equally exempted from participation in the political and social spheres. Just as there were "feminized" spaces in the architectural plan of the Greek home, women were also associated conceptually with what Plato calls the chora. In 
Timaeus, Plato describes "a mythological bridge between the intelligible and the sensible, mind and body, which he calls chora" (Grosz 47). Like the insurgent and mobile potential of space as conceived in the first chapter, chora is an historically appropriate concept of space at work in ancient Greek life, especially in terms of how it was used to describe "feminine" space. Chora, according to Grosz, has served "to produce a founding concept of femininity whose connections with women and female corporeality have been severed, producing a disembodied femininity as the ground for the production of a (conceptual and social) universe" (48). To this end, she offers further definitions of chora as "'site," 'region,' 'locale' [and] associated with a series of gender-aligned terms-'mother', 'nurse', 'receptacle', and 'imprint-bearer'" (48). Grosz finds that spatial concepts like chora have served to appropriate a disembodied feminine space that has no characteristics of its own, but is always in a position to "be occupied [and colonized] ... an extension which can be ... (taken)" (Algra 33). That is to say, chora is the space of appropriation, one wherein the particularity of gender is philosophically divorced from lived bodies.

While Grosz argues that foundational concepts of space have been attempts to "colonize" woman in philosophical thought, I would like to suggest, as Kristeva has, that chora is an important and useful discursive space. I do not, however, equate this revaluing of chora with Kristeva's notion of chora as a prediscursive or "maternal" space for this may be perceived as yet another discourse that attempts to regulate the female body. Rather, I support her attempts to overturn Plato's association of chora with "the mysterious' and 'incomprehensible"' (6). The point here is that in aligning chora with the feminine, the mysterious, and the amorphous, Plato created a question, an ambiguity that had to be answered and defined. The answers to this ambiguity defined woman by function--mother, nurse, receptacle. The move to (re)place the body and its sexual "script"--which may be further written over with the asymmetries of race, class, gender, sexuality, and age-is an ethical and rhetorical task because this interpretation of chora 
will work to recharge this space as a political, ethical, and thus, "embodied" one. In other words, chora represents the relationship between gender and ethics and is a spatial metaphor for the philosophical connection between woman and passivity. If she can be "occupied," she is incapable of maintaining the moral rigor needed for ethics. If she is disembodied, she cannot stand her ground.

In my reading, chora can provide an operative space for reconciling feminism with feminist ethics. If the problems I have identified stem from the responsibility to represent difference in the critique of Woman, especially as that woman often falls prey to maternal metaphors, then we need to consider how this project often assumes "that there is an identity that we share as women and that the differences between us are secondary" (Cornell 85). Claims of a female identity can often disguise privilege, in particular, those privileges based on racial and class differences. The result, according to Cornell, is a "dearth of symbolizations of the feminine within sexual difference that yields the experience of silencing" (78). We can read the ethic of care as one of the few "symbolizations" of the feminine that creates limited, silencing discursive spaces and one that has easily been taken up by feminists who "pass" into and are "accepted by institutional structures" (84).

Cornell's reading of the paradox inherent in Lacanian lack is helpful for evaluating the space of chora and for providing epistemological directions for feminism, and more specifically, feminist ethics. Because she is identified with lack and "lacking meaning, [woman] can 'be anything.' The impossibility of absolutely fixing the meaning of woman yields endlesss transformative possibility" (87). Like the feminine space of chora, lack represents the empty, passive space of woman. "The hole we leave in reality is filled with masculine fantasy" (90). The few discourses available to women as "feminine Other ... set the stage for a very limited conversation" (90) because we as feminists have unconsciously and inadvertently replicated existing gender dichotomies and the few available roles in this drama. If we consider chora as an equivalent to lack, 
then I think we can begin to see one possibility in reconciling ethics and embodiment, if only in the responsibility for representing "new symbolizations" of other bodies, relationships, and places speak. For rhetoric, this means creating new rhetorical tactics-feminist discursive spaces--that allow for intervention. For ethics, this means contesting "the assumed sexual neutrality of moral judgment" (Diprose vi). Revaluing the space of chora not as a masculine fantasy, but as a feminist rhetorical space that includes tactical discourses of intervention may prove beneficial. Indeed, it may even lead us to consider that "gender is a place, one which can be entered or left, not an identity" (Allen and Faigley 163). Thus, the work of feminist rhetoric is to keep this warehouse full. As I have argued throughout, Cynic rhetoric provides us with an "arsenal" of strategies with which to begin this work.

\section{The Problem of Difference}

At issue for feminism is the "genesis of identity and difference" (Diprose 28) that serves as the foundation for feminist theories. For earlier feminists like Gilligan and Noddings, this quest has brought them to psychological explanations of women's inclination for ethical caring. They each opt for a valorizing of women's unique expressions and contributions to moral development. Indeed, the explanatory power of Gilligan's work is one of the reasons she has maintained such a foothold across the disciplines. However, as the earlier mention of Cornell's work suggests, a gender skepticism about the viability of the category of woman and a critique of feminism's homogenizing tendencies has served to fracture feminism into difference, rather than building feminism on a psychological or essential discourse of Woman. As Teresa Ebert outlines, this fracturing has produced feminisms of "differences within" (892), rather than differences between men and women, as the source for a feminist pluralism. Her observation of this trend speaks to my own concerns about building a feminist politics that maintains a responsibility to difference: "And of course, the question for feminism 
is how can it build a transformative politics on a postmodern difference that throws out certainty and destabilizes identity" (892).

Difference suggests a pluralism that potentially authorizes what Susan Bordo calls the construction of "an Other who is an exotic alien, a breed apart" (140). Bordo worries that theoretical moves to encourage difference, while important epistemologically, risk ignoring real bodies in real worlds. "They refuse to assume a shape for which they must take responsibility" (145). Ebert too remains skeptical about a feminist pluralism because "[it]. . involves a very insidious exclusion as far as any politics of change is concerned: it excludes and occludes the critique of global or structural relations of power as 'ideological and 'totalizing'" (898). Ebert's solution to this impasse offers something along the lines of a coalition politics that is not based upon sameness or identity; rather, feminism is created by subjects who are differently positioned within patriarchy, but who are also "subjects of the same structures of oppression" (901). Ebert bases this feminist practice, then, on differences-in-relation rather than differences within to form the base for a feminist politics.

In short, professing difference is not enough. Ebert's re-theorizing of difference draws attention to the inadequacy of difference as well as the benignly liberal moves difference can make for feminist politics. And while I agree with her reconfiguration of a feminism of differences-in-relation, I want to extend this search for feminist politics to include questions of ethics and a "justice of multiplicities" (Fraser and Nicholson 23). In my mind, we can only represent differences-in-coalition if there is a theory of justice to ground political action, for as Cornell argues, our "solidarity is not just given to us on the basis of our shared identity as women" (83), but extends to our responsibility for generating confining fantasies of Woman (83). But this theory of justice must also be an "in-between" space like that of chora; it cannot replicate the exclusions and assumptions of traditional concepts of justice. ${ }^{25}$ As Jane Flax provides, 
Justice can be understood as belonging to the 'transitional space'. . a 'third world' that is neither subjective nor objective, neither purely inner or outer. This world has its own processes, tasks and ways of making sense out of experience. This space is transitional only in the sense that it bridges the gaps between self and other and inner and outer reality .... It does... continually grow in complexity and richness. (204)

Our inquiry, then, must turn toward making the "ethics of difference" a viable political practice. For feminist rhetoric, this means making differences speak with an eye toward discursive practices that maintain political responsibility. As I contend throughout, it is the business of a feminist ethics of rhetoric to invent new spaces for discourse that can simultaneously provide tactical exigencies for speaking as well as the apparatus for critiquing how discourses silence and exclude.

\section{Toward a Feminist Ethics of Rhetoric: Hipparchia and a Political Somatics}

Beginning with the ethical task of insuring a "justice of multiplicities," one that is attentive to difference and the ways specific bodies are positioned in discourse and culture, I want to look at what Cynic rhetoric, especially in its attention to the body and discourse, can provide for a feminist ethics of rhetoric. In particular, how can Hipparchia provide an example, if not a model, of what a feminist rhetoric might look like, as well as how to make an "ethics of difference" (Gatens) speak outside of overused models of care and maternal alignment.

Cynicism provides a space, "a theatre for practical actions" (DeCerteau 175). It creates a field that authorizes dangerous and contingent social actions (125). In Hipparchia and the Cynic corporeal enactment of ethics, we engage with a rhetorical practice of the body, but one based on the contradictions of ascetic practice. For example, the Cynics professed the negation of physical desire, but Crates and 
Hipparchia are renowned for having sex in the agora. Branham adds to this Diogenes' use of the body as a source for his "serious laughter":

[M]any of Diogenes's jokes are aimed at the body or call attention to the bodily aspects of his interlocutors and targets, e.g., a woman bending over as she prays, a boy exposing his rear ..

.. The ungovernable body recurs in many forms upsetting the pretenses to serious or civilized behavior. It is the ideal instrument for the Cynic attack on the artificiality and falsity of official codes of civilized life. ("Cynic Rhetoric" 351)

Moreover, what do we make of Hipparchia in the "body politic," not just for the flouting of strict social conventions, but for assuming the position of rhetor and philosopher? Like Diogenes of Sinope, Hipparchia engages in a "political somatics" (Hodge and Mansfield 200), an intersection of the body, the public sphere, and resistance. What Hipparchia adds for a specifically feminist rhetoric is the creation of spaces that speak of bodies that negotiate contradictions between speech and action, belief and desire, convention and ethics.

Cynic rhetoric and ethics provide a range of discursive tactics whose task it is to point out injustice. A feminist "political somatics" uses the body to forge new combinations and contradictions. But this body is not an essential female self; it is, rather, the space afforded a political body that is regulated and limited by the spaces in which it can speak. As a "political body" in a "body politic," Hipparchia contests these spaces by calling attention to the limited range of spaces available to exiled and ambiguous bodies. In the example of Hipparchia and Crates, bodies and their ability to speak and support ethical stances were invoked to compel audiences to follow the example of just living. As Rosalyn Diprose explains, the body cannot be divorced from discourses, but "the body always refers beyond itself, its production is incomplete .... Sexed bodies are always opened to other possibilities beyond those which position 
woman as other to man" (80). Diprose goes on to advocate new possibilities derived from the "ambiguities and contradictions" (135) of this binary, new ways of engaging resistance that also offer discursive positions to seek out how injustice is made possible by regulative discursive practices (Diprose).

In this way, the body becomes the locus of rhetorical enactment, "a trope" to be used in persuading listeners to an ethical life of action (Branham, "Cynic Rhetoric" 350). Considering the Cynic tactics of resistance, we can also see how the body becomes involved in a political somatics. Ethics and politics are thus predicated upon what one does with one's body. In light of the few available literal and discursive spaces afforded to the body of woman in the polis, Hipparchia's asceticism and her flouting of convention followed through on the Cynic commitment to naturalism. By engaging in sexual intercourse with Crates in a the agora, she exposes an "ungovernable body" in the affront to standards of feminine modesty (Branham, "Cynic Rhetoric" 231). At the same time, however, she risks not having the demonstration of her ethical stance taken seriously. This is, after all, a central problem with interpreting ancient practices in light of a contemporary framework. Nevertheless, I can see a similar bodily demonstration of ethical belief in the contemporary example of women and men who accompany women into protested abortion clinics, using their bodies in support of an ethical and political position.

At the very least, Cynic rhetoric is useful in enacting a political somatics and by creating discourses and stances that account for a body. But if, as I maintain, Hipparchia provides us with directions for a feminist ethics of rhetoric, then we need to examine her attempt to disrupt the private sphere of moral behavior. I should note that one of the central reasons the Cynics lived in public places was to address the hypocrisies that often went on "behind closed doors." Epictetus recalls:

For this you ought to know: Other men have the protection of their walls and their houses and darkness, when they do 
anything of [the] sort, and they have many things to hide them ..

.. But the Cynic, instead of all these defences, has to make his self-respect his protection; if he does not, he will be disgracing himself naked and out of doors. His self-respect is his house, his door, his guards. [He has no need of something to conceal him]. (135-137)

This passage is significant in light of the relationship between the private and public sphere in ancient Greece. A citizen's status in the polis was dependent upon ownership in the private or "private property." The private was governed by the public citizen assumedly according to the ethical and political practices and beliefs of the public sphere; thus, there was a unity between the ancient public and private spheres that we do not now experience. Because of this, the Cynic public embodiment of ethics was an affront to the assumptions of private ownership. In addition, it did not allow for "a hiding" of discrepancies between a public and private self. If we reconsider Seyla Benhabib's assertion that "the struggle to make something public is the struggle for justice" (94), then we can consider how the role of the woman rhetor becomes more complicated in the struggle to "go public" with a political somatics.

By taking female bodily experience-especially experiences carefully managed by discourse--from the private sphere and into the public where they might not even be recognized in light of the entirely male participation in the ancienct public sphere, Hipparchia challenges the universal of male embodiment by complicating this narrative with the female body. We need only recall the spatial arrangement of the ancient Greek home to witness the extent to which female bodies were privatized by both ideology and architecture. As "partial" citizens, women were public bodies without the freedom and rights available to those of men. Their bodies were legislated publicly to maintain the private sphere. The public sphere of the Greek polis was based upon the public 
participation of propertied, free, slave-holding males, while women, slaves, and by association, Cynics, were identified with oikos-the sphere of the home and family.

In terms of its gender implications, the public sphere has historically excluded women. As Joan B. Landes outlines in "The Public and Private Sphere: A Feminist Reconsideration," the bourgeois public sphere is an ideal space for democratic discourse, one that was intially separate from the market and the family. Based on his recuperation of the eighteenth-century model, Jürgen Habermas in The Structural Transformation of the Public Sphere identifies neutrality and universality as the presuppositions of the public sphere and its attendant model of ideal speech. It was assumed that the subjects and concerns discussed in the public sphere-those of white, propertied men--carried the force of universality. By reinstating this paradigm, Landes observes that "Habermas overlooks the strong association of women's discourse and their interests with 'particularity;' and conversely the alignment of masculine speech with truth, objectivity, and reason" (98). Moreover, it was the assumption of a male body, of a "(male) particular" that established the public sphere and masculine embodiment as a universal norm (Landes 98).

The Greek polis, not unlike the Enlightenment ideal, maintained that "'the civil public where citizens meet in terms of equality and mutual respect is too rounded and tame an ideal of public. This idea of equal citizenship attains unity because it excludes bodily and affective particularity, as well as the concrete histories of individuals that make groups unable to understand one another"" (Iris Young as qtd. in Landes 99). Similarly, in the Greek polis, women's particularity was excluded spatially, discursively, and politically from the public sphere. Hipparchia's discourses and actions therein forge a moment of visibility and audibility for women's particularity. Furthermore, the public sphere of the polis was even more restrictive of democratic discursive freedom. As Landes examines of Habermas, the Greek model did not provide for the vital component of communicative rationality with other citizens against and in response to 
government. Because the organizing concerns of the Greek polis focused on maintaining military strength and military competition among citizen males, this model of the public sphere does not provide a space for dissent from government since the polis is maintained against external threats rather than internal ones (Habermas as qtd. in Landes 95). And in light of women's almost non-existent role in military exploits, we can assume that the polis, simply by virtue of its organizing principle, strictly maintained public and private spheres, offering little room for even those dissenting male voices that did participate in the democratic forum.

While the problems and contradictions of a feminist ethics of rhetoric are not resolved entirely in exporting from Cynic rhetoric an emphasis on embodiment, ethics, and rhetoric, they are met with an important example of Hipparchia, who, as I have argued, simultaneously complicates Cynic rhetoric as a "double exile" and foregrounds the role of the body in maintaining the injustice of exclusion from the public sphere. Furthermore, as Landes criticizes of Enlightenment rationality and the public sphere, privileging speech-acts and communication for the fostering and development of democratic polity "distorts the performative dimension of human action and interaction" (108). Like the Cynic emphasis on action and ethical practice, Landes advocates a pragmatic account of the public sphere. "Pragmatics, the formal use of language in interaction, is best accompanied by a theory and observation of (stylized and informal) bodily gestures and postures" (109). I think a similar argument could be made against rhetoric as well. While we often pay lip-service to nonverbal communication and a rhetoric of the body, we seldom examine this rhetoric on its own terms or its relationship to larger issues of gender and embodiment. As I have implicitly argued throughout, gender is mediated by language, and so too are the performative acts that both derive from and maintain gendered spaces. But these discourses have opened up and maintained fairly regulated discursive spaces, especially as feminist rhetoric and ethics have worked to replicate maternal models of care. I do not want to suggest that 
these are wrong; they are not. Rather, our goals now are for complication, ambiguity, and contradiction.

I think the story of Hipparchia provides us with an important example of the risks and complications of "going public" in the body politic, as well as the complications that issue from "placing" her in working toward a feminist rhetoric. Indeed, bodies often do this; they can both destabilize and institute discourses. In either sense, embodiment challenges us to deal with real bodies in real spaces. If we consider that female bodies and feminine space has been excluded from the public sphere, then we can understand the important attention that must be paid to particularity. The recent example of Fauziya Kasinga brings together the terms of this discussion--exile, resistance, ethics, and embodiment-and exemplifies to what extend the female body and its particularity still remains outside the concerns and responsibilities of the public sphere, a case-study that highlights both the problems and imperatives of dealing with embodiment and ethics.

In the case of Kasinga, we might revise Fraser and Nicholson's "justice of multiplicities" (23) for a "justice of particularity." Fauziya Kasinga's case is by now the well-publicized story of the seventeen-year-old woman who escaped from an arranged marriage and genital mutilation in her native Togo. Upon entering the United States, Kasinga alerted customs officials that she had entered the country with an illegal passport and that she was seeking asylum. She has spent the last two years of her life being transported from one penal facility to another. During this time, she suffered abuse and humiliation as her case awaited judgment. And while her story has a positive ending--Kasinga was eventually granted asylum in the United States--her case and the reasoning used to deny her plea in the first ruling directly address the ethics of embodiment and the neutral body assumed in the legislation of the public sphere.

Kasinga's case marks the first that takes on the issue of female genital mutilation "'as the basis of an asylum claim"' (Musala as qtd. in Dugger A12). According to 
lawyers involved in the case, "[b]y law, people can win asylum if they are found to have a well-founded fear of persecution because of their race, religion, nationality, political opinions or membership in a social group. The statute does not mention gender" (Dugger A12). Kasinga's lawyers will argue in her appeal that she was a member of a persecuted social group, including all young women of her tribe who were subject to genital mutilation. The judge at her initial hearing denied Kasinga asylum because he had serious reservations about the facts of her case, ultimately ruling that she was not credible (Dugger A12). Another INS judge in an earlier case also denied asylum to a woman, ruling that "the woman could not change her gender, but she could choose whether or not to submit to her tribe's customary genital mutilation" (A12). It is my contention that the general trend to deny asylum in cases of female genital mutilation observes a rule of "abstract equality" (Landes 97), one that ignores the particular issues of female embodiment.

In the courtroom, Kasinga's case challenges the assumption of male embodiment that passes for the standard of neutrality and objectivity. And while the conditions for granting asylum do attend to the particularities of ethnicity, race, and religion, they do not consider gender and women's bodies as within the domain of causes for persecution. As I argue, one primary reason for this omission stems from the privatization of women's interests and the particularity of their bodies, which are thus deemed "improper subjects for public debate" (Landes 98), especially when these bodies may fall within "private" tribal economies and fall far beyond the discourses normally used to talk about them. Moreover, American judges, grounded in a democratic polity, look for the choices that these women had to escape mutilation, a search that recklessly places genital mutilation within the realm of free choice. In doing so, the logic of one judge's refusal to grant asylum because a woman "could choose whether or not to submit to ... genital mutilation" (Dugger A12) constructs this act as something that most women choose to do-as if pain, infection, banishment, or possible death are 
choices; the logic used to dismiss her case follows a logic not unlike the one that suspends much public and legal treatment of rape in this country. Furthermore, this ruling assumes that members of these communities share equality, and that tribal customs are a matter of exercising a neutral individual choice, one unfettered by the constraints and conditions of embodiment. The language of law, and even immigration law that deals explicitly with difference, maintains the truth, objectivity, and reason so associated with this sphere. To this end, the judge's determination of Kasinga's testimony as lacking "rationality, . . . lack of internal consistency, and [a] lack of inherent persuasiveness in her testimony" (A12) fails to meet the "norms of reason" and rationality of the public sphere (Landes 97).

Furthermore, I think race certainly played a role in complicating an already complicated refusal to consider gender as a protected category. Notably, if she had claimed persecution on the basis of race, Kasinga would have had a "better" case, at least according to the terms of immigration law. Also, the stereotypical association of women's speech as emotional and irrational may have been further enhanced by a long history of associating a racial, African "other" with the tribal, the incoherent, and the amorphous (Deane 356). Thus the "colonial" position articulated earlier by Elizabeth Grosz finds application here in the example of "the unreasonable" body, one situated differently within a discourse of woman because of the particularity of race and nation. Not unlike the questions surrounding the epistemological space of chora, the question of embodiment was answered by the first judge's ruling by "colonizing" the threat to the plaintiff's body with gendered assumptions about the experience of female embodiment; that is to say, the judge used patriarchal, masculinist norms when deciding upon a perceived threat of persecution, ignoring the particularities of gender within a specific tribal community and the consequences that might have resulted had Kasinga refused this tribal practice. 
Like Hipparchia, Kasinga occupies the position of exile, a literal and discursive position that provides both with a space from which to speak; but for the latter, this is a persecuted position that puts the terms of this discussion into immediate effect and makes the ethical implications of using the term exile all the more significant. Moreover, this literal example precludes any celebration of exile as postmodern strategy of resistance. I see Kasinga's case as a starting point as well as a practical enactment of a feminist ethics of rhetoric. For, in one sense, her situation highlights our responsibility to respond in both theory and practice. In yet another, she contests the exclusions of female embodiment in the public sphere, a confrontation that must be met with tactical rhetorics, including, as Susan Jarratt would insist, the force of better argument. She also shows how exile is not always merely a discursive position, but one that may be difficult, even disturbing to imagine. In so doing, she, like Hipparchia, upsets those spaces already reserved for women in the public sphere by forcing a confrontation with embodiment in all its complicated and painful reality. As feminist rhetoricians, we should look to a variety of spheres, not just the public sphere of the academy, to find examples and narratives that help to tell this story and provide new speaking positions-those spaces of contradiction and ambiguity that "real lives" can create.

A further, key distinction must be made, however, in appropriating the space of exile. Hipparchia is an example of what Benhabib calls "the social critic" who chooses a social space of exile outside the critical comforts "everyday certitudes" (226). This positioning, or "leaving home" as Benhabib calls it, is part of the vocation of social criticism "insofar as criticism presupposes a necessary distantiation" from the object of critique (227). This is a key point I want to emphasis: the space of the social critic, like that of the feminist rhetorician, is one that may require the "distantiation" of exile. In many obvious ways, exile for Fauziya Kasinga is much more than a rhetorical space of discourse. But in her example and the use of exile as a tactical exigence of rhetoric, I find a new directive for a feminist ethics of rhetoric that is attentive to the problem of 
embodiment. Feminist rhetoricians like myself who want to develop a feminist ethics for rhetoric must turn our focus away from our comfortable "disciplinary homes" to real, lived examples of how our theories are challenged, complicated, and enriched by the the lives and bodies that are affected by the inequities created in the very rhetorics that structure our public sphere. This emphasis takes away from the comfort of categorical Woman to the study of both discourse, the body, and its "performance" within a political field. Ethics involves, then, our response to these embodiments in a public way. So while Hipparchia provides an historical example of "going public" with ethical stances and offers exile as another, differentiated foundation for a feminist ethics of rhetoric, Kasinga's case makes the task of publicly responding to the locations of real bodies in exile, pain, need, and loss all the more imperative. 


\section{Chapter 4}

Ethical Subjects: Composition, Pedagogy, and the Postmodern Classroom

Ethics: Local or regional customs, like Basque folk songs or Bolivian hats. Sold at steep discounts in the global economy.

Lewis H. Lapham, from "Economic Correctness"

Rhetoric and composition studies has embraced critical and feminist pedagogies ${ }^{26}$ for their political possibilities in the classroom. The first assumption of these pedagogies is that the classroom is a place where the political and cultural contests of the culture are addressed on a local level. Signing on after Paulo Freire, Ira Shor, Gerald Graff, Kathleen Weiler, and Henry Giroux--to name a few names involved in this project-continue to engage both students and teachers in the study of how critical literacies can generate the kind of thinking needed for radical social change. "Hegemony," "resistance," and "agency" are some of the shared vocabulary of these projects, and they reflect the very political terms in which education is being discussed. But in focusing on the politicization and critique of education, critical and feminist pedagogues have sidestepped the very ethical moves that their works make. In turn, and as a consequence of rhetoric and composition's embrace of critical and feminist pedagogy, we can read this same omission in our own field. In many ways, composition has made a semantic move away from the ethical in favor of the political. As I contend, this move betrays what we are really talking about when we talk about politics.

The politicization of composition pedagogy has and continues to be a topic rife with contention. Maxine Hairston, certainly not the first to decry the politicization of the classroom, but perhaps the loudest, argues in her 1992 article, "Diversity, Ideology, and Teaching Writing," that the teaching of writing has and is currently being taken over by the ideological agendas of instructors who are substituting politics for pedagogy. This move to the political in the teaching of writing serves to undermine the long- 
standing model of teaching writing as an assumedly non-political and ideologicallyneutral task. "It's a model that puts dogma before diversity, politics before craft, ideology before critical thinking, and the social goals of the teacher before the educational needs of the student" (180). Later that same year, a conversation among Susan Jarratt, Patricia Bizzell, Richard Marius, and Louise Wetherbee Phelps in the ADE Bulletin concerns the still quite controversial issue of politics in the composition classroom. Contrary to the vision of composition Hairston projects, Bizzell takes aim at the assumed neutrality of non-political pedagogy; she argues, instead, for a frank acknowledgment in the classroom of the positions and agendas held by instructors: "what we should be doing is ... frankly acknowledging that we are promoting those values that seem best to us, as liberal arts instructors have always done" (5). Bizzell qualifies later that the value-forming task of liberal education should be "outed" from the closet of its implicit moral commitments (5).

Bizzell's argument for acknowledging one's politics and ethics in the classroom implicitly responds to the advent of postmodernity and poststructuralism, an engagement that has helped to usher in radical changes to the foundations that have supported the way instructors teach writing. Accordingly, the field's politicization of the teaching of writing is paired with the commitment to social and cultural change that has developed from the emergent spaces revealed through the political strains of poststructuralism. The classroom is the site of that enactment, a space where a community of writers can engage in the examination and critique of the potential and consequent silences and oppression(s) of consumer culture. In short, this critical stance of the field would have us look for politics in places where it is said there are none.

My task here is not to provide an historical overview of the rift between those who would have us politicize the teaching of writing and those, like Maxine Hairston, who argue that the composition classroom has already become a site for political indoctrination; indeed, this argument continues to resonate, as I think it should. My goal 
here is to recover and, in some sense, to reveal the ethical commitments that support politicized classrooms and the liberatory goals that drive them. That is to say, composition pedagogy, in its political commitment to social change, harbors often unacknowledged commitments to the ethics of its politics. As teachers of composition, we do not often consider ourselves involved in the teaching of ethics when, in fact, our political views are fundamentally about ethical norms--those ways of living in, being in, and responding to the world that serve as implicit "ought" statements about our goals for a more democratic culture and critical literacies. In other words, whether we realize it or not, we are equally engaged in projecting not only our politics but also our ethics in the classroom.

I think the tacit connection between politics and ethics in the field is a fairly obvious one. Nevertheless, the use of "politicization" as a descriptor of composition's pedagogies overlooks the equally important influence of ethics in the making of these pedagogies. One central reason for using politics to describe ethics may stem from our associations of politics with public discourse; in democratic societies, politics is the name of public discourse, and because of this association, politics is a much more comfortable way of describing what it is we are doing when we politicize the writing classroom. That is, our attempts at political pedagogies are simultaneous attempts at public, political change. Clearly, the key term here is public; the assumption is that a discussion of the political constitutes an intervention into the life of the public and to social change. In addition, politics is a term that has consequence, either in the act of public discourse or in the democratic process. The ethical, on the other hand, has traditionally been associated with the personal, private experiences of individuals. Because of this association, the ethical is bound up with notions of the private individual and her "right" to make ethical decisions apart from public influence. Teresa Henning adds to this alignment of the private with the ethical by noting that the moral and ethical are areas of inquiry that we have yet to negotiate comfortably: "Our 
personal, public, and disciplinary experiences with moral debate also hinder us from making a thorough inquiry into the relationship between ethics and our field" (1). This tendency to sidestep the ethical points to two important, initial contentions that will guide this discussion: the fact that we do not have enough public ways of talking about ethics and that we have only recently begun to reconcile productively a postmodern ethics in the composition classroom.

This chapter examines initially how composition studies' emphasis on the political reveals its ambivalent relationship with ethics. This emphasis on the political "silences" a direct discussion of the ethical and effectively highlights the scarcity of models for discussing ethics in a public way. But this ambivalence is not recent; it has an historical precedent in the teaching of writing. To illustrate this, I want to delineate historical traces of the ethical in composition pedagogy, especially because this admittedly-cursory glance finds a curious commensurability: With the rise of training for business and professions in the early university came the decline of ethical themes in classroom. The liberal arts' historical commitment to ethics in the curriculum was met, more often than not, with an increasing emphasis on practical knowledges and professional training, a move that squelched discussions of ethics or turned them into prescriptive expositions on the preservation of liberal culture. Such an examination finds that, far from going underground, the relationship between ethics and composition studies has been an "uncomfortable" one, surviving on long-standing tensions between the ethical and the political, traditional and postmodern conceptions of ethics, and the public and private spheres. I want, then, to fashion both a theoretical and practical model, an "architecture of resistance" (Peters 93) that will not succumb to either a prescriptive morality or "the imposition of moral codes and agendas" (Henning 2) that have classified discussions of ethics and pedagogy or the appropriation of ethics to the private sphere. In doing so, I want to offer a Foucauldian ethics, for its emphasis on 
subjectivity as well as its practicality for the classroom, in the project of reconciling the ethical in composition pedagogy--an ethics that matches its politics. ${ }^{27}$

\section{Composition Studies and the Ethics of Ambivalence}

The politicization of composition studies runs into a curious paradox when we come to the implicit, and in my view, uncomfortable prospect of admitting the ethics of our politics. Patricia Bizzell aptly articulates this tension when she describes the "catch-22" of admitting one's agenda while simultaneously attempting to avoid making this agenda an imposition on students. "Because we view the imposition of ideological agendas as morally questionable, we become reluctant to exercise power in the classroom. But on the other hand, our moral sensibility motivates us to promote particular ideological agendas, or, if you prefer, particular ethical positions" (4). Bizzell goes on to describe the effects of such a tension as paralyzing to academics who need now, perhaps more than ever, to intervene and "exercise moral leadership" (4). Whereas Bizzell traces this tension to instructors' comfort with "hiding" behind the formal requirements of teaching students to write competent, expository prose, I tend to see the advent of politicized pedagogies as an attempt to exercise the very moral leadership she's calling for. The distinction, however, is in what I read as a use of the political that rests upon strongly held ethical foundations. Nevertheless, Bizzell appears to be arguing that even in cases where instructors have taken up a poltiical position as institutional authorities, linking their political commitments to pedagogy, they should also be aware of and open about the moral and ethical beliefs that inform their politics.

In a more specific example of how discussions of ethics in a politicized pedagogical climate are foreclosed, Terry Rassmussen in "Antifoundationalism: Can Believers Teach?" refers to the "offending essay scenario" posed to a group of teaching assistants as an event that exposed the ethical implications of politics. While the 
offensive essay is never clearly identified, readers are left to assume that it is the dreaded paper in which a student argues for "racism, sexism, or gay-bashing," an essay that does more than just make an instructor wince at an opposing political view (152). My first year in graduate school, this offensive essay scenario was posed to me and a group of fellow teaching assistants. Not surprisingly, an awkward silence followed. My initial response was that I would call the student in for a conference, discuss her views beside my own, and hopefully persuade the student towards my own way of understanding. On second thought I questioned that position, wondering if I had any business calling upon a student to witness my ethical inclinations. (151)

Rasmussen's description of the silence surrounding the question of what one was to do in reponse to such a paper is a key example of the ambivalence surrounding the question of ethics in composition studies, in general, and for writing pedagogy, in particular. Rasmussen also situates the question of the ethical after postmodernism and poststructuralism, suggesting that this feeling of "groundlessness" has developed from the field's attempt to question its own epistemological foundations. The effect of this has made ethics all the more difficult to consider for the postmodern classroom. In a field that has embraced new pedagogies for their political potential, Rassmussen asks, "Why is it that today's educators are so squeamish about sharing values in the classroom when we daily express our epistemological biases in what and how we teach?" (151).

In response to her own question, Rassmussen sees the discomfort with talking about ethical and moral views issuing from the "risky business" (151) of sharing these views in a discussion that may get contentious (151-52). While I do think that the threat of heated and potentially ugly debate in the classroom is one immediate reason for "silence" on such questions, I think our discomfort with discussions of the ethical in 
public goes deeper than that threat. As I have already alluded to, and will argue later, the ethical in pedagogy is aligned with private and individualist notions of one's freedom to choose and decide upon ethical decisions away from responsibility to a social whole. The very American foundations of liberalism insure that the individual will retain her status on questions of the private and personal to insure the cohesion of the social whole. Thus, to bring in a public discussion of personal ethics threatens to tear the fabric of a liberal democracy-and one small example of this democracy is a student's freedom to argue any point she likes in the classroom, however ethically questionable that argument might be.

While they both point to composition studies' dis-ease with the ethical, Rassmussen and Bizzell also implictly suggest further reasons why we either do not deal with the ethical as well as why such an engagement will erupt in a heated and uncomfortable exchange. In my view, one major obstacle to discussing ethics is that we do not have a public way of talking about them, a point that might partially explain the discursive options of silence or "unpleasant confrontation" that Rassmussen describes (152). She observes the uncomfortable silence about what one is to do in the face of an ethically-challenging essay with her own inability to articulate a response. Perhaps for a lack of viable models, Rassmussen falls back on her "gut reaction" that something certainly authorizes the teacher's voice as a rhetorical authority in reponse to an unethical paper, but "[t]hat opinion was never voiced: I had not proof, no line of support" (152).

Both Bizzell and Rassmussen respectively create solutions to this problem. For Bizzell, a more general inquiry into finding ways of talking about our ethical commitments is in order. "I feel strongly that we academics need to find more ways to promote social justice. The problem is how to talk about such values without promoting exclusions" (6). Rassmussen and Bizzell both argue for the increased importance of the teacher as a rhetorical and ethical authority. Interestingly, however, Rasmussen 
contends with the postmodern refusal to authorize anything in arguing that the authority of the instructor's position is not negative, that the student-teacher relationship is not always a negative power relationship, and that some authority is necessary to maintain the ethical in composition pedagogy (155). To this end, she advocates that we take responsibility for our positions as instructors and demonstrate that ethos is a "legitimate persuasion" (160) that students should be taught to recognize and investigate as they argue in their own work. In short, we should take the risks of taking a position rather than allowing for a situation in which "one belief is as good as another" (161).

I will return to other possible solutions to finding a way to talk about the ethical in the classroom in Chapter Five. For now, though, I want to emphasize that composition studies and its pedagogies have been uncomfortable, and at times, ambivalent about the ethical in the field and in the classroom. Furthermore, both Bizzell and Rassmussen point to the fact that we do not yet have established ways of talking about the ethical, unless, of course, we talk about it as epistemology or politics. In their acknowledgment of postmodernism, they both also attempt to work out ways of talking about ethics that do not rely on civic discourse models or Aristotelian models of the public sphere, a move that has remained a standard of composition's engagement with ethics. They attempt to work in the local space of the classroom, instead of calling up a model of the Greek agora to "go public" in their discussions of ethics. They also tacitly examine the formation of teacher subjectivity in an honest acknowledgment of teaching authority, but an authority that harbors possibility and positivity for shaping--not students' ethics--but their appreciation for and articulation of ethical positions. In the following section, I provide an historical reading of composition's changing and ambivalent relationship with the ethical as well as its reliance of Aristotelian civic discourse models. My critique of the Aristotelian civic discourse model and its attendant model of the public sphere serves to open up a space for a more historical and critical ethics. 


\section{In Brief: A History of the Ethical Subject in Composition}

While I contend that composition maintains an ambivalent relationship with ethics, there are voices from the field who have clearly established an explicit commitment to creating ethical subjects-of students in the classroom and in the projects in which they are involved. Bruce Herzberg's community service and writing course ${ }^{28}$ and Brook Thomas's constitutional literacy course ${ }^{29}$ serve as examples of the ways writing teachers are responding to our profession's historical commitment to ethics and rhetoric by asking students to "go public" in their writing and thinking. By turning toward models of critical, political literacies, these instructors are asking students to respond to social injustice and understand their imbrication in systems of power and exclusion. In addition, these three courses are predicated upon an appreciation of civic education for civic participation, a goal that holds much in common with Aristotle's concept of education for political participation. My goal is, then, to observe the field's long-standing relationship with Aristotelian notions of education and civic participation, that ethics after Aristotle tends toward an ethics of public discourse. As I contend, this linkage situates ethics in terms of a clearly-defined public sphere, one that involves positivistic and populist conceptions of democratic community.

To begin this trace, I must first look to the rhetorical tradition to find the traces of ethics in pedagogy and the curriculum, especially as ethics has often become a question of "moral rightness" (Henning 7) and prescriptive morality. Teresa Henning's observation of what I will call prescriptive ethics in composition pedagogy has been the dominant model used in composition classrooms. What we find in even a cursory glance at this presence in pedagogical history, is the need for a new paradigm for thinking ethics in the classroom, one that centers more on student agency, questions of subjectivity, and the mediation of private and public spheres--in short, a critical ethics. At the same time, I look to standards of literacy and the purpose of education in 
different historical periods to understand how the ethical has always maintained a relationship with education for citizenship and liberal culture, in general and to writing pedagogy, in particular. As I argue, the belief in education for critical literacy and citizenship has had a confusing and contradictory relationship with the rise of American industry: With the rise of business and vocational training in American colleges throughout the later nineteenth and twentieth centuries came the decline of ethical themes in rhetoric and composition classrooms, an emphasis that further conflates spatial relationships of private and public ethics.

\section{Aristotle, Moral Education, and The Public Sphere}

Historically, the central purpose of rhetoric was to train students "in communal public discourse on civic issues" (Applebee 171), a central tenet of early education which survived in the liberal arts college in America. The goals of a liberal education developed with the Sophists in what came to be known as the medieval trivium of writing, argument, and speech and quadrivium of artithmetic, geometry, astronomy, and music (Verbeke 2) and remained consistent until the nineteenth century when demands for specialized and business professions changed the demand for a liberal arts education. The Sophistic schools also favored practical skills that encouraged good citizenship and the attainment of an influential position in society (Verbeke 6). Quite early on in educational history, then, the function of a liberal arts education was linked to citizenship, to the fundamental needs of the citizen to function productively in a democracy. In Aristotle, we meet a fuller articulation of the relationship between civic participation and moral education.

According to Gerard Verbeke in Moral Education in Aristotle, the role of a moral education in the lives of young people was of paramount importance to Aristotle. For Aristotle, humans are ultimately political and moral animals who strive for the good and define this good in communities guarded by laws and custom. Thus, the importance of 
an educated and informed citizenry only increased in democratic Greece to insure the maintenance of community; laws "are [then] a permanent expression of the moral sense of a community" (Verbeke 12). In brief, Aristotle's goals for a moral education include three factors: 1) nature; 2) reason; and 3) training. Man is by nature a moral being, capable of reasoning and emotion, but his passions must be tempered by training. As a result, Aristotle believed that virtue is achieved through the practice and habit of moral behavior.

In the Nicomachean Ethics, Aristotle develops his concept of eudaimonia, or happiness, as the greatest goal of human life, but this happiness is achieved not through the indulgence of sensual pleasures; rather it is the achievement of "moral virtue and intellectual contemplation" (Verbeke 51). Once he has acquired the habit of virtue, an individual can turn to questions of judgment. Passions and desires "obscure the mind and prevent agents from having a clear view of what is to be done" (52). In theory, the agent will make correct judgments if he values reason and is not swayed by desire and passion. For Aristotle, then, the student must participate in a habit of virtue that educates desire toward ethical behavior; ethics is not, then, about constraint but the education of desire toward an innate propensity to be moral.

In short, an Aristotelian view of education relies on or is formed within a political community. And like the education of taste and sensibility, ethical behavior has to be imparted by habits of virtue. As Verbeke mentions, however, the role of teachers is never directly addressed in Aristotle. The assumption here is that teachers are virtuous persons who will work to educate students toward the goal of the political community (212). Notably, the political and ethical role of the teacher is assumed to be in line with the dictates of local government, supporting rather than resisting the hegemony of propertied Greek men. Ironically, however, Aristotle testifies to the inextricable link between the goals of a democratic community and the education of its 
ethical behavior. "Aristotle believes that outside a political community moral education is impossible" (Verbeke 233).

Composition studies has, to a great extent, continued Aristotelian ideas of civic discourse, political virtue, and moral education. To find evidence of this, I look to Sandra Stotsky's "Conceptualizing Writing as Moral and Civic Thinking" as an attempt to reconcile "the moral" with an Aristotelian responsibility to civic participation.

Stotsky begins with an important comment on the general lack of scholarship dedicated to the moral reasoning necessary to the making of academic texts, noting that most scholarship concerns making an instructor's political and ethical agenda the mainstay of the course, citing Bizzell and Dale Bauer as examples of this. Stotsky then offers a list of ethical and rhetorical imperatives of a writer's responsibilities to observe the conventions of academic writing, assumedly to guide students in their selection of evidence, attribution of sources, fair presentation, and coherence in writing (799). With the Aristotelian goals of civic virtue and responsible citizenry in mind, Stotsky confers that "it is possible that learning to understand and observe the obligations embedded in academic writing may contribute more to the development of a student's moral character as a citizen than discussions of the teacher's personal values and the moral meaning of historical events, contemporary public issues, fictional dilemmas, or applied science and technology" (799).

Though I applaud Stotsky's schema for locating ethics in a local way and for providing students with a means of constructing texts by way of the ethical imperatives of academic writing, that is, in terms of their responsibilities as writers, there is no critical consideration of how the ethics of academic writing create the subjectivity of students or discussion of how what we adopt as conventions of academic writing come to have the force of authority; Stotsky sees these conventions "as static bundles of rules, rather than contingent practices" (Friend 553). Ultimately, Stotsky echoes Aristotle's conception of ethics as consensus-driven virtues that must be imparted to the minds of 
students to acquaint them with "the habits of responsible thinking" (806). Furthermore, Stotsky suggests a model of the public sphere, drawn from Aristotle, that assumes a unity between what students learn in the classroom and their conscious will to bridge school and civic participation in a seamless "carry over" of educational virtue to the political sphere. Because of this assumed unity or relation, the Aristotelian public sphere does not meet with the complexities forged by an encounter with late capitalism, and therefore risks situating students ahistorically within an "early model" civic public.

While looking to the moral questions involved in academic writing, Stotsky draws upon Aristotelian notions of virtue, judgment, and civic responsibility. In doing so, Stotsky leaves the emphasis on prescriptive ethics firmly in place, while leaving questions of student subjectivity unanswered. This is, of course, not her goal in constructing guides for student choices in academic writing. I point to this omission in her work because it repeats the field's historical tendency toward prescriptive moralities in the formation of student ethical subjectivity and draws on a theoretical foundation in Aristotle. Furthermore, Stotsky, while criticizing the political turn in composition studies by advocating an ethical formalism in writing, does not engage with or reconcile the field's attempt to think through a more critical approach to ethics, one that might benefit from postmodernism. The central tenets of Stotsky's pedagogy retain the autonomy of students in deciding questions of ethics, but their autonomy is linked with agreement of the common good and the civic participation necessary to maintain it; dissensus or the contingency of community norms is a questionable or secondary practice in these classrooms, a characteristic that replicates one major obstacle in responsibly appropriating Aristotle: the problem of difference.

I do not want to suggest that Aristotle is just "bad all the way 'round" for ethics in the classroom; rather, my purpose is to show how few contemporary models of ethics have offered a view toward integrating the lessons of postmodernism as well as criticisms of community and consensus. I would argue that it is because of the recurrent 
turn to Aristotle that we do not have more critical models for thinking ethics in the classroom. It is as if we have found something that works in just about any historical and pedagogical context and therefore assume that it should be used because it can so easily be appropriated. Because of this trend, I think we should be skeptical of a model that can be taken from one very different historical period for which it served certain needs and performed certain functions and placed into another, far more complex and heterogenous one and expected to operate in much the same way. To examine what I see here as the "incommensurability" of the Aristotelian public sphere upon which civic discourse is built and our current one, I want to examine further the problems of ahistorically employing Aristotle's ethics in the classroom.

\section{Problems with Aristotle's Ethics and the Public Sphere}

Aristotle really provides a "mixed bag" when it comes to providing models of ethics, discourse, and the public sphere. While he provides an understanding of ethics that shares some of the contingencies of postmodern ethics, Aristotle's civic discourse assumes a public sphere that is undifferentiated and unmediated by the confusions of a late twentieth-century, industrially-advanced public sphere. Thus, appropriations of this sphere in models of public discourse, civic participation, and ethical responsibility that characterize composition's import of Aristotelian ethics and civic polity risk misrepresenting both the contemporary public sphere as well as any theory of ethics. What is useful to retain in Aristotle's concept of moral education is that ethical norms do not bear the authority of transcendent imperatives. The derivation of ethical norms is more tentatively situated in terms of the community-based discussion and consensus of what virtues and habits are best for the polis. Indeed, composition pedagogy keeps returning to Aristotle for public discourse models because Aristotle provides a comprehensive understanding of the role of rhetoric in a community bound by ethics. Nevertheless, the value given to Aristotle's model of public discourse is based upon its 
"success" in a homogenous community, one built upon exclusions that we would today find unacceptable.

In The Structural Transformation of the Public Sphere, Jürgen Habermas traces the origins of the bourgeois public sphere to ancient Greece. His analysis highlights that even though Aristotle offers some important foundational premises to keep in mind for moral education and civic discourse, namely an emphasis on the social construction of virtue and the importance of civic participation, the Greek public sphere was established upon premises that make this model of limited use for contemporary composition studies. The public sphere of ancient Greece included the spatial particularity of place, such as the agora, or the marketplace, lexis, or the discussions that took place in law courts and public gatherings, and the actions needed to organize for war (3). The relationship between the public and private sphere relied on the individual's status as master of oikos, or household (3); in other words, a freeborn male had to own property, including slaves, to maintain status in the public sphere (3-4). Inextricably bound up with politics, the public sphere in ancient Greece was closely related to the state and centralized government, unlike the public sphere of the eighteenth century, which formed against these authorities (27). Not until the eighteenth century do we find a modern sense of the public sphere as a community of individuals, private citizens, coming together as a public; "they soon claimed the public sphere regulated from above against the public authorities themselves, to engage them in debate over the general rules governing relations in the basically privatized but publicly relevant sphere of commodity exchange and social labor" (27). Discussions were formed and expanded by citizens; the polis "provided an open field for honorable distinction... The virtues, whose catalogue was codified by Aristotle, were ones whose test lies in the public sphere and there alone receive recognition" (4). Because status in the public sphere was directly related to status in the private--in terms of the ownership of property--the opposition 
between public and private did not exist in ancient Greece to the extent that it did in the eighteenth century or that it does now (5).

In both Habermasian and Aristotelian or Greek configurations, ethics is located within a sphere that has been created explicitly for abstraction and transcendence; this is what makes the public sphere public, the eradication of difference and the assumption of a universal and highly rational bourgeois subject, or in the case of Aristotle, the propertied political subject. As Michael Warner argues in "The Mass Public and the Mass Subject," the Habermasian concept of the public sphere, not unlike that of the Greek model, creates a space that is designated by the desire either to transcend difference in the goal of universality and consensus or to maintain a public sphere based on the shared, equal status of participants (382). However, a key historical distinction between the Greek and contemporary public spheres is the assumed unity of public and private spheres in their early formation. In other words, the Greek sphere relied on the continuity between private and public spheres in that "publicity" in the public sphere relied on ownership in the private. "Status in the polis was therefore based upon status as the unlimited master of an oikos" (Habermas 3). Likewise, a continuity of "value, judgment, and reputation" (Warner 378) moved between public and private spheres. In Warner's critique, the bourgeois public sphere laments this initial unity that has become further separated by capitalism in the separation of the private sphere from its public function. Notably, and as I will return to later, these subsequent, exclusive, concepts of public and private spheres, while further dissociated from their original relationship in direct democracy, were also mediated by the increasing force of capitalism, a force that simultaneously occludes and distinguishes private and public ethics.

\section{Prescriptive Ethics in the University Curriculum}

Aristotle's community-based moral education, in its emphasis on linking the political and ethical, foregrounds the theoretical foundation of the liberal arts curriculum 
in American colleges. As David Russell observes in Writing in the Academic Disciplines 1870-1990, until the mid-nineteenth century, American colleges adopted an approach of "mental discipline" (36), not unlike Aristotle's concept of educating habits of virtue and ethical behavior, that required training "through drill and exercise, the various 'faculties' of the mind, memory, judgment, will and so on" (36). Rhetoric remained an integral part of the liberal arts curriculum in the production of predominantly oral compositions. In addition to the four-year course in rhetoric, mathematics, Greek, and Latin, many schools included a course in "moral philosophy, a course that went by a variety of names and included an even wider variety of subject matter ... but [the] goal was almost always to affirm the truths of Protestant Christianity against its detractors" (37). Rhetoric was bound up with such teaching, for most faculty with training in ministry taught rhetoric. Russell finds that even when departments began to be recognized in colleges during the 1830s and 1840s, "rhetoric or English was variously combined with moral philosophy, history, logic, or metaphysics, as well as with modern and classical languages" (41). In practice, the almost interdisciplinary effect of moral philosophy found its way into the curriculum through rhetorical demonstrations on lofty, value-laden themes that, more often than not, modeled a prescriptive approach to ethics (40-42).

David A. Jolliffe's work on ethical themes in "The Moral Subject in College Composition: A Conceptual Framework and the Case of Harvard, 1865-1900" gives Russell's general description of ethical themes in rhetoric of the nineteenth century more detailed support. Jolliffe observes a trend in "assignments that direct students to write about matters of moral obligation" (164). Moreover, Jolliffe notes, in contrast to Berlin, that despite the emphasis on objectivity in prose, including an abandonment "of concern for the ethical as it became completely positivisitic in intent," there was a concern for ethical themes, as the example of Harvard testifies (Berlin qtd. in Jolliffe 167-68). Nevertheless, the ante-bellum university brought with it huge changes in the organization 
and purpose of the university, and with it, a new place for ethics in the teaching of rhetoric.

After the Civil War, Russell observes "the utilitarian chorus" (46) pervaded what what was increasingly becoming the new university. Students, business leaders, and parents all called for a more practical education, one that would respond to the needs of economic expansion (46). Some of these changes involved the rise of an elective curriculum and specialization rather than a general liberal arts curriculum. The role of rhetoric in its purely oral form was met with an increasing demand for writing. The proliferation of new disciplines and their attendant, specialized languages required more writing and less rhetoric. By 1872, formal courses in writing emerged, and by 1900 , Harvard required English A for all of its students, thereby instituting the teaching of writing in the modern university. And as writing requirements changed to meet the demands of an emerging economy and the new role of the university in producing the "captains of industry," so too did the role of ethics in the curriculum.

Jolliffe provides the most concrete example of the ethical in writing courses. Jolliffe observes the promotion of moral obligation in themes ranging from "Respect for Women" to the more explicitly ethical, "The Duty of Rich Americans" (168). Harvard students followed the assumption that the essay was "an essentially moral form, a genre that allowed the writer to observe everyday occurrences and to suggest how those occurrences reflected the ethical nature of the entire society" (Besmaia qtd. in Jolliffe 170). Jolliffe adds that social, cultural, classroom, and institutional contexts all contributed to students' belief that "their themes were exercises in cultural criticism and, as pieces of art must have a moral dimension" (170). The belletristic tradition further fostered this assumption by examining moral themes and ethical dilemmas in the literature used to teach writing, what Jolliffe calls the development of a "moral aesthetic" in the reading of literature that arrived after, and perhaps in support of, Arnold's Culture and Anarchy (170). 
Notably, Jolliffe also contends that with the rise of post-war markets and industry came social and political unrest. In response, Harvard men were echoing Arnold's thesis by writing about moral obligation and the ethical imperative to preserve culture (171). Perhaps in awareness of their role as an elite group elected to safeguard the values of Western culture, Harvard students wrote of their responsibilities to mediate and illuminate the conflicts of the period. Despite their dealings with ethical themes, Jolliffe's tracing of the ethical in composition pedagogy serves his larger purpose of pointing to the conservative strand in composition that survives, as evinced in his recent, informal survey of themes used in composition courses. For my purposes, Jolliffe's work establishes both the persistence of ethics in writing pedagogy as well as a sense of ethics as a conservative, prescriptive field of inquiry that dictates the values and beliefs of the elite culture of students at Harvard in the late nineteenth century. The subjectivity of the Harvard student was one of inspired revelation-a romantic conception of the unfettered mind engaged in the pursuit of Truth. Accompanied by the study of literature, the student could then make value judgments and prescriptions for an outside world, meeting the anxiety and doubt that accompanied national industrialization.

In contrast, Berlin identifies that later in the period Jolliffe studies, Fred Newton Scott's transactional pedagogy stressed an ethical focus but certainly one very far from the ethics advocated by Harvard students' themes. "Against extreme individualism and class bias of current-traditional rhetoric and the rhetoric of liberal culture, Scott posed a rhetoric of public service, a system distinguished by its ethical commitment to the public good" (Berlin 49). Berlin goes on to distinguish transactional rhetoric as a nascent epistemic rhetoric, one very different from the aims of either current-traditional or belletristic rhetorics. For Scott, the transactional paradigm offered "the rhetoric of public discourse" (35) in its acknowledgment of the dialogic interplay between subjective perception and objective reality in the formation of knowledge and discourse. 
In Berlin's scheme, transactional rhetoric comes closest to epistemic rhetoric in this acknowledgment of the social, interactive dimension of language.

Although it is never stated explicitly in Rhetoric and Reality, Berlin's description of epistemic rhetoric and its democratic foundations establishes this strand as the one which connects historically to the field's commitment to ethics. Nevertheless, Jolliffe's study gives voice to the consideration of ethical themes that remained consistent in the belletristic tradition. The varying applications of ethics in the writing curricula mentioned here display an ambivalence toward the approach to ethics taken in the classroom. In the case of Harvard, instructors opted for a clearly prescriptive approach to ethics in student themes. Further titles from Jolliffe's study substantiate this assertion: "Whether Rank, Fame, and Fortune Contribute to Real Happiness" and "May we Rightly Indulge in Luxuries While Our Fellow Men Are in Want?" are two other titles from his research that clearly assume an ethical position prior to the act of composition, one that can be applied to general social questions in the authorizing voices of Harvard students, who perhaps saw themselves as carrying on the preservation of liberal culture. Moreover, as both Jolliffe's and Berlin's studies demonstrate, the explicit role of the ethical in rhetoric and the establishment of composition as a discipline changes with the demand for more practical applications of writing. This is not to suggest that ethics was abandoned in the early twentieth-century American university; rather, it is to suggest that the teaching of writing and rhetoric came increasingly under the sway of nationalist and economic goals, and because of this, the ethical was amended to meet these needs. At the same time, the ethical gradually, and as is evident in our present "discomfort" with the ethical in composition pedagogy, becomes divorced from its relationship with the political. It becomes, like the pre-war economy, increasingly privatized. Notably, as early as 1880 , the rhetoric of capitalism had "trickled down" into student essays. This example from Jolliffe entitled "The Duty of Rich Americans" 
blends a bit of social Darwinism with the language of capital investment. The result is a curious mix of writing for the public sphere with the language of private investment.

Man's responsibility. .. increases in proportion to his possessions, whether these consist of life, health, wealth, knowledge, power, genius, or any other of the innumerable gifts received by him. We may consider this the working capital of mankind, for any one or all of which a return is required, sufficient to renumerate [sic] the investment. (Cook qtd. in Joliffe 168)

\section{From Prescriptive to Critical Ethics}

With the involvement of American forces in WWI and the firm establishment of English as a discipline, writing in English courses tended toward the reproduction of the values of patriotism and national culture (Berlin 170); literature and language become integral to this project of maintaining a national front. As J. Michael Sproule's essay, "Whose Ethics in the Classroom? An Historical Survey," outlines, the war marks an important curricular response to the ethical problems of propaganda and the news. Working out of the field of communication studies, Sproule's essay brings several interesting facts to bear on the role of ethics in the curriculum before, during, and after the war, as well as a provocative example of how discussions of the ethics of private industry in the public sphere were met. In short, he observes how the technology of mass communication is mediated by ideological, economic, and political concerns and how the subsequent ethical implications of this knowledge affected the curriculum.

Sproule traces the work of psychology departments in forging a critique of mass communication and its unethical practices in the public sphere. This critique is built upon several events that, in turn, influenced the pedagogical attention to studying the ethics and politics of cultural texts. The first of these theoretical events came from the 
social sciences; psychology and psychoanalysis revealed that public opinion was not autonomous but a product of propaganda and the ideological basis of the news (317). Second, because of this "new" knowledge, the assumed objectivity in reportage of national events was called into question. Sproule dubs this the emergence of the "ethical question in politics" (317). Thus, a concern for ethics in the curriculum is in direct correlation with both an academic and public awareness of the ideological filters that crafted the assumed rationality and objectivity of communication.

This trend in communication studies affected the curriculum in several ways: Censorship of textbooks that painted any favorable picture of the Germans; the formation of the CPI, the Committee on Public Information, a group that developed propaganda; and the recruitment of teachers who would create curricula to serve national and military goals (319). In response to the threat of unethical communication, academics in the field of communication studies, in their awareness of propaganda campaigns, developed a theory of "ethical communication as a prerequisite for democratic government in the modern industrial world" (319), but Sproule notes that "[e]ducators as a whole were eager to get in step with the CPI's view of the Great War as a contest between absolute good and absolute evil" (319). Nevertheless, some instructors focused on critical reading and analysis of mass communications to combat the CPI and propaganda campaigns. Intellectuals spearheaded attacks against the bias rooted in all forms of a quickly growing "communication industry" (319). In 1937, the Institute for Propaganda Analysis was founded, thus institutionalizing an interdisciplinary critique of mass communication. It "was a wide ranging investigation that explicitly encouraged students to probe major social institutions of business and government, paying particular attention to how various points of view [read, ideologies] were presented through the media of radio, film, and newspaper" (320). Moreover, I see this move as an explicit turn toward a critical ethics, one that took aim at the ideological formation of ethics inspired by a nationalist agenda. 
The success of the Institute for Propaganda was short-lived, however. With the advent of another world war and a strengthening economy, the Institute had to curb the politics of its ethics that often came into direct conflict with the goals of advertising and propaganda (321). After W.W.II, the Institute came under HUAC investigation, partially because it was openly critical of HUAC's methods. As Sproule contends, the emphasis on social ethics in communication had come to be seen as an attack on American ideals. Furthermore, disciplinary trends made it difficult to continue examinations of social ethics; the social-science approach that had come to characterize the critique of mass communications came under pressure to align with the methodology of the natural sciences. "The rise of statistical-experimentalism in social science dampened interest by academicians in social ethics" (322). Moreover, social scientists were forging new links with business in war-related analysis of enemy propaganda (my emphasis 327). After the late forties, Sproule sees a general decline and then gradual reemergence of ethical analysis in social criticism of the $60 \mathrm{~s}$, a trend that has remained fairly consistent in speech communications (323).

What Sproule's analysis provides is a concrete depiction of the changing place of ethics in the communications curriculum. His survey fills in the spaces that Berlin's history misses in its emphasis on writing curricula. In contrast, Berlin's focus on writing curriculum paints a more conservative picture of the place of ethics in the English curriculum during the period in which departments of communications and psychology were taking risks analyzing propaganda and advertising. Not until after the Depression does Berlin see a theoretical shift toward the view of education for social reform, citing evidence of this trend in the NCTE policy statement of the 1930s, which renewed its commitment to social responsibility. In the classroom, Aristotelian and public discourse models survived and re-emerged as tools for critical citizenship (81-82). Berlin observes the mid-late forties as a moment when many universities were adopting a general communications course that, among other things, engaged students in recognizing "bad 
argument and bias in discourse (especially propaganda)," a focus not unlike that adopted earlier in communications studies (97). I think this is significant considering that Berlin sees the shift toward a more critical ethics in general communications courses later than Sproule does, suggesting, perhaps, that the communications curriculum Sproule surveys did influence greatly the ways in which universites later tailored their rhetorical and ethical approaches in the classroom.

The surveys discussed here outline composition's response to historical changes in culture, politics, and the curriculum. Ethics, rather than disappearing in response to external demands for a more expedient education, survived in communications departments in fascinating, productive ways. Moreover, when there was an explicit focus on the ethical in writing courses, as in the example of Fred Newton Scott's transactional rhetoric, ethics was derived from an Aristotelian concept of public discourse, one that linked political life to an espousal and practice of virtuous community. Criticism of the exclusions of Aristotelian notions of community aside, ${ }^{30}$ Fred Newton Scott's project is not far from more contemporary adaptations of Aristotelian models of public discourse and communitarian-virtue ethics for the classroom. Indeed, composition pedagogy often returns to Aristotle for public discourse models, because Aristotle provides a comprehensive understanding of the role of rhetoric in a political community bound by the force of ethics. Moreover, the derivation of ethical norms is not reduced to the force of metanarrative in Aristotelian ethics.

Nevertheless, I find Aristotle of limited use in the postmodern classroom, especially one that attempts to focus more readily on how students are called upon as ethical subjects, rather than on generating a battery of virtues to be practiced in daily life. In other words, the writing curriculum has yet to provide a critical approach to ethics, one that would investigate the self's relationship to and negotiation of ethical norms; the "good" of a political community seems to be an static assumption in Aristotelian notions of community and the public sphere. The trend in composition 
pedagogy has been one whereby students are asked either to draw upon or generate existing prescriptive morals or to practice models of public discourse based upon the political virtues associated with this sphere. As I have argued, the public sphere of ancient Greece bears little resemblance to our contemporary notions of the public sphere. More importantly, the Aristotelian public sphere and its purpose of civic discourse maintains a very clear connection to status in the private, a unity that we no longer assume.

Sproule's work shows a commensurate resistance to discussions of ethics in the public sphere as industry and mass communications became more privatized. The resistance appears to come from an assumption on the part of propaganda industry-and we can substitute a wartime propaganda industry with a general understanding of our contemporary consumer culture and the ideological foundations of capitalism--that a critical ethics should be eliminated from the public sphere, especially when such a critique involves a perceived attack on American ideals. Such a move pushes ethics further into a highly privatized sphere, a move that simultaneously conflates notions of the private in a confusing dualism of "private industry" and "private individuals." The propaganda industry as a private sector machine aligns itself and its ethical responsibilities to "truth" and "objectivity" in reportage with the right of individuals to decide upon questions of ethics. The unfettered freedom of capitalism insures private industry of maintaining their "private" status to generate jingoist, conservative propaganda and advertising. In short, I think we might read the alignment of "private industry" with the private sphere as a move that capitalizes and profits from the association of the private sphere and ethics. As Sproule's work testifies, once critical ethics went "public" in its attacks on the ideological foundations of private industries such as advertising, businesses reacted by targeting academics involved in this work as "unAmerican." 
In many ways, the public discussion of ethics performed by communications educators did not draw upon an entrenched Aristotelian model of the private sphere, one that had clear connections to state, government, and civic responsibility. Rather, they appear to have been working on what I have identified as a Habermasian notion of the public sphere--the space developed not in tandem with a state sphere but for the purpose of "debate over the general rules governing relations in the basically privatized but publicly relevant sphere of commodity exchange and social labor" (my emphasis 27). But once the subject of critical ethics and rhetorical responsibility participate in this sphere in an effort to adjudicate it, strategic disciplinary and political moves are made to (re)align and diffuse ethics as either part of the "soft social sciences" that cannot be quantified or to bring it under the wing of emerging industries whose goal it is to build a stronger economy and a new Cold War nationalism. In effect, a public discussion of ethics constitutes a threat to both ensconced notions of individualism and its partnership with an American legacy of entrepreneurship.

Perhaps as a response to the consistent resistance of those spheres outside of the university, ethics, in our field, has been transformed into political pedagogies that, like Sproule's study of communications courses, draw from and react to the ideological mediation of mass culture by a variety of "isms." The work of the classroom is to decode and reread these narrative "isms"; ethics is then transformed into politics. Such a model keeps questions of private ethics out of the realm of public discourse, further entrenching the reliance on social issues--in terms of their politics rather than their ethics-in the classroom. I will return to the relationship between private and public spheres and ethics later; for the moment, I want to turn to more current applications of ethics in composition studies in an effort to sketch a preliminary outline of what a critical ethics needs to consider in its theory and practice. 


\section{The Subject of Ethics in the Postmodern Classroom}

The field's ongoing encounter with postmodernism and poststructuralism has made it even more difficult to reconsider and reconfigure a viable ethics that benefits from some of the insights and complications gleaned from an engagement with the radical skepticism and anti-foundationalism of postmodern ethics. Nevertheless, as ethics and the foundations for thinking them have been entirely ungrounded, ethical and political decisions have become simultaneously more difficult and more imperative. In many ways, and as I have already suggested, pedagogy has stepped in to maintain an ethical anchor of the field by enacting practical applications of politicized pedagogies. If, according to Lyotard, we have a "responsibility to respond," then I think it is fair to assert that composition's political pedagogies have worked to respond to injustice.

In the following discussion, I look at how Lester Faigley and Christy Friend import postmodern and poststructuralist theories in their respective attempts at negotiating these discourses for the postmodern classroom; both yield insights as well as potential problems in grappling with a critical ethics that does not replicate the historical penchant for normative or prescriptive ethics in the field. Neither, in my view, deal explicitly with how notions of private and public spheres mediate discussions of ethics; however, both engage with the problem of subjectivity and ethics in the postmodern.

Lester Faigley's Fragments of Rationality: Postmodernity and the Subject of Composition resituates the rational foundations of subjectivity upon which composition pedagogy has been based. His historical survey of the subject of composition takes us to the present moment when, in the wake of theory, the fragmented subject, who can no longer lean on defining narratives of truth, objectivity, and ethics, must negotiate an increasingly technological and commodified culture with little to guide her. Fragments thus provides a thorough history of the subject in composition, shifting, in the process, 
an emphasis on what is taught as a defining marker of composition's history to how subjectivity is constructed by the rational assumptions of pedagogies. Most readers are by now familiar with Faigley's project, so I will not labor his argument beyond this general summary. What I wish to address in detail, however, is Faigley's less-thansuccessful attempt to discuss a specifically postmodern ethics, especially as it confronts the lack of viable models both for bringing ethics into the classroom and offering agency as a way of mediating a host of unauthorized discursive positions, none of which hold any external validity.

For an encounter with postmodern ethics, Faigley turns to Lyotard's later works, Just Gaming and The Differend. He defends that "The Differend can be read as an argument for locating ethics in a postmodern pedgagogy" (236). After a concise explanation of Lyotard's contribution to this project, Faigley determines that the proposal of the incommensurability of language games is important for composition studies. He looks to Lyotard's use of genres as a way of recognizing this incommensurability. Genres are, in a sense, speech contexts that submit phrases to their order. For example, argument and narration are genres of discourse between which there is the possibility of linkage. Faigley observes that "ethics becomes a matter of recognizing the responsibility of linking phrases... Thus in the choice of genre there is an ethical decision" (237). Faigley provides an example of this in James Britton's replacement of transactional rhetoric with more expressivist models in British schools, observing, however, that this example highlights the replacement of genres rather than the refusal "to accept the denial of conflict within the limits of a single genre" (238). Lyotard would have students look not to ethics but to "the implications of their linkages" (238). Interestingly, this would have students look at language, and in particular, the how of linkages-what we all call rhetoric. Students, in this pedagogical paradigm, would be encouraged to link genres, to make of stories and debate, of 
narration and argument, an ethical linkage, rather than simply replacing one with another.

In a similar way, Lyotard's ethics would not be the application of preexisting ethical norms to a given rhetoric but--to keep in line with demarcation between politics and ethics with which I began--a study of "the implications of ... linkages [and exclusions]" (238) between ethics and politics. In many ways, the incommensurability of politics and ethics within composition constitutes a differend; the genre of politics appears to have authority over ethics. The ethical responsibility, then, is to link these two genres, that are, ironically, intimately related in theoretical antithesis. But as I discussed earlier, the linkage between the political and the ethical is a difficult one because such rigid boundaries separate the two not only into discursive genres, but also into literal, spatial places where they are entrenched as genres appropriate to public and private spheres. What needs to be added to Lyotard's formulation is a spatial understanding of how genres can be determined not only in discourse but in the places and spaces of their circulation, which further determines how they can be linked. I will return to this theme in the following section; for now, though, I want to leave the reader with an indication of how Lyotard's penchant for narrative might be advanced, and perhaps illustrated, within an architecture of the subject and ethics, one that takes a closer look at how private and public conceptions of ethics and responsibility are already in the process of linking and confusing what Lyotard identifies as genres of discourse.

There is, however, an ad hoc quality to this last chapter of Fragments; that is, I had the sense while reading that, despite the helpful discussions of Iris Marion Young and Lyotard, the question of the ethical subject had yet to be thoroughly discussed. While this appears to have been Faigley's intent--to leave the question open--I am not convinced (and I am not sure Faigley is either) that Lyotard provides the best model of ethical subjectivity because he is ultimately discussing in both The Differend and Lust 
Gamingthe impossibility of answering a call for ethics and justice in the postmodern. We need only to consider the "laughter" that closes Just Gaming when Thébaud and Lyotard have arrived at the "metanorm" of maintaining mircronarratives as the only justifiable ethic to guide judgment. In my view, Lyotard is paradoxically both nihilistic and idealistic on the possibilities of justice in the postmodern simply by virtue of the incommensurablity of his own theories and the genre of composition studies.

I do not want to suggest that Lyotard is completely useless for composition studies; the deauthorization of dominant genres and the local politics of contingent judgment are important theoretical models. Furthermore, the differend is a helpful descriptor of what happens when justice must be determined and two disputants cannot agree on a relevant or dominant rule of justice. However, and as Faigley explicitly mentions in this final chapter, Lyotard "does [not] suggest how subjects are to be located" (238). Lyotard's discussion remains fairly vague, focusing on narratives rather than subjects, and at times, remains too idealistic for the local work of the classroom. What Faigley does provide, however, is a foray into other, possible ways of thinking ethics and composition, outside the purview of moral prescriptions or the creation of certain kinds of student subjects in character education. As I have argued throughout this section, most composition pedagogy that has an explicit commitment to ethics or ethical themes tends toward textual analyses of professional texts in tandem with or as a catalyst for student writing. Faigley makes a move for examining subjectivity in our discussions of ethics; unfortunately, Lyotard does not provide the most productive model for thinking the ethical subject in composition pedagogy. While he is valuable for destabilizing traditional notions of judgment and argument, as well as raising the issue of responsibility for linking incommensurate phrases, Lyotard inevitably leaves his own call for justice unanswered.

Christy Friend's "Ethics in the Composition Classroom" is an even more recent attempt to integrate ethics and the discourses of postmodernism into a workable 
framework for the classroom. Friend's attempt to bring ethics into the classroom brings her to side with Young's critique of distributive justice. In brief, Young finds that concepts of distributional justice, in their emphasis on distributing goods and services to eradicate inequality, do little to upset the existing structures responsible for inequity. In response, she advocates a nondistributive model, one that would emphasize deep, institutional change rather than remedying injustice with the distribution of goods.

Distributive models consider the consumption of goods and assume that doling out equal "portions" of material goods will result in justice. The goal of equity that supports a distributive logic relies on an assumption of sameness, ignoring questions of difference, as well as how individuals, as part of marginalized groups, are positioned differently in relation to what consensus has determined to be a fair allocation of "the just." In addition, distributive paradigms focus on "'end-state' theories. . .where justice is determined by the amount of goods each individual ends up with (Young qtd. in Friend 551). A nondistributive approach to justice would look at the structures that disallow persons from an active role in reforming and responding to injustice, focusing on those "nonmaterial concepts like rights, decision-making, power, and opportunity" (551); this new theory of justice would further consider nonmaterial issues of injustice, such a "procedures, division of labor, and culture" (Young qtd. in Friend 39). What we meet in Friend's work is a new vocabulary for talking about ethics and justice, as well as a comprehensive, theoretical inquiry into how a nondistributive paradigm would help to restructure ethics in the field.

Friend begins by asking "How is it possible to negotiate ethical issues productively and humanely in the postmodern classroom?" (549). Before presenting Young's nondistributional justice as a means toward talking about ethics in the classroom, Friend takes issue with Sandra Stotsky, C.H. Knoblauch, and Patricia Bizzell for each of their attempts at working ethics into the classroom, finding, in the final analysis, that all three in some way rely on foundationalist principles, infractions that 
violate the cardinal rule of postmodernism. Friend criticizes Knoblauch, for example, because he provides a recent example of one major approach in the teaching of ethics in composition, but one that does not go far enough to revise distributional paradigms of justice and ethics.

Knoblauch's "Critical Teaching and Dominant Culture" discusses strategies for engaging students in critical and ethical consciousness by reading multicultural fiction, discussion of issues raised in the reading, and extensive writing; the optimal result of these classroom practices is the kairotic production of ethical moments, when students glean flashes of insight into the very myths and assumptions that structure their lives. While productively focusing on the gradual, and not always successful fragments of insight, questions of difference, and interrogations of authorized discourses, Knoblauch makes a move toward nondistributional justice; nevertheless, he is faulted for crossing the distributional line in the hope that students' reading will perhaps result in the education of ethical character and critical consciousness (555). I would also add that Knoblauch uses the durable model of the belletristic tradition through the use of texts that may possibly extend students' "ethical horizons" (555); students read literature that will hopefully reintroduce them to their ethical assumptions and foster the conditions for ethical change.

The import of nondistributive ethics in the classroom, according to Friend, would involve more attention to examining and enabling critique of institutional inequities that foster injustice in the goal of insuring equality for all. Part of this project is to value "diverse perspectives" and indulge "productive conflict" by creating courses that will introduce students to different groups (563). To this end, Friend created a course based on Young's major tenets of nondistributive justice. She uses a hypertext unit entitled "Merit vs. Educational Diversity? An Introduction to Ethics" through which students must make ethical decisions from the various perspectives of those involved in college admissions process; these roles range from that of minority students applying for 
admission to an admissions officer under pressure to expand diversity initiatives.

Students are continually asked to write persuasive arguments to defend and support the decisions they render on issues generated from the hypertext application. The ultimate goal of this pedagogical project is to revise our distributive language for thinking about ethics and social justice to the more workable process of "productive conflict, change, and ever-present difference" (566).

While I support and defend her import of nondistributive justice, in particular, her engaging application of it to classroom practice, I find it ironic that, with the aid of computer technology, Friend is better able to transcend questions of goods to questions of abstract, institutional practices. My point here is not so much with her application but with the partial dismissal of distributive justice because of its built-in roadblocks to real, institutional change. I think we also need to consider, before adopting nondistributive paradigms, the inextricable link between material justice and nondistributive concepts of power. How can we talk about the division of labor if not in the distributive terms of wages and resources? I think there is a false dichotomy erected, albeit a rhetorically necessary one, to highlight the blind spots of distributive justice. For example, I find it ironic that the the distributive justice paradigm that underwrites student access to computer technology allows for an examination of nondistributive ethics. That is to say, the very institutional practices critiqued by a nondistributive paradigm are being done so with the material possessions--computers--that characterize a distributive logic. Furthermore, and in very pragmatic terms, it is easy to begin musing about the inadequacy of distributive justice because it elides any kind of analysis and consideration of abstract, institutional practices if you are not waiting or relying on the goods that will allow you to survive; I cannot help thinking of those for whom "possession" and "consumption" are immediate issues (Friend 566). Of course, nondistributive justice is imperative to seeking any kind of real, foundational change in society, and it is an excellent model for the writing classroom because it does engage 
with the concepts Young identifies as outside the purview of distributive justice: language, decision-making, and culture (551). Nevertheless, I think the university at large specializes in abstraction and philosophical introspection, a nondistributive practice of instituting the values of the larger culture. Students need to be acquainted with the process of distributive justice initially to critique it. If we bypass it, we neglect to open up a way for nondistributive thinking. "Breaking the distributional mold," as Friend puts it, should be a stage along the continuum of justice, rather than an assumedly better model of justice. Even though the question of goods is but one component of distributive justice, I think that it is important and immediate enough that we consider some tenets of the basic model that can, in concert with nondistributive models, go further in ameliorating injustice.

A final point I want to make is in regard to what Iris Young's work says about bridging the public and the private. Iris Young makes quite clear early on in Justice and the Politics of Difference her very public understanding of social justice. "Social justice in the sense I intend continues to refer only to institutional conditions, and not to the preferences and ways of life of individuals or groups" (36). Young looks only at social justice in relation to political groups and institutional practices, rather than at the private, even personal, experiences of individuals and groups. Young makes this sidestep of the private--the ethical-intentionally, however, to avoid liberalism or liberal notions of justice based upon "individual freedom and the consequent plurality of definitions of the good" (36). Social justice "concerns [then] the degree to which a society supports the institutional conditions necessary to the realization of these values [of justice]" (37). Young's avoidance of the private preferences of individuals testifies to the entrenched associations of liberal individualism and individual choice that structure our society; her neglect of that "plurality" of definitions of the good is an admission of this equation. What I have been suggesting throughout, and what Young's critical move away from private ethics to social justice makes clear, is that our emphasis on politics is 
a strategic institutional demand that we not consider ethics and the private experiences of individuals as they both influence and reflect social justice. To do so violates liberal notions of a private self. In effect, our historical commitment to liberalism and individual rights (to privacy, autonomy, and "the good life") often let us and others "off the ethical hook" because these longstanding beliefs are preserved, and even insured, institutionally as private--not public--concerns. Thus, to "go public," then, is to question these rights and choices as they affect a social whole. While I am not suggesting that we erase the private or simply make it public, I am interested in how private ethics are legislated publicly and how private conceptions of ethics shape public notions of the political.

Ethics in composition pedagogy has historically employed ethics as norms of judgment, ways of reading and judging the world that involve the creation of a general other--a group, an individual, their social practices and behaviors-who will absorb the dictates of ethical codes. What Faigley and Friend bring to the table is a complete shift away from normative or prescriptive ethics toward the theoretical and practical possibilities of critical ethics, that is, an ethics that is intimately involved in examining the ways in which discourses--micro- and meta-narratives--involve the creation of ethical subjectivity, either as the disciplinary subject of composition or the ethical choices students make when asked to occupy and defend various positions in argument. I would like to take the project of building a critical ethics further by advancing its full articulation in Foucault, an inquiry that helps to mediate the initial work done already in the field to resituate ethics and subjectivity.

\section{From Politics to Ethics: Foucault's Ethics of the Self}

In The Use of Pleasure Foucault provides a framework for understanding ethics, not as the rational generation of ethical norms to which all must submit and not as a reflection of a universal human nature, but as the self's relationship to itself. In short, 
Foucault attempts to provide a means of continuing ethical inquiry outside the normative framework of traditional ethics. In doing so, he turns the focus on ethics away from moral behavior toward the history of moral subjectivization (Davidson 118). As Bernauer and Mahon argue, Foucault's emphasis on the aesthetization of the self moves outside of the quest for universality in standards by focusing entirely upon the individual and the "private" exercise of making oneself an ethical subject (153). Because of this emphasis on ethical subjectivity and the exercise of the self on the self, I find in Foucault a working remedy--a critical ethics--for our field's emphasis on prescriptive ethics as well as an implicit understanding of the relationship between those public and private spheres that situate ethics and the subject in confusing and contradictory ways.

In The Use of Pleasure, Foucault outlines four modes and means of studying how one becomes an ethical subject. In doing so, he provides a methodology to study the process by which one makes moral choices toward the goal of ethical selfhood. Foucault begins by defining traditional morality as "values and rules of action" (25) that determine a field within which individuals are to behave. He considers as well "the manner in which one ought to form oneself as an ethical subject acting in reference to the prescriptive elements that make up the code" (26). The most helpful distinction Foucault makes here, however, is the dual emphasis on not only the active position of the individual as ethical agent, but also as an "ethical subject of this action" (26).

Foucault begins his technology of the ethical subject with "the determination of the ethical substance" (26), "the prime material of moral practice" (26). In other words, this would involve determining what part of the self is to be judged ethically. The second component is the "mode of subjection; that is the way in which the individual establishes his relation to the rule and recognizes himself as obliged to put it into practice" (27). I see this component as the subject's recognition of moral codes and her relationship to them based on cultural, familial, and/or religious identification that help 
to provide the reasons for adhering to ethical norms. Of import here is the implicit social dimension in the reasons for subjection; an individual recognizes this behavior working in concert with the behavior of others in an affiliated social group (27). The third component is in "the forms of elaboration, of ethical work that one performs on oneself, not only in order to bring one's conduct into compliance with a given rule, but to attempt to transform oneself into the ethical subject of one's behavior" (27). The final component of Foucault's paradigm is the "telos of the ethical subject," (27-28), the commitment to more than single ethical acts but to a whole way of being, an ultimate goal or model of ethical subjectivity.

As Foucault distinguishes, ethics involves a heightened relationship and dialogue with the self.

The latter [self's relationship to self] is not simply 'selfawareness' but self-formation as an 'ethical subject,' a process in which the individual delimits that part of himself that will form the object of his moral practice, defines his position relative to the precept he will follow, and decides on a certain mode of being that will serve as his moral goal. And this requires him to act upon himself, to monitor, test, improve, and transform himself. (28)

In short, Foucault's four modes allow for a systematic approach to discussing not only ethical codes but the myriad ways in which subjects negotiate these codes as they are urged to submit to them. The general rubric of morals is also redefined and repositioned to focus almost entirely on the self's relationship to and assimilation of ethical norms. In effect, this shift moves away from what Teresa Henning identifies, after Jaqueline Martinez, as ethical rhetorics. "That is to say that what is good, right, or of value is decided on prior to any rhetorical discussion or inquiry" (3). The underlying assumptions of ethical rhetorics are that norms are derived prior to any rhetorical 
context and serve as transcendent, acontextual constraints. Foucault, by positing the source of ethical inquiry in the subject, offers a paradigm that allows for a more rhetorical understanding of the contingencies and constructions of ethics and the subject. Rather than applying a universal ethics to a range of situations, Foucault would ask: How am I being called upon as an ethical subject? What discourses authorize my behavior, my "ethical work"? To what end do I offer these acts, behaviors, and examinations? Nevertheless, Foucault never directly addresses the role of private and public spheres in his critical ethics. He does, however, in the intense focus on the formation of ethical subjectivity, assume these practices of self-formation and selfexamination are conducted in private but mediated and directed by the public sphere, a relationship that will become more complicated in my discussion of HIV testing.

With the previous questions in mind, I want to discuss in Chapter Five how Foucault's methodology--a four-step process of ethical questioning-might work in reading and understanding the construction of AIDS and the rhetorical and ethical matrices of HIV testing. In particular, I am interested in how the ethical dimensions of home testing, as a metonym of the ethical issues surrounding the discourses on AIDS, conflate assumedly separate spheres of public and private ethics, an examination that will not work to replace or recover ideal spaces of the public sphere--as in many applications of Aristotelian community--but will work to foreground the anxious "disunity" between these two spheres and the mediation of ethics. 


\section{Chapter 5 \\ Ethics and HIV Testing: Toward a Pedagogical Project}

As I argued in Chapter Four, politicization has been the favored approach in the classroom, and one that has received adequate critical response. In my view, a postmodern ethics has been the least theorized for what it may offer for the classroom. This most definitely has occurred because postmodern theory continually grapples with how to conceive of a viable ethics on its own, and as a result, has yet to provide a range of models for the local work of the classroom. In addition, we overlook or bypass questions of the ethical in the classroom because they have traditionally concerned intensely privatized conceptions of morality. Ironically, this careful sidestep of the ethical and its associations with the private sphere, have arguably done more to entrench the very binaries of private/public that much critical pedagogy attempts to critique and dismantle. For example, feminist composition instructors often ask students to examine how gender operates in an economy of the public and private. That is, they highlight the complex interaction beteween the social construction of gender and the political relationships that symbiotically establish and support private edifications of gender hierarchy. In doing so, we have inadvertently helped to maintain the last pillar of liberal individualism--not altogether a bad thing-by suggesting that questions of ethics come under the purview of an individual's right to choose and decide questions of ethical conduct apart from social or political concerns. Indeed, to discuss ethics in the postmodern is to betray the "foundational" tenets of postmodernism. That is, ethics in the postmodern almost seems a contradiction in terms because ethics assumes some normative framework. As Patricia Bizzell observes in "Marxist Ideas in Composition Studies," 
to speak of justice and injustice is to define an ethical commitment, ... perhaps because our understanding of ideology has given ethical commitments a bad name.

Thus enmeshed in ideologies, we see ethical commitments as just another ideological construct, ratified by no transcendent authority or by no match with transcendent truth. The scholar who avows ethical commitments, then, looks foolishly ignorant of this postmodern understanding of ideology. (55)

Consequently, not only does it make us uncomfortable about the private intrusion into individual choices, a discussion of ethics confronts a curious paradox in the possibility of even conceiving a postmodern ethics. This "new" ethics would need, then, to abandon the prescriptive, normative trappings of "transcendent truth"--a difficult prospect both theoretically and practically.

As I argued in Chapter One, there are possibilities for a postmodern ethics inbetween the either/or dichotomies of foundationalism and non-foundationalism that can provide a tenable ethical and discursive base. I have earlier referred to this as a critical ethics. Foucault's later work, in particular, is one example of a critical ethics inbetween. His four modes of subjectivization provide ways of talking about ethics that do not fall into the extremes of the either/or dichotomy and that direct us to an examination of subjectivity and ethics, one that can be carried over into the classroom in an attempt to "go public" with a discussion of ethics. In short, and for the purposes of classroom application, Foucault's modes would ask students to identify: 1) the ethical question or dilemma; that is, to identify how this particular issue asks ethical questions; 2) how the ethical issue identifies them, or in my terminology, calls upon them to respond ethically; 3 ) the actions, practices, and behaviors that a person must perform to be--or not be--ethical; and 4) the ultimate goal of this ethical behavior; that is to ask, what model or ideal does the individual strive to achieve or maintain? 
The issue of HIV testing calls upon our most "private" associations and ideas about sexuality. HIV testing is also a very "public" issue that has a direct affect on our conceptions of sexuality, public health, and disease. Within the public sphere, HIV testing is part of a larger project of managing an epidemic. For the private individual, HIV testing is bound up with issues of trust, intimacy, and personal relationships. In many ways, however, HIV testing is an issue that demonstrates how private ethics are everywhere legislated publicly; the individual is publicly asked to get tested, to be responsible, to act ethically in her private relationships with others. In a sense, HIV testing threatens to explode this dichotomy in its public education and legislation of testing for private information. It also forces us to consider how sexuality and disease are constructed as public ethical issues. Because this issue works within an ecomony of the public and the private and is surrounded by a host of ethical issues and questions, I think it is an important and productive one for "going public" with a discussion of ethics. This issue is also rich for enacting a critical ethics in the classroom that simultaneously works to problematize strategic uses of the private and public on questions of ethics.

In this chapter, I propose a classroom application of the theoretical concerns raised throughout the dissertation, one that serves to bring together the key terms under discussion: ethics, the subject, discourse, and the private and public spheres. To this end, I have designed a unit for my Writing 101 class that would bring together the question of ethics and the construction of AIDS in late twentieth-century American culture. In particular, I want to have students examine--via Foucault's four modes of ethical subjection--how the call for HIV testing positions them as ethical subjects and asks them to "take care" of themselves in private to insure the maintenance of public health. Furthermore, I want them to investigate their intricate relationship to this larger discursive "event" by probing the implications and "otherings" that have been inscribed by the widely-held belief that testing is the best means of "containing" the 
HIV virus as well as an individual's only recourse for gaining a sense of agency in the face of a perceived uncontrollable virus.

\section{Going Public: The Ethics and Politics of HIV Testing}

Issues of public health are a ripe area for investigating not only how subjects are classified, questioned, and constructed to act upon themselves in ethical ways, but also to question the entrenched assumptions of the private and public that circulate in discussions of ethics. The issue of HIV testing, especially as it is bound up in an intricate web of relations between these two spheres, is both a timely foray into discussions of ethics and subjectivity, as well as a means to discuss how the discourses on AIDS have, even in their relatively brief circulation, constructed the HIV infected person as a pathogenic other, a position that is further complicated and entrenched by conservative moralism and race/class/gender ideologies. Furthermore, the uncomfortable tension that suspends the relationship between the assumedly private sphere of sexuality and the public management of disease raises questions of responsible citizenship, a tension that has periodically resulted in the call for the policing, cataloguing, and quarantining of infected persons.

Much of this discussion will draw upon the work of Cindy Patton's Inventing AIDS in which Patton traces the "discovery" of AIDS from the "gay cancer" to its current discursive, medical, and political circulation in American culture. Her insights

are invaluable to understanding how the treatment and reception of HIV/ AIDS is still firmly embedded in moral, racist, classist, and sexist assumptions of sexuality and disease. For my purposes, Patton continually interrogates the logic of HIV testing as the major, if not sole, means of preventing the spread of AIDS, an emphasis that creates a particular kind of subject to/ of the discourses of HIV by focusing on what amounts to a means of surveillance rather than practical knowledge about preventing transmission. Before I pursue the subjectivity created by the the demand for HIV testing, however, I 
want to re-examine Michael Warner's "The Mass Public and the Mass Subject" in an effort to explain and understand the assumptions that support ethics and the public sphere, an examination that will help both to contextualize Patton's critique of the discursive means of constructing AIDS as an issue of public health and to develop further an understanding of how ethics circulates within an "economy" of the public and private.

Warner begins by articulating the rhetorical effect of invoking "the public" on "subjects of publicity" (375).

No matter what particularities of culture, race, and gender, or class we bring to bear on public discourse, the moment of apprehending something as public is one in which we imagine, if imperfectly, indifference to those particularities, to ourselves. We adopt the attitude of the public subject, marking to ourselves its nonidentity with ourselves. (375)

Beginning with this "commonplace" of the effect a call to the public sphere has on adherents, Warner proceeds to complicate this vision of the public sphere in terms of the political purchase derived from the subjectivity created by those discourses and texts that are considered to be "publicly sayable" (378). In other words, the latent assumption of what he calls publicity, or "publicness," homogenizes a general public into a political force or body and is contradicted in late-capitalist societies. In tracing the public to the eighteenth-century culture of print and publication, Warner finds the "origin" of the relationship between public discourse and the creation of the public (381). Because this emerging public sphere created a public persona, "a very special rhetoric" developed alongside conceptions of appropriateness and impersonality as a certain style of the public sphere (382). In effect, this bourgeois public sphere worked off of the "strategy of personal abstraction [that] is both the utopian moment of the public sphere and a major source of domination" (382). Through abstraction, the public 
sphere "claimed to have no relation to body image at all" (382), except the "unmarked identities [of] the male, the white, the middle class, the normal" (383). Over time, and as is evident in our twentieth-century consumer culture, the former reliance on a disembodied public sphere has been replaced with the "display of bodies for a range of purposes: admiration, identification, appropriation, scandal, etc." (385). In this way, we become the "mass-public subject" who is always already cognizant of our nonmembership in the "they" of the mass public in the awareness of our particular difference from this homogenous public (387). Warner identifies this tension as "the public subject's self-alienation," one that is overloaded with political meanings (387). Thus, mass public and mass identification become transitive terms depending on rhetorical and political contexts. In fact, I would go so far as to suggest that the public sphere is an essentially rhetorical construction designed and invoked at various moments and for changing purposes in its various manipulations and inversions of abstraction and embodiment. In the case of AIDS, and as Warner also observes, normal embodiment is the standard for the public and public health, while the diseased body is "exiled ... by such a discourse" (396) in assumptions and images that edify the public sphere.

If we extend Warner's logic of the public sphere to ethics, it follows that the ethic of the body and of normalcy indicative of the public sphere locates ethics, at least spatially, in a sphere that has been predicated upon abstraction and transcendence; thus, there is "no space" for the assumed particularity of what, by default, is assigned to the private sphere. Public ethics are, then, those discourses that authorize the mass subject in all of his neutrality and abstraction; circulated within the public sphere, the mass subject attempts to create an identification of the public with these "norms," while simultaneously alienating the "inadequate particularity of individual bodies" and their attendant ethics (397) with the private spheres. In effect, Warner retheorizes the existing public/private ethics dichotomy I have maintained throughout the dissertation. 
What his work adds to this is an historical reading of how late capitalism has mediated the public sphere. This historical consideration identifies the problem of nonidentification with a mass public as a source of alienation indicative of postmodern culture. I turn now to Patton's specific reading of how the discourse of AIDS continues to capitalize on the characteristic condition of the contemporary public sphere as one of a "double movement of identification and alienation" (397).

In Inventing AIDS, Patton interrogates and destabilizes the medical, pedagogical, and cultural construction of AIDS. One of her major contentions is that the articulation and prevention of AIDS has focused almost exclusively on identifying groups who carry the HIV virus through testing, rather than on a more accurate discussion of a range of sexual acts that transmit HIV. The effect of this emphasis has remained throughout the medical life of the disease. Patton observes that even in its early stages, AIDS testing of blood supplies motivated more attention for surveillance and more accurate testing than any movement for "providing a prophylactic treatment" (36) of AIDS. Her point being that, from the start, the treatment and prevention of HIV/AIDS has focused on disciplinary measures, policing structures, and viral status, rather than on the ways and means of helping to prevent the spread of HIV. She effectively demarcates the problems involved with commuting AIDS as an issue of public health, with the public assumed to have "health" (108) and dangerous HIV+ persons assumed as belonging to communities that are "deviant" and both physically and morally contaminated. In doing so, groups and communities associated with infection, as in the case of the gay and IV drug-using populations when AIDS was first identified, are more easily appropriated and policed by the heaith industry and media. ${ }^{31}$

AIDS testing, the predominant mode of "educating" about the disease, assumes a certain behavioral ethics; the theory behind widespread testing is that seropositive results on an HIV test will change an individual's behavior. Public health and its attendant moral assumption of the public sphere assume that testing results will modify 
sexual ethics. Patton counters this assumption with the fact that there is little viable evidence that definitively establishes changing sexual behavior after a testing event. "There is now general scientific consensus that there is no predictable relationship between knowledge of HIV anti-body status and subsequent behavior change, although policy makers continue to place testing programs at the center of their education and prevention campaigns" (28). Remarkably, the media has overlooked the numerous other studies that suggest high-risk behavior changes occur only within communities whose members are perceived to be both generating and living a positive behavioral sexual ethic. Patton alludes to the example of the San Francisco gay community's strong support for eradicating HIV/AIDS in their politically powerful community; Patton quotes a CDC report that establishes the role of community in generating the kinds of changes that would, as we now know, reduce the rate of $\mathrm{HIV}+$ persons in the San Francisco gay community (30). "The apparent self-evidence of a relationship between behavior and knowledge of anti-body status rests on the assumption that drug use and sexuality are most importantly individual behaviors, ignoring the social norms and symbolic meanings that determine how sex is practiced or drugs are used" (29). Thus an educational program that is directed at examining risk behaviors rather than risk groups would implicitly work toward displacing the stigma associated with "those groups" identified in the media to have a high incidence of $\mathrm{HIV}+$ men and women. The relationship between behavioral ethics and community identification will be increasingly important in light of the private/public demarcations that are consistently made on questions of ethics.

The focus on the testing event has created an identity of other for those who are infected with HIV. The "people rather than acts" (48) and "testing event" approaches to AIDS education only make for the easy identification of those who are assigned social blame, who, because they are associated with a certain deviant group, are already subject to the moral judgments made about membership or affiliation with these groups. 
It also paves the way for legislation like the Helms Amendment (1987) "[which] forbids AIDS funding to projects which 'promote homosexuality,' which has been construed to include any gay-positive material" (40). Patton likens the penchant for testing to a sexual colonization by creating an other of the "AIDS world" (108) to be tolerated by those "health imperialists" (108) who do not have AIDS. When constructed in this way, AIDS education has the ability to "reinscribe. . . the sexual, class, and racial ideologies that are propped up by moralism and science" (105) by merely replacing these categories with greater and lesser values of positive and negative (41). The value ascribed to positive and negative persons is thus further criss-crossed with the ideological and political constructions of race, class, and gender. In addition, and in light of Warner's discussion, serostatus produces the anxiety of knowing one either belongs to the public sphere of health, in all of its abstract manifestations, or with the alienation and exile of belonging to a colony of others who are, despite their exclusion from the public sphere, expected to adhere to a whole range of behavioral ethics, beginning with the public event of testing.

Aside from discussing the construction of HIV/AIDS in terms of the other, as well as the ethical foundation for the continual reinscription of this marginalization, Patton looks to the use of media in (mis)educating and edifying the longstanding assumptions of sexuality and disease. At the same time, she provides a framework for a classroom examination of the various media that situate students as subjects of / to the discourses on AIDS. What I want to take from her work and highlight in my own, is the fundamentally ethical assumptions and selves created by, in particular, the advertising for home-testing. Patton advocates an examination of the ways in which groups and individuals field AIDS information as disseminated through the media. She advocates an explicit emphasis on how "group and individual media use and secondary discussions" (31) reflect the ways in which the uses of media depend upon perceptions of AIDS. Notably, Patton endorses a rhetorical look at the ways in which subjects, as 
individuals and community members, use information on HIV/ ADS; she calls this emphasis "the individual and group interpretive practices of the people to whom media information is directed" (31). She also observes that AIDS education is reaching those who need it the least; that is, it is focusing on those who are good learners, not those populations and communities that are ravaged by poverty and illiteracy (44). Her rhetorical emphasis leads her to ask for solutions to misinformation, or the lack thereof, that would cater to the different communities who need AIDS education. For example, and keeping in mind her understanding of behavior change occurring within groups who have made safe-sex a positive part of the group identity, she argues that different groups, especially groups in poor or rural communities, need an educational apparatus that speaks to the unique forces that bind them. Finally, I think the way in which Patton discusses how individuals and groups are constructed as knowledge consumers assumes some of the same ways Foucault envisions the process whereby subjects are called upon to act ethically, responsibly, and consciously in line with a whole set of practices designed to insure certain types of behaviors, a particular style of life. The problem with such an examination is that it yields a multitude of responses, all of which depend upon the media's entrenched identification of AIDS with "high risk groups" rather than specific sexual acts

The effect of constructing "deviant" groups has had a detrimental effect on the call for the straight population to heed the dangers of HIV transmission through unsafe sex. Because AIDS has historically been tied to groups, rather than risky behavior, most heterosexuals had and still have a difficult time integrating AIDS into the list of possible sexually transmitted diseases to avoid. My predominantly heterosexual students generally do not perceive AIDS to be a major concern of theirs. While they espouse safe sex in all they do and say, most of them, even against their better judgment and knowledge of transmission, are subject to the dominant logic that equates seropositive status with a responsibility for safety (100), a move that assumes that the test alone will 
be responsible for changing an individual's behavior. Patton also observes that "many people have difficulty associating transmission promoting acts with the people they love and trust" (100). Because of this, safe-sex practices are "adopted or rejected based on known or perceived serostatus of the partner or the quality of feelings of trust, rather than universal adoption of practices to prevent transmission" (100). To combat transmission, safe sexual practices, and not the mere identification of HIV+ persons, should be endorsed in AIDS education.

The testing-event logic of HIV prevention is replicated in the media images designed to sell the concept of home testing. Moreover, testing as self-diagnosis is of limited value, as HIV-Antibody+ results do not necessarily mean that one has AIDS (30). Patton also makes the acute point that "similarly complex illnesses like cancer, multiple sclerosis, or arthritis" (30) would never be packaged as a quick home test because of the need for interpretation and counseling (30); counseling is offered, however, with both home tests I surveyed for this project. What Patton's discursive analysis makes clear and what Foucault's four modes provide is both a timely subject for an investigation of private and public ethics as well as a means of studying ethics and subjectivity critically.

\section{(Re)Inventing Ethics in the Classroom}

The project I am designing begins by surveying the range of texts within the discourses of public health that are made available to students. After initially asking students what their perceived risks are of contracting HIV, where they have received this perception of risk, and how they have responded to it, I would send them to health services to canvass the information available to them. After initially engaging questions of transmission, the construction of "high risk" groups, and the ethical issues raised by the discourses of AIDS, I would then move the discussion to media representations of AIDS through the analysis of commercials and print advertising promoting the home 
test. These advertisements are effective for most of my students in that they specifically address heterosexually-identified populations. The goal here would be to get students to reflect self-consciously on their interpretive practices in reading advertising that targets a group to which they belong. This starting point reflects Foucault's identification of "ethical work," in terms of how these groups are called upon to be knowledge consumers and positioned ethically in relationship to the testing event and assumed behavioral changes.

In tandem with an analysis of the various media circulating around AIDS and HIV testing, students will write a three-part rhetorical analysis in which they present the arguments that surround the call for testing. For example, students will examine three different groups or voices on the issue: 1 ) those of public health; 2) consumer media, such as commercials, print advertising, school-sponsored literature; and 3) the ethical discourses that make testing a question of personal responsibility, drawing on their personal experiences and impressions of AIDS as an ethical issue based on religious, familial, and social messages about sexuality and sexual ethics. The purpose of such an approach is to have students engage critically with these three major positions and study their arguments in terms of how audiences are "subjected" to the call for testing without actually maintaining a position themselves. Once they have identified three major positions, they will then analyze the arguments and presentations made with a clear rhetorical focus, identifying strategies used and appeals made to present positions. The final component of this project is to have students put together their own educational apparatus for teaching about HIV and the value of testing, one that targets a wide-range of student audiences, and one that I hope will reflect their understanding of the misconceptions surrounding testing-as-prevention.

In many ways, the advertising for home testing inscribes the very constructions of health and disease and private and public ethics that Patton describes. In one commercial for "Home Access" the "domestic" scene of HIV+ status is readily 
perceived in contrast to notions of public health and "okayness." As a result, these commercials work toward entrenching questions of public and private, shifting the responsibility for transmission, not to a public sphere where acts rather than persons can be discussed, but to an individual's responsibility to know their HIV status and behave accordingly. One of the series of "Home Access" commercials takes place in that locus of health, the co-ed gym, where very muscular, "healthy-looking" individuals are slowly drawn from their workouts to a television screen in the center of the room. The object of their curiosity is the commercial advertising "Home Access." Potential consumers are directed to the phone number and the accepted credit cards through which to purchase this product; after home testing, they can send in their results, call five days later, and receive their results. After this message, the camera focuses on a man and a woman who after looking quite introspective about their HIV status, glance at each other with knowing looks and nod in assent to the call for testing, assuming their positions as ethical subjects to this call. Another in the "Home Access" series focuses on a single white female who is persuaded by the voice over that she should be HIV tested. We remain with her during her days of wondering what the test results will be, when, at the moment she phones for her negative results, she breathlessly says, " $\mathrm{I}$ 'm okay." There is no indication that any behavioral changes will be taken to insure continued seronegative status.

To be infected, then, is to be associated with an undesirable group; public health is maintained in the example of the "Home Access" commercial because the single white female, as well as the people at the gym, are privately engaged in home testing, the results of which will be dealt with in the personal recesses of their own emotional support networks. Nevertheless, even though Patton is highly suspect of the goals of home testing, I think we might read the proliferation of home tests as a reaction to the policing effect that the testing campaign has had on the larger culture. Because HIV test results may be reported to insurance companies and the $C D C$, there is the fear that such 
testing is never entirely private. Moreover, the arrival of home testing confronts the public/ private confusion that HIV testing fundamentally raises. What home testing reinscribes is belief that questions of sexuality are for the individual and not associated with any social organization of sexuality (Patton). Furthermore, testing is more often used as a process of surveillance and disease control rather than an event that marks the adoption of safer sexual practices. In light of this, we might consider the sale of another home test, Confide--and we could easily re-label this product "confess"--not in terms of maintaining an individual's right to privacy but a public policing of the private sphere. Combined with conservative moralism about sexuality, the testing event becomes an individual's solution to staving off a "public" epidemic that risks exploding the association of private the private sphere, sexuality, and individual choice. The "panoptic space" (McLaren 67) created by the discourse on AIDS temporarily confuses and questions the very demarcation of private and public without actually undermining these demarcations. For example, in the case of home-testing we meet the reinscription of this demarcation of public and private as these spheres are bound up with associative values of health, disease, and deviance. Add to this the commodification of HIV home-testing as a "private sector" product and we are again well within the confusing dualism of "private industry" and the private sphere, but one that serves to edify the entrenched notion of sexuality and individual behavior. As I discussed in an earlier example of ethics and private industry, such a move to align the private sphere and individual choice not only maintains public/private dichotomies, but it also helps to solidify the home-testing industry in its identification with the private citizen and her right to know.

The call for home testing constructs the ethical subject in a variety of ways. For my students, the ethical substance revolves around the question of HIV testing: To test or not to test? The question thus posed makes an ethical determination of the subject's relationship to knowledge, a knowledge that will further ask him or her to exercise 
certain practices of the self. The mode of subjection would have the heterosexual audience see themselves represented in the advertising for testing because they may, after repeated viewing, identify not only with the heterosexual population identified in the advertisement, but also with the inscription of public health. Ethical work would include those practices that an individual performs--or refuses to perform--in response to being called upon as an ethical subject of and to AIDS. The ethical work is perhaps the most obvious mode of subjection as the subject works "to bring one's conduct in line with a given rule" (The Use of Pleasure 27). But ethical work is not to change behavioral ethics, but to answer the call for testing. Finally, the ethical telos would have subjects complete the ethical work of testing in the goal of being and remaining HIV-. Once again, Patton's contention that the focus on the testing event does more to transmit the virus than to prevent it comes full circle in the Foucauldian paradigm.

This initial mapping of a Foucauldian ethics through the issue of HIV testing is still in its early stages. What it does provide already, though, is a way of talking about both ethics and politics in the classroom: Our commitment to political pedagogies is maintained in the examination of cultural texts that survive on concealed relationships of knowledge and power. In terms of ethics, we meet a pedagogy that does not replicate prescriptive moralities by asking students to apply unexamined ethical norms to random dilemmas requiring ethical decision-making. Rather, they are asked to look critically at the ways in which ethical norms act upon them as well as call upon them to act as ethical subjects. In short, the critical ethics offered through Foucault provide a very specific range of questions to be asked of students who, in turn, can apply these questions to the study of the self within the issue of HIV testing; using the self as a site for ethical examination moves us away from judging persons and behaviors to a selfconscious attempt to look at how ethical discourses construct subjectivity in terms of health and disease. Finally, the issue of HIV testing alone is suspended in the tenuous position between the public and private spheres, a positioning that allows us not to 
argue for a merging of these spheres in a naive attempt to reconcile this dichotomy, but to understand how ethics circulates within a complex economy of the private and public.

\section{Notes}

${ }^{1}$ Here the term will be used to demarcate a broadly defined cultural change of the postmodern from the historical epoch of modernism. In my usage of postmodernism, I include poststructuralism under this rubric; however, I distinguish the latter in its specific address of discourse and signification. For the purpose of simplicity and to avoid repetition, I have chosen to use only postmodernism to describe both the condition of this historical period as well as the body of theory and inquiry that has issued from and about this "movement." I agree, however, with Edward Soja's hesitation to see a clean break with or replacement of modernity in the postmodern (5). Rather, he observes the postmodern is a "deep and broad restructuring of modernity" (5). Indeed, the goal of political transformation and emancipation so crucial to Englightenment thought finds its legacy in both critical and postmodern theory. In the work of Habermas and Lyotard, we see the renewed and "restructured" goals of the Enlightenment cast into foundationally -opposed but theoretically-joined projects.

${ }^{2}$ I observe key distinctions between Foucault's early work on subjectivity and his later turn toward the self in Hellenistic philosophy. What Davidson and Dreyfus and Rabinow make clear is the distinction we should make between Foucault's earlier work on subjectivity and his later turn to Greek ethics and the self. In other words, the distinctions these critics make attempt to explain how Foucault's late work should not be read: we should not read it as the development of a theory of subjectivity. To do so would open up the seemingly contradictory and inconsistent use of the self as distinct from the subject. In contrast to this warning, this is exactly how I will read Foucault's late work-not to point out inconsistencies in his theory, but to highlight the fundamental problems of theorizing subjectivity and ethics. I am working, then, on the description Gary Gutting gives of Foucault as an "[historian] of the present" (14). If 
we agree with this characterization--and I do- then we can draw a conclusion about what Foucault was doing in this late work, especially because Gutting qualifies that such histories deal with "subject matter [that] corresponds to some contemporary ideas and practices that he finds especially dangerous" (14). Foucault's work on ethics attempts to interrogate the moral tyranny imposed by humanism, rationality, and normative ethics. However, if Foucault, as an historian of the present, was working on locating Greek ethics within a history of the subject, then I think it is safe to assume he was equally fascinated and frustrated with a current problem of reconciling ethics and the subject-because ethics invariably forces us to talk about subjectivity.

${ }^{3}$ I am referring to Thomas Flynn's “Foucault as Parrhesiast: His Last Course at the College de France" from The Final Foucault.

"Algra distinguishes topos as a "space when it is occupied by a body (i.e. place)" (38).

${ }^{5}$ My use of tactic in this and all chapters derives from Michael de Certeau's distinction between tactic and strategy discussed in the introduction to The Practice of Everyday Life. De Certeau names the structural differences between tactics and strategies, aligning strategies with institutional practices of resistance. Since they assume fixed places from which to act, strategies are tied to the very locations from which they derive; institutions "serve as the basis of generating relations with an exterior distinct from it" (xix). In a sense, strategies are like the practices available under the structure-agency model that I discussed earlier, a model that has limited use in this discussion as a descriptor of political and social relations.

Not suprisingly, tactics are spatial, according to de Certeau's concept of space as changeable, unstable, and defined by the practices that occur within it; place, on the other hand, is a "distinct location" (117) from which strategies are generated. Tactics are appropriate for my discussion of Cynic and feminist rhetorics in chapters two and three because, like the spatial positions of speakers "in exile," tactics describe a logic of action that have "at [their] disposal no base where [they] can capitalize on [their] advantages" (xix). Rhetorical tactics are bound to speech contexts; they are "always on the watch for opportunities that must 
be seized 'on the wing'" (xix), as in the example of Diogenes of Sinope, whose reputation was based upon his tactical, and often insurgent responses. Reactionary and disruptive, tactics describe the logic of actions used by "the weak" who must plot and seize discursive moments. Tactics also do not pretend to any revolutionary goals for "[w]hatever it wins, it does not keep" (xix). Distinctly kairotic, tactics are aware of the intersection of time and space: Opportunities are "achieved in the propitious moments when they are able to combine heterogeneous elements. . ;the intellectual synthesis of these given elements takes the form, however, not of a discourse, but of the decision itself, the act and manner in which the opportunity is 'seized'" (xix). Thus the logic of decision-making and reaction creates a tactical rhetoric, not the discourse itself. Rhetoric is an effect of the discursive constraints and "heterogeneous elements" of a given situation.

${ }^{6}$ I am appropriating the conclusions drawn in Peter Sloderdijk's analysis of the ethical shift in Cynic philosophy. He sees a distinct shift from norm-driven statements of "ought" and "should" to the philosophically transgressive opportunity of "can" when deciding upon ethical choices. While Lyotard does share some theoretical similarities with the early Cynics, my emphasis here regards the rhetorical possibilities and implications of the shift from imperative to choice in Lyotard.

${ }^{7}$ A key distinction between critical theory and postmodernism is how each school approaches modernity: Critical Theorists do not acknowledge that the moment of the postmodern is taking place; rather, they wish to recupuerate and continue some of goals of the Enlightenment:.

Postmodernists, such as Lyotard, find that we are living a distinctly different moment, one that demands different ways of reading and representing reality. This is, of course, a gross oversimplification of the complex distinctions between critical theory and postmodern theory, but this demarcation helps to position the project of normativity and justification in fundamental terms.

${ }^{8}$ As discussed in Best and Kellner, Adorno and Horkheimer's Dialectic of Enlightenment responds to "the ways that reason turned into its opposite and produced new rationalized forms 
of social domination" (218). This is an oversimplification of what exactly is going on in this text; however, it does give some sense of what Adorno and Horkheimer were responding to. Habermas, while remaining within the tradition of critical theory, does not take as stark a view of the direction of contemporary culture and advanced capitalism. To this end, Habermas, while rejecting technological action and the negative potential of scientific rationality, supports the symbolic action of communication and argument (Poster 460-461). In my reading, his basis for the "essential" impartiality of the ideal speech situation rests in formal rules of logic, a system of reasoning that is quite unlike real speech situations, and one that risks the hyper-rationality embedded in advanced technology.

${ }^{9}$ Chaim Perelman in The New Rhetoric: A Theory of Practical Reasoning, offers a similar theory of moral justification as that of Habermas, albeit one derived from a different tradition. Unlike Habermas, though, Perelman identifies rationality within the realm of empiricism and formal logic. The new rhetoric involves argument as its central model while it excludes formal logic; the reasonable as well as the task of finding good reasons is the realm of this rhetoric. From this philosophical basis, Perelman goes on to analyze the important rhetorical considerations of audience in his theory of argumentation.

${ }^{10} \mathrm{~A}$ central criticism of Habermas's Moral Consciousness and Communicative Action is that it does not ground the procedure for testing the validity of norms in an historical framework. Unlike the very historical and contextual reading of the public sphere in The Structural Transformation of the Public Sphere MoralConsciousness offers a very ahistorical procedure for communicative ethics.

${ }^{11}$ Kinneavy discusses the importance of continued interpretation and study of kairos. But aside from a smattering of articles and the historical insights of Untersteiner, suprisingly little has issued from such a rich concept. There is some demonstrated interest in communications studies, in particular, work on kairos in religious and evangelistical discourse. 
${ }^{12}$ In their recent article, Kinneavy and Eskin locate an Aristotelian use of kairos. Kairos is generally traced back to the Sophists; however, Kinneavy and Eskin attempt to add Aristotle to the tradition of kairos.

${ }^{13}$ According to Malherbe, the letters of both Diogenes and Crates were not actually written by them, at least not the extant manuscripts. The letters are the product of possibly several authors, and some can be dated as late as the second century A.D. This would help to explain the increasing assimilation of Cynicism with Christianity.

${ }^{14}$ As I will discuss later in this section, parrhesia shifted during the Hellenistic period from a political practice to a philosophical one. In my tracing of its different uses, parrhesia varied in meaning from simple impudence to the civil right of freedom of speech.

${ }^{15}$ This polarization is intended to highlight Plato's distrust of democracy and how such suspicion might influence his appropriation of parrhesia. For the record, Plato supported the abolition of slavery and allowed for some movement between social classes. "Even if such a State were capable of realization, it is too unnatural a thing to bring good results. From the first Plato saw that no community would voluntarily adopt it, and in his old age substituted a more workable political system in one of his latest writings, the Laws. The chief value of the Republic lies in its individual suggestions as to educational, social and political reforms" (Botsford 440).

${ }^{16} \mathrm{I}$ am inverting the hierarchy Relihan constructs in Ancient Menippean Satire. Rather than reading Menippean satire as the umbrella for several "sub-genres" of parody, I am using parody as the term that houses the Cynic genres, including satire.

${ }^{17}$ Hutter identifies two kinds of pleasures, a primary one "associated with the mere movements of being alive" (122), and a secondary one in the pleasure that is gained through the "incorporation of objects" (122). In his interpretation, askesis is used as a therapy to secondary pleasures. This reading tends to come too closely to a Christian sense of asceticism as a remedy for materialism. I am reading the dissonance between Cynic practice and asceticism as a strategic contradiction. 
${ }^{18}$ I do not want to suggest that the experience of exile is always operative or attractive. This would overlook the very real, painful conditions of exile that exist for people all over the world. There is also a great difference between self-imposed and forced exile, as well as physical and mental exile. I agree with Jane Marcus that there is indeed an "ethic to the study of elsewhereness" (275) that must be taken into account as we argue about these issues intellectually. My purpose in using exile is only to offer a location that has historically and politically held great deal of potential for resistance.

${ }^{19}$ In Women in Hellenistic Egypt Sarah B. Pomeroy distinguishes the citizenship rights available to women. "Although women as citizens did not enjoy political rights in a modern sense, they did have civic status. According to Aristotle's definitions, citizenship does not entail only the right to rule, hold political offices, and administer justice, but it also can include upholding the laws made by those in power and submission to being ruled. Greek women, as citizens, belonged to the latter category" (46-47).

${ }^{20}$ To my knowledge, Susan C. Jarratt and Nedra Reynolds' chapter "The Splitting Image: Contemporary Feminisms and the Ethics of ethos" is the most explicit address of ethics, rhetoric, and feminism. They argue that feminist theory can inform a new understanding of ethical $e$ thos, one that provides for a viable sense of agency and the subject as well as responsibility toward difference.

${ }^{21}$ Nedra Reynolds makes an earlier and similar move in arguing for ethos as location in "Ethos as Location: New Sites for Discursive Authority." Diprose, however, develops further the concrete connections between ethos and embodiment.

${ }^{22}$ Foss, Sonja K. and Cindy L. Griffin, "A Feminist Perspective on Rhetorical Theory: Toward a Clarification of Boundaries, " Western Journal of Communication 56 (1992): 331-349.

${ }^{23}$ Gearhart, Sally Miller, "The Womanization of Rhetoric," Women's Studies International Ouarterly 2 (1979): 195-201. 
${ }^{24}$ Flynn, Elizabeth A. "Composition Studies from a Feminist Perspective," The Politics of Writing Instruction: Postsecondary, Eds. Richard Bullock and John Trimbur, Portsmouth: Heinemann, 1991.

${ }^{25}$ I am referring here to Iris Young's definition of justice which critiques a longstanding distributive model. Young contends that thinking justice only in terms of doling out equal goods overlooks the need for deep institutional change and makes recipients passive. Her definition of justice concerns the commitment to eradicating oppressive conditions.

${ }^{26}$ In Women Teaching for Change: Gender, Class \& Power Kathleen Weiler distinguishes between critical and feminist pedagogies. Critical pedagogy informed by Antonio Gramsci and Paulo Freire seeks to understand schooling as a fundamentally political process shaped by the hegemony of powerful ideological and class interests. Weiler's project seeks to join the insights of critical pedagogy with feminist theory. "While critical educational theorists have been concerned with the production and reproduction of class through schooling under capitalism, feminist theorists have been concerned with the production and reproduction of gender under a system of patriarchy" (3). Her work serves as a model for those working within rhetoric and composition to build a bridge between critical pedagogy and the concerns of feminist theory. I retain an initial distinction between critical and feminist pedagogy here to account for the different emphases in various approaches. To avoid unecessary repetition, I will hereafter refer to both as politicized pedagogies.

${ }^{27}$ Teresa Henning makes a similar argument in "Resisting Ethical Paralysis: A Postmodern Critique of Ethics." She observes a rather unproductive trend in composition studies to reproduce the dominant political culture's emphasis on generating normative ethics rather than stimulating discussions of ethics. To remedy this, she offers a very general admission of Foucault's ethics of the self as a way of shifting dialogue from judgments of right and wrong to questioning how the self becomes a moral subject. 
${ }^{28}$ Bruce Herzberg, "Community Service and Critical Teaching," College Composition and Communication 45 (1994): 307-319.

${ }^{29}$ Brook Thomas, "Constitutional Literacy: Plessy and Brown in the Writing Class," College English 58 (1996): 637-653.

${ }^{30} \mathrm{My}$ point here is simply to point to the reality of Aristotelian community, one that included only free-born, propertied males. Because of this, I think we need to be skeptical, although not dismissive, of Aristotelian models of discourse situated within this assumption of a democratic polity.

${ }^{31}$ In "HIV Testing on Campus: The Next Step," Joanna Hayden, Assistant Professor of Community Health at William Patterson College, repeats the same health/disease dichotomy that Patton observes. Her report studies the advantages of offering HIV testing on a suburban college campus. What is most interesting about the testing project is that students who tested positive for HIV were not notified of their results at campus health services, where trained counselors were available for all other students who were tested. They had to report to the health department to receive their results, even after students were given the option of receiving their results on campus or at the health department. Testing protocol, according to Hayden, determined that any HIV+ students were to be identified at the health department, assumedly even when students requested that they receive their results on campus. Hayden attributes the change in initial testing protocol as a decision made, not by the individual who tests HIV+, but by personnel and the program coordinator who felt that "Igliven the emotional state of individuals after receiving notification of sero-positivity" (210), students would need to be notified by the health department. In effect, such a shift from initial testing procedures, as well as the complete overrule of students' choices results in the students' loss of privacy. The assumption here is that, by becoming infected, they no longer have the right to privacy given to those with HIV-status. However, they are no longer associated with the abstract, universal good of "public health." They lose their right to privacy and individual choice, the two 
enduring qualities of the private sphere. Their private behaviors become everywhere legislated publicly. 


\section{Bibliography}

Ainely, Alison. "The Subject of Ethics: Kierkegaard and Feminist Perspectives on an 'Ethical' Self." The Oxford Literary Review 11:1-2 (1989): 169-188.

Algra, Keimpe. Concepts of Space in Greek Thought. Ed. J. Mansfield. Philosophia Antiqua Series 65. New York: E.J. Brill, 1995.

Allen, Julia M. and Lester Faigley. 'Discursive Strategies for Social Change: An Alternative Rhetoric of Argument." RhetoricReview 14.1 (1995): 142-172. Aristotle. The Nichomachean Ethics. Trans. J.A.K. Thomson. London: Penguin, 1976.

Bammer, Angelika. "The Woman Question--And Some Answers." The Philosophy of Discourse: The Rhetorical Turn in Twentieth-Century Thought. Vol. 2. Eds. Chip Sills and George H. Jensen. Portsmouth: Boynton/Cook Publishers, 1992. 235-264.

Baumlin, James. "Decorum, Kairos, and the 'New' Rhetoric." Pre/Text 5: 3-4 (1984): 171-181.

Benhabib, Seyla. Situating the Self: Gender, Community and Postmodernism in Contemporary Ethics. New York: Routledge, 1992.

Bernstein, Richard. "Foucault: Critique as Philosophical Ethos." Critique and Power: Recasting the Foucault/Habermas Debate. Ed. Michael Kelly. Cambridge: MIT Press, 1994. 211-241.

Best, Steven and Douglas Kellner. Postmodern Theory: Critical Interrogations. New York: Guilford Press, 1991.

Biesecker, Susan. “Rhetoric, Possibility, and Women's Status in Ancient Athens:

Gorgias' and Isocrates' Ecomiums of Helen." Rhetoric Society Quarterly 22: 1 (1992): 99-108.

Bizzell, Patricia. "Marxist Ideas in Composition Studies." Contending with Words: Composition and Rhetoric in a Postmodern Age. Eds. Patricia Harkin 
and John Schlib. New York: The Modern Language Association, 1991.

$52-68$

-. "The Politics of Teaching Virtue." ADE Bulletin 103 (1992): 47.

Bordo, Susan. "Feminism, Postmodernism, and Gender-Skepticism." Feminism/

Postmodernism. Ed. Linda Nicholson. New York: Routledge, 1990. 133-156.

Botsford, George Willis. HellenicHistory. New York: Macmillan Company, 1934.

Branham, R. Bracht. "Defacing the Currency: Diogenes's Rhetoric and the Invention of Cynicism." Arethusa 27 (1994): 329-359.

--. Unruly Eloquence: Lucian and the Comedy of Traditions. Cambridge: Harvard University Press, 1989.

--. "Utopian Laughter: Lucian and Thomas More." Moreana 86 (1985): 23-43.

Burke, Kenneth. The Rhetoric of Religion. Boston: Beacon Press, 1961.

Calhoun, Craig. "Introduction: Habermas and the Public Sphere." Habermas and the Public Sphere. Ed. Craig Calhoun. Cambridge: MTT Press, 1992. 1-48.

Cantarella, Eva. Pandora's Daughters: The Role of Women in Greek and Roman

Antiquity. Trans. Maureen B. Fant. Baltimore: Johns Hopkins University Press, 1987.

Carter, Michael. "Stasis and Kairos: Principles of Social Construction in Classical Rhetoric." RhetoricReview 7 (1988): 97-112.

de Certeau, Michel. The Practice of Everyday Life. Trans. Steven Rendall. Berkeley and Los Angeles: University of California Press, 1984.

Charland, Maurice. "Norms and Laughter of Rhetorical Culture. Quarterly Journal of Speech 80 (1994): 339-342.

Corbett, Edward P.J. "The Rhetoric of the Open Hand and the Rhetoric of the Closed Fist, 1969." Selected Essays of Edward P.J. Corbett. Ed. Robert J. Connors. Dallas: Southern Methodist University Press, 1989. 99-113.

Cornell, Drucilla. "What is Ethical Feminism?" Feminist Contentions: A Philosophical 
Exchange. New York and London: Routledge, 1995. 75-106.

Deane, Seamus. "Imperialism/Nationalism." Critical Terms for Literary Study. 2nd.

Ed. Eds. Frank Lentricchia and Thomas McLaughlin. Chicago: University of Chicago Press, 1995. 354-368.

Deleuze, Gilles. "Foldings, or the Inside of Thought (Subjectivation)." Kelly 312-346.

Demosthenes. Demosthenes. Ed. E.H. Warmington. Trans. J.H. Vince. London: William Heinemann Ltd., 1970. 7 vols.

DeMott, Benjamin. "Seduced by Civility: Political Manners and The Crisis of Democratic Values." The Nation 9 December 1996: 11-19.

Diprose, Rosalyn. The Bodies of Women: Ethics, Embodiment, and Sexual Difference. London and New York: Routledge, 1994.

Diprose, Rosalyn and Robyn Ferrell. "A genethics that makes sense." Cartographies: Poststructuralism and the Mapping of Bodies and Spaces. North Sydney: Allen \& Unwin, 1991.

Dreyfus, Hubert L. and Paul Rabinow. Michel Foucault: Beyond Structuralism and Hermeneutics 2nd. ed. Chicago: University of Chicago Press, 1983.

Dudley, Donald R. A History of Cynicism: From Diogenes to the 6th Century A.D. London: Methuen \& Co. Ltd., 1937.

Dugger, Celia W. "Women's Plea for Asylum Puts Tribal Ritual on Trial." New York Times 15 April 1996, natl. ed.: A1 \& A12.

Ebert, Teresa. "The 'Difference' of Postmodern Feminism." College English 53 (1991): 886-904.

--- "For a Red Pedagogy: Feminism, Desire, and Need." College English 58 (1996): 795-819.

Edwards, Robert. "Exile, Self, and Society." Exile in Literature. Ed. Maria-Ines Lagos-Pope. London and Toronto: Associated University Press, 1988. 15-31. Epictetus. The Discourses as Reported by Arrian, The Manual and Fragments. Trans. 
W.A. Oldfather. Vol. 2. London: William Heinemann Ltd., n.d. 2 vols. Flax, Jane. "Beyond Equality: Gender, Justice and Difference." Beyond Equality and Difference: Citizenship, Feminist Politics, and Female Subjectivity. Eds. Gisela Bock and Susan James. London: Routledge, 1992. 193-210.

Flynn, Thomas. "Foucault as Parrhesiast: His Last Course at the College de France (1984)." The Final Foucault. n.p. MIT Press, 1991. 102-118.

Foucault, Michel. The Care of the Self. Volume 3 of The History of Sexuality. Trans. Robert Hurley. New York: Pantheon Books, 1986.

-. The History of Sexuality. Vol. 1: An Introduction to The History of Sexuality.

Trans. Robert Hurley. New York: Vintage Books, 1978.

-. from "The Order of Discourse." The Rhetorical Tradition: Readings from Classical Times to the Present. Eds. Patricia Bizzell and Bruce Herzberg. Boston: Bedford Books of St. Martin's Press, 1990. 1154-1164.

--. "Questions on Geography." Power/Knowledge: Selected Interviews and Other Writings, 1972-1977. Ed. Colin Gordon. Trans. Gordon et. al. New York: Pantheon Books, 1980. 63-77

--. Technologies of the Self: A Seminar with Michel Foucault. Eds.

Luther H. Martin, Huck Gutman, and Patrick H. Hutton. Amherst: The University of Massachusetts Press, 1988.

--. The Use of Pleasure. Vol. 2 of The History of Sexuality. Trans. Robert Hurley. New York: Vintage Books, 1990.

--. "What Is an Author?" Language, Counter-Memory, Practice: Selected Essays and Interviews with Michel Foucault. Trans. Donald F. Bouchard and Sherry Simon. Ed. Donald F. Bouchard. Ithaca: Cornell University Press, 1977. 112-138. Fraser, Nancy and Linda J. Nicholson. "Social Criticism without Philosophy: An Encounter between Feminism and Postmodernism." Nicholson 19-38. Frentz, Thomas S. "Rhetorical Conversation, Time, and Moral Action." The 
Quarterly Journal of Speech 71 (1985): 1-18.

Freud, Sigmund. Jokes and Their Relation to the Unconscious. Trans. James

Strachey. New York: W.W. Norton \& Company, Inc., 1963.

Friend, Christy. "Ethics in the Writing Classroom: A Nondistributive Approach."

College English 56 (1994): 548-567.

Gatens, Moira. Imaginary Bodies: Ethics, Power and Corporeality. New York and

London: Routledge, 1996.

Gilligan, Carol. In a Different Voice: Psychological Theory and Women's Development

1982. Cambridge and London: Harvard University Press, 1993

Glenn, Cheryl. "Remapping Rhetorical Territory." RhetoricReview 13 (1995): 287-

303.

Grosz, Elizabeth. "Women, Chora, Dwelling." Postmodern Cities \& Spaces. Eds.

Sophie Watson \& Katherine Gibson. Cambridge and London: Basil

Blackwell, 1995. 47-58.

Gutting, Gary. "Michel Foucault: A User's Manual." The Cambridge Companion to

Foucault. Ed. Gary Gutting. Cambridge: Cambridge University Press, 1994. $1-27$.

Habermas, Jürgen. Moral Consciousness and Communicative Action. Trans. Christian

Lendhardt and Shierry Weber Nicholsen. Cambridge: MIT Press, 1990.

--- The Structural Transformation of the Public Sphere: An Inquiry into a Category

of the Bourgeois Society. Trans. Thomas Burger with the assistance of

Frederick Lawrence. Cambridge: The MTT Press, 1989.

Hairston, Maxine. "Diversity, Ideology, and Teaching Writing." College Composition and Communication 43 (1992): 179-193.

Harpham, Jeffrey. "So ... What is Enlightenment? An Inquiry into Modernity."

Critical Inquiry 20 (1994): 524-56.

Hartsock, Nancy. "Foucault on Power: A Theory for Women?" 
Feminism/Postmodernism Ed. Linda J. Nicholson. New York: Routledge, 1990. 157-175.

Harvey, David. The Condition of Postmodernity: An Enquiry into the Origins of

CulturalChange. Cambridge and Oxford: Blackwell Publishers, 1990.

Hayden, Joanna. "HIV Testing on Campus: The Next Step." Journal of College StudentDevelopment 35 (1994): 208-211.

Henning, Teresa. "Resisting Ethical Paralysis: A Postmodern Critique of Ethics."

Conference on College Composition and Communication. Washington, D.C., 23 March 1995.

Herodotus. Herodotus. Ed. G.P. Goold. Trans. A.D. Godley. n.p. n.d. 4 vols.

Herrick, James. "Rhetoric, Ethics and Virtue." CommunicationStudies 43. 3 (1992): 133-149.

Hoagland, Sarah Lucia. "Some Thoughts about 'Caring," Feminist Ethics. Ed.

Claudia Card. Lawrence: University Press of Kansas, 1991. 246-263.

Hodge, Bob and Alan Mansfield. "Nothing left to laugh at...': humour as a tactic of resistance." Language and the Nuclear Arms Debate: Nukespeak Today. Ed. Paul Chilton. Dover: Frances Pinter Publisher, 1985. 197-211.

Hutter, Horst. "With the 'Nightwatchman of Greek Philosophy': Nietzsche's Way to Cynicism." Nietzsche and the Rhetoric of Nihilism: Essays on Interpretation, Language, and Politics. Ottowa: Carleton University Press, 1989. 117-132. Isocrates. Antidosis. Vol. 2 of 3 Volumes. Trans. George Norlin. Cambridge and London: William Heinemann Ltd., 1968. 181-365.

--. Busiris. Trans. Vol. 3 of 3 Volumes. Trans. Larue Van Hook. Cambridge and London: William Heinemann Ltd., 1968. 100-131.

Jarratt, Susan C. and Nedra Reynolds. "The Splitting Image: Contemporary Feminisms and the Ethics of ethos." Ethos: New Essays in Rhetorical and Critical Theory. 
Eds. James S. Baumlim and Tita French Baumlim. Dallas: Southern Methodist University Press, 1994. 37-63.

Jarratt, Susan C. "Feminism and Composition: The Case for Conflict." Contending with Words: Composition and Rhetoric in a Postmodern Age. Eds. Patricia Harkin and John Schlib. New York: The Modern Language Association of America, 1991. 105-123.

--- Rereading the Sophists: Classical Rhetoric Refigured. Carbondale and Edwardsville: Southern Ilinois University Press, 1991.

Jolliffe, David A. "The Moral Subject in College Composition: A Conceptual Framework and the Case of Harvard, 1865-1900." College English 51 (1989): 163-173.

Jones, Ann Rosalind. "Writing the Body: Toward an Understanding of $l$ 'Ecriture Féminine." Feminisms: An Anthology of Literary Theory and Criticism. Eds. Robyn R. Warhol and Diane Price Herndl. New Brunswick: Rutgers University Press, 1991. 357-370.

Joyce, James. A Portrait of the Artist as a Young Man. New York: Viking Press, 1969. Junker, Clara. "Writing (with) Cixous." CollegeEnglish 50: 4 (1988): 424-436.

Kaplan, Caren. "Deterritorializations: The Rewriting of Home and Exile in Western Feminist Discourse." The Nature and Context of Minority Discourse. Eds. Abdul R. JanMohamed and David Lloyd. New York and Oxford: Oxford UP, 1990. 357-368.

Kennedy, George A. A New History of Classical Rhetoric. Princeton: Princeton University Press, 1994.

Kersey, Ethel M. "Hipparchia the Cynic." Women Philosophers: A Bio-Critical Sourcebook New York: Greenwood Press, 1989. 132-133.

Kimmel, Lawrence. "The Dialectical Convergence of Rhetoric and Ethics: The Imperative of Public Conversation." Rhetoric and Ethics. 1-31. 
Kinneavy, James and Catherine Eskin. "Kairos and Aristotle's Rhetoric" Written Communication 11:1 (1994): 131-142.

'Kinneavy, James L. "Kairos: A Neglected Concept in Classical Rhetoric." Rhetoric and Praxis: The Contribution of Classical Rhetoric to Practical Reasoning. Ed. Jean Dietz Moss. Washington: Catholic University of America Press, 1986. 79-105. Kirby, Kathleen M. "Thinking through the Boundary: The Politics of Location, Subjects, and Space." boundary 2 20:2 (1993): 173-189.

Kristeva, Julia. Desire in Language: A Semiotic Approach to Literature and Art. Ed. Leon S. Roudiez. Trans. Thomas Gora, Alice Jardine, and Leon S. Roudiez. New York: Columbia UP, 1980.

Kroeger-Mappes, Joy. "The Ethic of Care vis-a-vis the Ethic of Rights: A Problem for Contemporary Moral Theory." Hypatia 9.3 (1994): 108-131.

Kustas, George L. Diatribe in Ancient Rhetorical Theory. Ed. W. Wuellner. Colloquy 22. n.p.: The Center for Hermeneutical Studies in Hellenistic and Modern Culture, 1976.

Laertius, Diogenes. Lives of Eminent Philosophers. Trans. R.D. Hicks. Vols.1-2. London: William Heinemann Ltd., n.d. 2 vols.

Landes, Joan B. "The Public and the Private Sphere: A Feminist Reconsideration." Feminists Read Habermas: Gendering the Subject of Discourse. Ed. Johanna Meehan. New York and London: Routledge, 1995. 91-116.

Lanham, Richard A. A Handlist of Rhetorical Terms. Second Edition. Berkeley: University of California Press, 1991.

Lapham, Lewis H. "Economic Correctness." Harper's Magazine February 1997: 9-12.

Le Doeuff, Michele. Hipparchia's Choice: An Essay Concerning Women, Philosophy, etc. Trans. Trista Selous. n.p.: Blackwell Publishers, 1990.

Lipsey, Roger. "Diogenes the Hound." Parabola 14 (1989): 50-60. 
Long, A.A. Hellenistic Philosophy: Stoics, Epicureans, Sceptics. 2nd. edition. Berkeley: University of California Press, 1986.

Looser, Devoney. "Composing as an 'Essentialist?: New Directions for Feminist Composition Theories." Rhetoric Review 12: 1 (1993): 54-69.

Lyotard, Jean François. The Differend: Phrases in Dispute. Trans. Georges Van Den Abbeele. Minneapolis: University of Minnesota Press, 1988. Vol 46 of 46 to date.

Lyotard, Jean François and Jean-Loup Thébaud. Just Gaming. Minneapolis: University of Minnesota Press, 1985. Vol. 20 of 46.

Malherbe, Abraham J. The Cynic Epistles. Missoula: Scholars Press, 1977. Marcus, Jane. "Alibis and Legends: The Ethics of Elsewhereness, Gender, and Estrangement." Women's Writing in Exile. Eds. Mary Lynn Broe and Angela Ingram. Chapel Hill: University of North Carolina Press, 1989. 269-294.

Massey, Doreen. Space, Place, and Gender. Minneapolis: University of Minnesota Press, 1994.

McCance, Dawne. "Julia Kristeva and the Ethics of Exile." Tessera 8 (1990): 23-39.

McLaren, Peter. Critical Pedagogy and Predatory Culture: Oppositional Politics in a Postmodern Era. New York and London: Routledge, 1995.

Miller, Carolyn R. "Kairos and the Rhetoric of Science." A Rhetoric of Doing: Essays on Written Discourse in Honor of James L. Kinneavy. Eds. Stephen P. Witte, Neil Nakadate, and Roger D. Cherry. Edwardsville and Carbondale: Southern Illinois University Press, 1992. 310-327.

Minson, Jeffrey. "The Sovreignty of Ethics." The Genealogies of Morals: Nietzsche, Foucault, Donzelot, and the Eccentricity of Ethics. New York: St. Martin's Press, 1985. 147-164.

Morris, Meaghan. The Pirate's Fianceé: Feminism, Reading, Postmodernism. London and New York: Verso, 1988. 
Nealon, Jeffrey T. "The Ethics of Dialogue: Bakhtin and Levinas." College English 59 (1997): 129-148.

Noddings, Nel. Caring: A Feminine Approach to Ethics \& Moral Education. Berkeley and Los Angeles: University of California Press, 1984.

Patton, Cindy. InventingAIDS. New York: Routledge, 1990.

Perelman, Chaim. "The New Rhetoric: A Theory of Practical Reasoning." Bizzell and Herzberg 1077-1103.

Pile, Steve and Nigel Thrift, eds. "Introduction" and "Mapping the Subject." Mapping the Subject: Geographies of Cultural Transformation. London and New York: Routledge, 1995. 1-51.

Plato. Republic Trans. G.M.A. Grube. Revised by C.D.C. Reeve. Indianapolis: Hackett Publishing Company Inc., 1992.

Platter, Charles. "The Uninvited Guest: Aristophanes in Bakhtin's 'History of Laughter.'" Arethusa 26 (1993): 201-216.

Pomeroy, Sarah B. Goddesses, Whores, Wives, and Slaves: Women in Classical Antiquity. 1975. New York: Pantheon, 1995.

--. Women In Hellenistic Egypt: From Alexander to Cleopatra. New York: Schocken Books, 1984.

Porter, James. "Developing a Postmodern Ethics of Rhetoric and Composition." Defining the New Rhetorics. Vol. 7. Eds. Theresa Enos and Stuart C. Brown. Newbury Park: Sage Publications, 1993. 207-226.

Poster, Mark. "Technology and Culture in Habermas and Baudrillard." Contemporary Literature 22 (1981): 456-476.

Probyn, Elspeth. "Technologizing the Self: A Future Anterior for Cultural Studies." Cultural Studies. Eds. Lawrence Grossberg, Cary Nelson, and Paula Treichler. New York and London: Routledge, 1992. 501-511.

Rankin, H.D. Antisthenes Sokratikos. Amsterdam: Aldolf M. Hakkert, 1986. 
Rassmussen, Terry. "Antifoundationalism: Can Believers Teach?" Rhetoric Review 13:1 (1994): 150-163.

Relihan, Joel C. Ancient Menippean Satire. Baltimore: The Johns Hopkins University Press, 1993.

Reynolds, Nedra. "Ethos as Location: New Sites for Understanding Discursive Authority." Rhetoric Review 11 (1993): 325-338.

Rich, Adrienne. "Notes toward a Politics of Location." Blood, Bread, and Poetry, Selected Prose, 1979-1985 . 1st. ed. New York: Norton, 1986.

Russell, David, R. Writing in the Academic Disciplines, 1890-1990: A Curricular History. Carbondale: Souther Mlinois University Press, 1991.

Said, Edward. "Reflections on Exile." One World, Many Cultures. 2nd.

Edition. Ed. Stuart Hirschberg. Needham Heights: Allyn \& Bacon, 1995. $447-453$.

Schwartzman, Roy. "A Re-examination of Kairos: Implications for Moral Accountability and Rhetorical Criticism." Annual Meeting of the Speech Communication Association. Boston, 5-8 November 1987.

Sheard, Cynthia Miecznikowski. "Kairos and Kenneth Burke's Psychology of Political and Social Communication." College English 55 (1993): 291-310.

Sloterdijk, Peter. Critique of Cynical Reason. Trans. Michael Eldred. Theory and History of Literature Series, Vol. 40. Minneapolis: University of Minnesota Press, 1987.

Soja, Edward. Postmodern Geographies: The Reassertion of Space in Critical Social Theory. London and New York: Verso, 1989.

Sproule, J. Michael. "Whose Ethics in the Classroom? An Historical Survey." CommunicationEducation 36 (1987): 317-326.

Stotsky, Sandra. "Conceptualizing Writing as Moral and Civic Thinking." College English 54 (1992): 794-808. 
Sullivan, Dale. "Kairos and the Rhetoric of Belief." Quarterly Journal of Speech 78 (1992): 317-332.

Tillich, Paul. The Interpretation of History. Trans. N.A. Rasetski. New York and London: Charles Scribner's Sons, Ltd., 1936.

Untersteiner, Mario. The Sophists. Trans. Kathleen Freeman. New York: Philosophical Library, 1954.

Vaage, Leif E. "Like Dogs Barking: Cynic Parresia and Shameless Asceticism." Semeia 57 (1992): 1-39.

Verbeke, Gerard. Moral Education in Aristotle. Washington: Catholic University Press, 1990.

Walzer, Michael. "Politics and the Welfare State: Concerning the Role of American Radicals. Beyond the Welfare State. Ed. Irving Howe. New York: Schocken Books, 128-154.

Warner, Michael. "The Mass Public and the Mass Subject." Habermas and the Public Sphere Cambridge: MIT Press, 1992. 375-401.

Watson, Russell, Katherine Chubbuck, and Charles S. Lee. "Struggling "Through Hell and High Water.'" Newsweek 11 September 1995: 42.

Weiler, Kathleen. Women Teaching for Change: Gender, Class \& Power. New York: Bergin \& Garvey Publishers, 1988.

Worsham, Lynn. "Writing against Writing: The Predicament of Ecriture Feminine in Composition Studies." Harkin and Schilb. 82-104.

Young, Iris Marion. Justice and the Politics of Difference. Princeton: Princeton University Press, 1990. 